\title{
Mitochondrial Structure and Bioenergetics in Normal and Disease Conditions
}

\author{
Margherita Protasoni ${ }^{1}$ and Massimo Zeviani ${ }^{1,2, *}$ \\ 1 Mitochondrial Biology Unit, The MRC and University of Cambridge, Cambridge CB2 OXY, UK; \\ mp802@mrc-mbu.cam.ac.uk \\ 2 Department of Neurosciences, University of Padova, 35128 Padova, Italy \\ * Correspondence: massimo.zeviani@unipd.it
}

check for updates

Citation: Protasoni, M.; Zeviani, M. Mitochondrial Structure and Bioenergetics in Normal and Disease Conditions. Int. J. Mol. Sci. 2021, 22, 586. https://doi.org/10.3390/ijms 22020586

Received: 16 December 2020

Accepted: 4 January 2021

Published: 8 January 2021

Publisher's Note: MDPI stays neutral with regard to jurisdictional clai$\mathrm{ms}$ in published maps and institutional affiliations.

Copyright: $(\odot 2021$ by the authors. Licensee MDPI, Basel, Switzerland. This article is an open access article distributed under the terms and conditions of the Creative Commons Attribution (CC BY) license (https:// creativecommons.org/licenses/by/ $4.0 /)$.

\begin{abstract}
Mitochondria are ubiquitous intracellular organelles found in almost all eukaryotes and involved in various aspects of cellular life, with a primary role in energy production. The interest in this organelle has grown stronger with the discovery of their link to various pathologies, including cancer, aging and neurodegenerative diseases. Indeed, dysfunctional mitochondria cannot provide the required energy to tissues with a high-energy demand, such as heart, brain and muscles, leading to a large spectrum of clinical phenotypes. Mitochondrial defects are at the origin of a group of clinically heterogeneous pathologies, called mitochondrial diseases, with an incidence of 1 in 5000 live births. Primary mitochondrial diseases are associated with genetic mutations both in nuclear and mitochondrial DNA (mtDNA), affecting genes involved in every aspect of the organelle function. As a consequence, it is difficult to find a common cause for mitochondrial diseases and, subsequently, to offer a precise clinical definition of the pathology. Moreover, the complexity of this condition makes it challenging to identify possible therapies or drug targets.
\end{abstract}

Keywords: ATP production; biogenesis of the respiratory chain; mitochondrial disease; mi-tochondrial electrochemical gradient; mitochondrial potential; mitochondrial proton pumping; mitochondrial respiratory chain; oxidative phosphorylation; respiratory complex; respiratory supercomplex

\section{Mitochondria}

\subsection{Origin of Mitochondria and Mitochondrial Genome}

According to current theories, mitochondria evolved from free-living bacteria and participated in the origin of eukaryotic cells through a process known as endosymbiosis [1]. The endosymbiotic hypothesis proposes that original anaerobic eukaryotic (modern views indicate endosymbiosis with a non-eukaryotic archaeon organism) cells engulfed the primitive mitochondria and established a favorable interaction (although this occurred after massive negative selection due to gene shuffling) for both the organisms. Indeed, mitochondria were able to drastically improve the cell energy production, generating adenosine triphosphate (ATP) through the respiratory chain, while the host cell offered a safe environment for bacterial proliferation [2].

This theory was supported by the discovery in the 1960s of mitochondrial DNA (mtDNA) and an independent mitochondrial translation system. Indeed, mitochondria contain their own genetic material, mtDNA, which maintains the typical features of bacterial DNA: it is a circular 16,569-base pairs (bp) double-stranded molecule, does not contain introns and is polycistronic [3]. In fact, apart from one non-coding region, called the displacement loop or D-loop, each gene is contiguous to the next one, albeit some are partly overlapped. Moreover, contrary to nuclear DNA, mtDNA is present in many copies in the cell, between 100 and 10,000 copies, proportionally to the energy demand of the specific tissue [3]. Finally, the mtDNA genetic code differs slightly from nuclear DNA, presenting different codons encoding for tryptophan and methionine and only two stop codons. This is true in different species, the genetic code being different, for instance, 
between vertebrates and other metazoans, but it is a universal code in plants; this implies that the change in the genetic code of mtDNA occurred several times during evolution and it cannot be the primary cause for the maintenance of mtDNA within the organelle.

During evolution, most of the mitochondrial genes were lost or transferred to nuclear DNA, and today, mtDNA only contains 37 genes: 11 messenger ribonucleic acids mRNAs, translated to 13 proteins, 2 ribosomal RNAs (rRNAs, 12S and 16S) and 22 tRNAs [4]. The structure of mtDNA is represented in Figure 1.

\subsection{Mitochondrial DNA Mutations}

As for nuclear DNA mutations, alterations in mtDNA can have important pathological consequences. However, because of the differences between mitochondrial and nuclear DNA, mtDNA inheritance does not follow the canonical mendelian genetics. Firstly, in sexuate organisms, mtDNA is maternally inherited [5]; therefore, only the mother can transmit mutant mtDNA to offspring. Secondly, whilst nuclear genes are present in only two copies per cell, every cell contains multiple copies of mtDNA. These copies can all be identical in sequence, giving a condition known as homoplasmy. However, inheritance of mutated copies, replication errors, oxidative stress or inefficient DNA repair can lead to mtDNA mutations in a percentage of copies, causing heteroplasmy [3]. The proportion of mutant DNA versus the wild-type variant has a strong impact on the development and the severity of the pathological phenotypes.

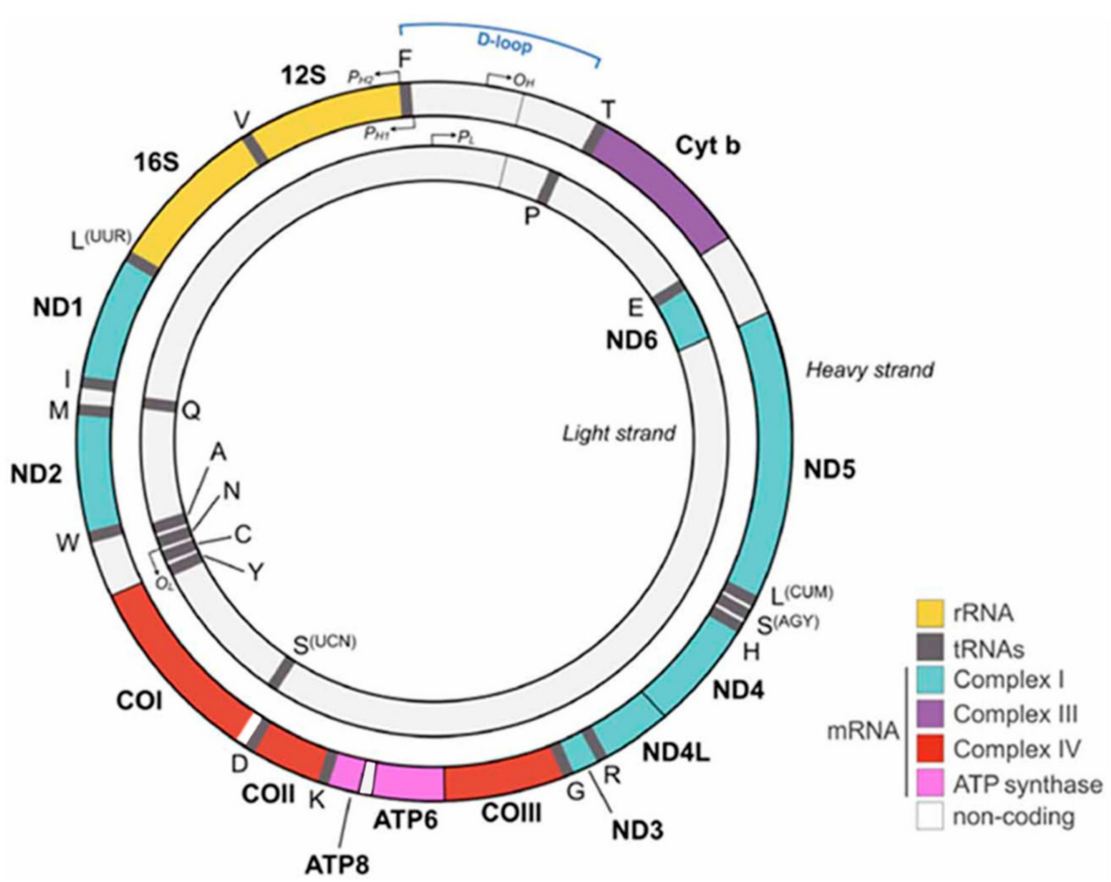

Figure 1. Schematic representation of mitochondrial DNA (mtDNA). Each protein-encoding gene is indicated with a colored bar and all the genes encoding for subunits of the same complex are represented with the same color. rRNAs are indicated in yellow and tRNAs in gray. Source: adapted from Hoffmann and Spengler, 2018 [6].

\subsection{Mitochondrial Membranes}

Mitochondria are surrounded by two phospholipidic membranes, the outer mitochondrial membrane (OMM) and the inner mitochondrial membrane (IMM), which divide the organelle into two spaces, the matrix and the intermembrane space (IMS) [7]. The two membranes present significant differences in lipid composition, characteristics and roles of the transmembrane proteins, permeability and shape and are the result of the endosymbiotic origin of the organelle. Indeed, the OMM is more similar in lipid composition to 
eukaryotic cell membranes, while the IMM resembles the cardiolipin-containing bacterial membranes [2]. The IMM is characterized by a higher protein/lipid ratio and forms highly packed invaginations in the matrix, called cristae [8]. Embedded in the cristae resides, together with many other proteins, the oxidative phosphorylation (OXPHOS) machinery and one proposed reason for the IMM folding is to increase the available surface for energy production. The part of the IMM that does not protrude in the matrix but, instead, runs parallel to the OMM is called the inner boundary membrane (IBM). Cristae and the IBM are connected via narrow tubular or slit-like structures, the cristae junctions (CJs) [9] (Figure 2).

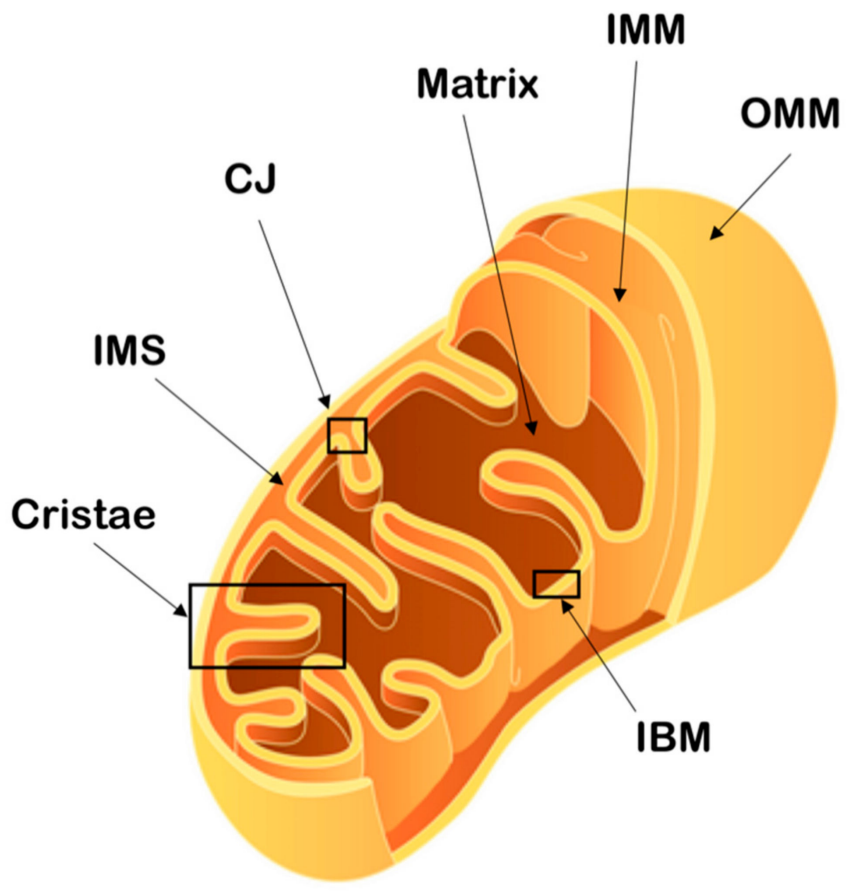

Figure 2. Schematic representation of mitochondrial architecture. The outer mitochondrial membrane (OMM), inner mitochondrial membrane (IMM), inner boundary membrane (IBM), cristae junctions (CJ), intermembrane space (IMS), cristae and mitochondrial matrix are indicated.

Moreover, the OMM and IMM differ largely in their permeability. While the OMM allows the passage of ions and small molecules through voltage-dependent anion channels (VDACs) [10], only water, oxygen $\left(\mathrm{O}_{2}\right)$ and carbon dioxide $\left(\mathrm{CO}_{2}\right)$ can pass freely through the IMM. This selectivity allows the formation of an electrochemical gradient across the membrane, which forms the basis for ATP production, and the tight regulation of other ions concentrations, such as calcium, largely used in cell signaling [11,12].

\subsection{Mitochondrial Cristae}

Mitochondria are internally organized into cristae, invaginations of the IMM, which can be dynamically reorganized according to various stimuli, such as changes in energy requirements or apoptotic signals, becoming more or less compact [13]. The formation and maintenance of these structures is a complex process that requires the participation of many proteins, including the mitochondrial contact site and cristae organizing system (MICOS) and the fusion protein Optic atrophy type 1 (OPA1). The MICOS and OPA1 have been widely associated with the regulation of the cristae architecture, specifically at the cristae junction [14].

The MICOS complex was originally characterized and largely studied in yeast, where it is composed of six subunits: Mic10/MINOS1, Mic12/Aim5, Mic19/CHCHD3, Mic26/ ApoO, Mic27/ApoOL and Mic60/Mitofilin [15]. In mammals, this system is more complicated and two additional subunits have been described: Mic25/CHCHD6 [16] and 
Mic13/QIL1 [17]. All of these subunits are transmembrane proteins, except for Mic19 and Mic25.

Mic60 and Mic10 are the core subunits of the two subcomplexes forming the MICOS architecture (Figure 3). From one side, Mic60 contacts directly with Mic19 and Mic25, while the remaining subunits assemble with Mic10 [18]. Mic10 interacts with Mic26 and Mic27 and is stabilized by QIL1 [17]. Mic10 has been shown to be able to induce membrane curvature even in the absence of the other MICOS subunits [19]. Both subcomplexes are necessary for the formation and stabilization of the cristae at the CJ.

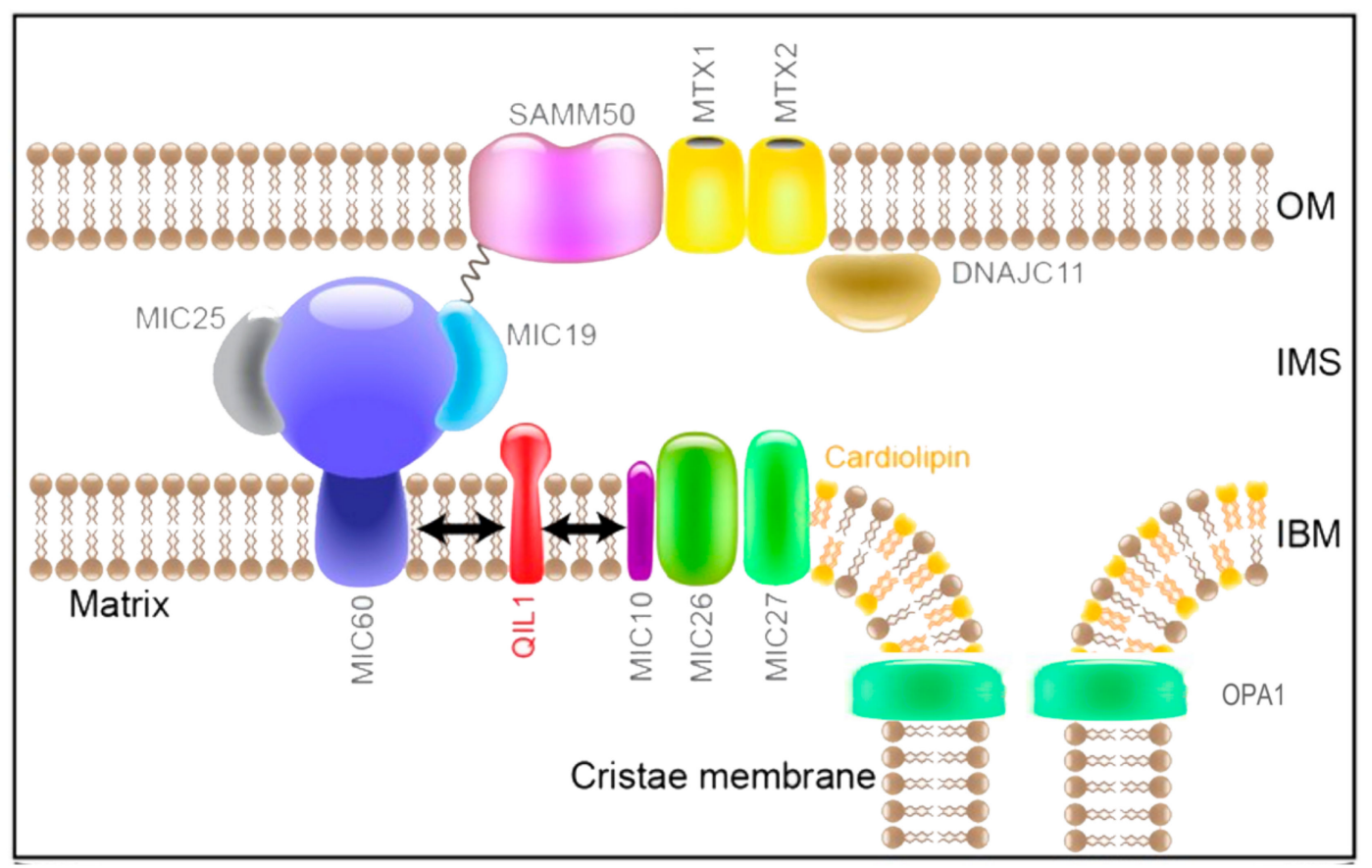

Figure 3. Cartoon of the mitochondrial contact site and cristae organizing system (MICOS) complex at the cristae junction. Source: adapted from Guarani et al., 2015 [17].

The Mic60/Mic19 module is also associated with the OMM. Indeed, Mic19 has been shown to form a bridge between Mic60 and Sorting Assembly Machinery $50 \mathrm{kDa}$ subunit (SAM50), the outer membrane protein that regulates the import and assembly of $\beta$-barrel proteins [20], creating tight OMM and IMM contact sites. Other proteins have been specifically associated with this OMM-IMM junction such as Metaxin-1 and 2 (Mtx1/Mtx2) and DnaJ homolog subfamily C member 11 (DNAJC11) [21]. These OMM-IMM interactions create a specific environment of closed apposition of the two membranes favorable for protein import and lipid and phospholipid transport [22].

Immunoprecipitation experiments indicate that both Mic19 and Mic60 interact with OPA1. OPA1 is an IMM protein with a double role in mitochondrial dynamics and architecture: it is involved in mitochondrial fusion of the IMM and it participates in cristae remodeling [23,24]. Indeed, OPA1 has been shown to be upstream and epistatic to MIC60 and to be the sole regulator of cristae width and junction diameter and number [25].

Finally, the formation of the cristae rims has been proposed to be also linked to the dimerization of the ATP synthase. Indeed, Complex V (CV) dimers reside at the apex of the cristae and, when dimerization is abolished, the IMM loses the typical tubular organization of the cristae and forms onion-like structures instead, a typical feature associated with MICOS deregulation [26]. 


\subsection{Protein Transport through Mitochondrial Membranes}

The mechanisms of protein and ion transport through the OMM and the IMM differ in many aspects [27]. As described previously, the IMM is much less permeable than the OMM and is characterized by $\alpha$-helical transport proteins such as protein translocases and other carriers for metabolites and ions. The OMM, instead, contains channel-forming proteins, such as $\beta$-barrel transmembrane hydrophilic pores, that allow the passage of precursor proteins, small hydrophilic metabolites and ions.

Human mtDNA only contains 37 genes, while it has been estimated that the mitochondrial proteome is composed of approximately 1200 proteins [28]. Consequently, most of the proteins required are encoded by nuclear genes, translated in the cytosol and transported to or into the organelle. Indeed, newly synthesized proteins carrying a mitochondrial target signal are transported to the OMM by chaperones and, according to the nature of their signal, they can be inserted in the OMM, imported in the IMS or transported to the IMM translocases [29]. At the OMM, proteins transport is ensured by the two main complexes: the Translocase of the Outer Membrane (TOM) complex and Sorting and Assembly Machinery (SAM) complex $[30,31]$. For insertion of proteins in the OMM, integral proteins containing one or more spanning helices are not imported, but rather inserted in the OMM via initial interaction with TOM70 (receptor subunit of TOM) and then, in yeast, with Mim1, while $\beta$-barrel proteins pass through TOM40 (pore subunit of TOM) and are then transported by chaperones to SAM. The main component of SAM is SAM50, a $\beta$-barrel protein, which interacts with the new protein, accommodates the folding and inserts it laterally into the membrane [32].

Proteins localized in the IMS can have different fates: they can undergo modifications to stabilize the protein and prevent retrograde transport, such as insertion of a heme group or oxidation of cysteine residues in order to form a disulfide bridge via the Mia40 pathway [33]. In addition, modified proteins with a specific target peptide can be directed to the IMM or the matrix via TIM23 [34].

Proteins that have to be inserted in the IMM are delivered by the IMS chaperones TIM9-10 to the IMM insertase/translocase complex TIM22, the main pathway for import of polytopic inner membrane proteins [35]. The import through TIM22 requires the mitochondrial membrane potential, responsible for an electrophoretic effect on the positively charged targeting sequences of these proteins, but it is not ATP-driven [36]. Finally, Oxa1, a conserved membrane protein, mediates the insertion of both nuclear and mitochondria-encoded precursors into the inner mitochondrial membrane [37].

For matrix-targeted proteins, the translocase involved in this process is TIM23 and three different forces drive the transport: the membrane potential, the increasing affinities of the precursor proteins to the components on the trans side of the translocase, compared with the affinities to the cis side, and the motor force generated upon ATP hydrolysis by the chaperone $\mathrm{mtHsp70}$ and its associated subunits [38].

\subsection{Mitochondrial Dynamics}

Mitochondria are dynamic organelles that form a complex network of tube-like structures [39]. They undergo opposing fusion and fission events to generate a specific mitochondrial morphology network according to the cellular energy needs, the metabolic state of the cell or to adapt to cellular cues. Mitochondrial fusion allows the organelles to share metabolites, proteins and mtDNA, and a hyperfused mitochondrial morphology is associated with a mechanism of defense to enhance cell survival (and impede mitochondrial clearance). In contrast, while mitochondrial fragmentation is often associated with mitochondrial dysfunction and cell death, this process is also required for mitochondrial motility or segregation of damaged portions of the reticulum for degradation through a process known as mitophagy [40].

Mitochondrial dynamics are controlled by Guanosine Triphosphatase (GTPases) proteins belonging to the Dynamin family of proteins, where GTP hydrolysis leads to structural change, subsequently driving membranes remodeling [41]. During mitochondrial division, 
the constriction of the tubule and membrane scission of one mitochondrion into two separate organelles is carried out by recruitment of the cytosolic GTPase Dynamin-related/-like protein 1 (Drp1) to mitochondria-endoplasmic reticulum (ER) contact sites, via interaction with fission protein 1 (Fis1) and mitochondrial fission factor (Mff) [39]. At these sites, Drp1 oligomerizes into a ring-like structure and upon GTP hydrolysis drives mitochondrial division. Mitochondrial fusion, instead, is a two-step mechanism with the OMM localized GTPases mitofusin 1 and 2 (Mfn1 and Mfn2) ensuring OMM fusion, and the IMM GTPase OPA1 responsible for IMM fusion. Again, the shape and dynamics of mitochondria are tightly linked to their bioenergetic status. Failing mitochondria usually appear fragmented, due to a prevalence of the fission machinery, whereas mitochondria hyperfuse as a mechanism of defense against autophagy in conditions of stress, including bioenergetic stress. In addition, specific disorders of some main actors of mitochondrial fission (e.g., mutations in the dynamin-related protein, DRP, the key factor of mitochondrial fission [42,43]) or fusion (e.g., mitofusin 2, Mfn2 [44], and optic atrophy protein 1, OPA1 [45-47]) can be associated with OXPHOS failure and, in particular for some OPA1 mutations, with the accumulation of multiple mtDNA deleted species and multiple defects of the respiratory chain complex activities [48]. In addition to its profusion role, OPA1 acts also as a sealer of the cristae junctions and regulates the ordered distribution of the ETC complexes along the mitochondrial cristae $[49,50]$. Therefore, alterations in mitodynamics are, nowadays, considered part of the possible causes of OXPHOS deficiency and bioenergetic failure leading to mitochondrial disease.

Mitochondria need to move within the cell and their localization is crucial for different functions such as cell division [51]. Directed mitochondrial transport happens on microtubule filaments, typically through force-generating motor proteins, classified into three families: myosins, kinesins and dyneins [52]. Milton, syntabulin and the GTPase Miro have been identified as mitochondria-specific molecules involved in microtubule-based transport [51].

Mitochondrial trafficking is fundamental for a constant supply of healthy mitochondria generating ATP at the right time and place, especially in neuronal cells, where organelles have to move over long distances along the axon, from the cell body to the presynaptic terminal [53].

\subsection{Mitochondrial Functions}

Mitochondria are commonly known as the "powerhouse of the cell", due to their role in energy production. However, in the last 30 years, mitochondria have been characterized also as a signaling organelle involved in numerous physiological functions, including calcium homeostasis, apoptosis and heme and iron-sulfur clusters synthesis.

\subsubsection{Energy Production}

The main source of energy in cells derives from the de-phosphorylation of an ATP molecule to an adenosine diphosphate (ADP) molecule. In order to make this process sustainable, the cell needs to use nutrients to re-generate the ATP molecules used.

During a series of chemical reactions, indeed, a glucose molecule is gradually broken down into carbon dioxide, and its hydrogen atoms are stripped and used to combine with oxygen to form water. The first stage of this mechanism takes place in the cytosol, is anaerobic and is mitochondria-independent [54]. This pathway is known as glycolysis, and it produces only two molecules of ATP from one molecule of glucose metabolized, generating two molecules of pyruvate.

To optimize ATP production, glycolysis is coupled to a second pathway, known as the citric acid cycle (or tricarboxylic acid cycle or Krebs cycle, Figure 4), which takes place in mitochondria and is aerobic. This cycle is composed of nine different enzymatic reactions and each round generates three nicotinamide adenine dinucleotide (NADH) molecules, one flavine adenine dinucleotide $\left(\mathrm{FADH}_{2}\right)$ and one guanosine triphosphate (GTP). One molecule of glucose is catabolized by glycolysis into two molecules of the 
ketoacid pyruvate. Pyruvate enters through the mitochondrial pyruvate carrier (MPC) into the mitochondrial matrix [55], where it is decarboxylated, oxidized and coupled with coenzyme A by pyruvate dehydrogenase, $\mathrm{PDH}$, to form acetyl-CoA. Thus, the two glucosederived acetyl-CoA molecules in the mitochondrial matrix lead to a complex catabolic cycle, the Krebs cycle, which gives rise to two molecules of $\mathrm{CO}_{2}$, whereas their electron equivalents (hydrogen atoms) are stripped off and used to produce, in total, six NADH, two $\mathrm{FADH}_{2}$ and two GTP.

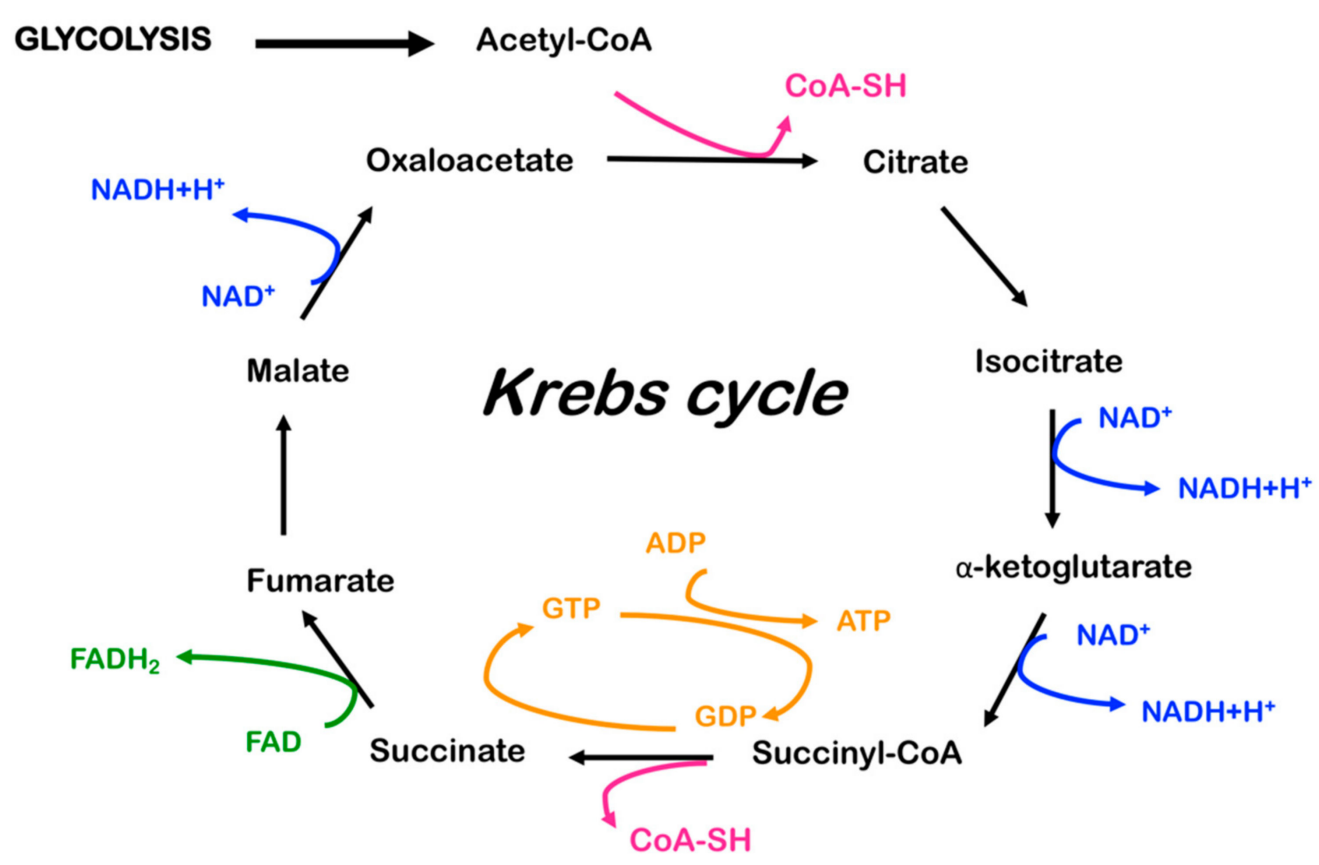

Figure 4. Schematic representation of the tricarboxylic acid cycle or Krebs cycle.

$\mathrm{NADH}$ and $\mathrm{FADH}_{2}$ molecules can then be used in a process known as oxidative phosphorylation, where the majority of the energy is finally converted to ATP. This process consists of the passage of electrons from NADH and $\mathrm{FADH}_{2}$ to the final acceptor, oxygen, through the electron transport chain (ETC). This process, which involves molecular oxygen as a sink for binding electrons, is called cellular respiration. Respiration is coupled with ATP production by ATP synthase or complex V of the ETC. In total, the complete oxidation of a single molecule of glucose is used by the cell to produce 30 ATP molecules [56].

Importantly, $\mathrm{NADH}$ and $\mathrm{FADH}_{2}$ can also be produced by a process known as fatty acid $\beta$-oxidation. A fatty acid is converted to fatty acyl-CoA and then to acyl carnitine, in order for it to enter the mitochondria and eventually be reconverted in intramitochondrial acyl-CoA. In the organelle, a long-chain acyl-CoA is broken down to acetyl-CoA molecules, producing one NADH and one $\mathrm{FADH}_{2}$ for each couple of carbons hydrolyzed from the acyl chain [57].

The proton gradient produced during respiration, similar to an accumulator, supplies energy to operate the ATP synthase (complex V) which, through dissipating it, provides the energy to condense ADP and Pi into ATP. Thus, respiration is distinct but coupled to phosphorylation, in the oxidative phosphorylation pathway. In a normal adult human being, this process leads to the daily production of approximately $70 \mathrm{~kg}$ of ATP, which provides the energy necessary for all exergonic reactions of the organism. 


\subsubsection{Apoptosis}

Mitochondria also play a role in the regulation of programmed cell death, called apoptosis, which is required for embryonic development and numerous physiological functions. Apoptosis leads to a controlled and programmed cell death, which can occur as a response to various damages or stressors, such as DNA damage, oxidative stress, immune reactions and absence of certain growth factors, hormones and cytokines, or as a natural part of development and aging [58]. Different apoptotic pathways exist, characterized by different triggers but with a common final execution pathway. Indeed, these different pathways lead to activation of initiator caspases (as caspase 8 and 9), which then activate executioner caspases (as caspase 3 or 7), to finally induce the degradation of cellular components. The extrinsic or death receptor pathway, which does not directly involve the mitochondria, is activated by extracellular ligands binding to death receptors on the plasma membrane and leads to the formation of the death-inducing signaling complex (DISC), which subsequently activates the initiator caspase 8 and then the executioner caspase 3 [59]. The best characterized is the mitochondrial or intrinsic pathway of apoptosis. Mitochondrial apoptosis is initiated by internal signals of stress or damage that usually lead to a bioenergetic failure and decrease $\Delta \mathrm{P}$ and it consists in the mitochondrial outer membrane permeabilization (MOMP), regulated by the Bcl-2 family of proteins. Upon stressors, the pro-apoptotic members BAX and BAK oligomerize at the OMM [60,61], where they induce the release of pro-apoptotic proteins from the IMS into the cytosol, including cytochrome $c$ [62]. Once in the cytosol, cytochrome $c$ binds and activates apoptotic protease activating factor-1 (Apaf-1) as well as procaspase-9, forming a complex known as the "apoptosome". Active caspase 9 is then able to cleave and activate caspase 3, starting the communal execution pathway $[63,64]$. The execution pathway leads to DNA fragmentation, degradation of cytoskeletal and nuclear proteins, cross-linking of proteins and formation of apoptotic bodies. Thus, bioenergetic failure often leads to mitochondrial apoptosis, although it may also cause autophagy of individual spent mitochondria, or even to ablation of a portion of dysfunctional portions of mitochondria that are left surviving. Therefore, apoptosis and related phenomena constitute one of the possible deleterious outcomes of mitochondrial disease. Importantly, in addition to the release of cytochrome $\mathrm{c}$ and formation of the apoptosome, other mitochondrial proteins can determine apoptosis through alternative mechanisms, such as the apoptosis inducing factor 1 (AIF1) [65], a redox mitochondrial membrane-bound protein that in stress conditions can be cleaved by cathepsin or other proteases, released outside mitochondria and there activate caspases independently from the formation of apoptosome, eventually leading to apoptosis. Recessive mutations of AIF1 have been reported in severe infantile syndromes associated with multiple defects of the mitochondrial respiratory chain activities [66].

\subsubsection{Calcium Homeostasis}

Calcium is largely used in cells as a signaling molecule; therefore, its regulation is critical. Cellular organelles such as the ER and mitochondria are able to sequester and release calcium, regulating the cellular concentration of the ions. Vice versa, calcium signaling has a role in mitochondrial functionality, even if not all the molecular mechanisms involved are clear yet. What is largely accepted is that calcium in the mitochondrial matrix regulates various enzymes, such as pyruvate, isocitrate and 2-oxoglutarate dehydrogenases, modulating, as a consequence, mitochondrial respiration, and the induction of the mitochondrial permeability transition pore [67].

Calcium passes the OMM barrier through a VDAC, which is characterized by highconductance and weak anion selectivity [68]. The passage through the IMM, instead, is more controlled and involves the mitochondrial calcium uniporter (MCU), which transports $\mathrm{Ca}^{2+}$ inside the matrix, and a $\mathrm{Na}^{+} / \mathrm{Ca}^{2+}$ exchanger, mostly expressed in excitable cells, such as muscles and brain, or an $\mathrm{H}^{+} / \mathrm{Ca}^{2+}$ exchanger, in other cell types, which release calcium from the matrix to the IMS [69]. 


\subsubsection{Heme Synthesis}

Heme is an iron-containing porphyrin, essential in numerous biological processes, such as oxygen transport and storage, drug and steroid metabolism, signal transduction and microRNA processing [70]. Moreover, heme is incorporated in some subunits of the electron transport chain and it is necessary for cellular respiration [71].

The synthesis of this compound occurs both partially in the mitochondria and in the cytosol [72]. Heme is generated by the insertion of ferrous iron into the tetrapyrrole macrocycle of protoporphyrin IX [73] catalyzed by a mitochondrial matrix enzyme, called ferrochelatase. Protoporphyrin IX is produced starting from glycine and succinyl-CoA.

Most of heme production takes place in erythroid progenitors, followed by the liver for the formation of heme-containing enzymes [73]. The synthesis pathway is conserved in these two cellular types, while its regulation differs. The heme synthesis machinery in the liver has a rapid turnover in order to respond quickly to changes in metabolic requirements, while the synthesis in developing red cells is tied to the availability of iron.

\subsubsection{Fe/S Clusters Synthesis}

Iron-sulfur (Fe/S) clusters are prosthetic groups with a variety of biological functions. Indeed, several enzymes, such as glycosylases, helicases, primases and respiratory chain enzymes, require the incorporation of $\mathrm{Fe} / \mathrm{S}$ centers for their activity [74]. Both the proteins containing these centers and the proteins that are part of the biosynthesis machinery are highly conserved in prokaryotes and eukaryotes, suggesting an important role in the origin of life [75]. These cofactors originated probably in an environment characterized by low oxygen and co-evolved when the oxygen levels started increasing in the atmosphere, leading to the adaptation of anaerobic electron transport chains for an aerobic habitat. Most $\mathrm{Fe} / \mathrm{S}$ proteins contain a rhomboid $\left[\mathrm{Fe}_{2} / \mathrm{S}_{2}\right]$, a cuboidal $\left[\mathrm{Fe}_{3} / \mathrm{S}_{4}\right]$ or a cubane $\left[\mathrm{Fe}_{4} / \mathrm{S}_{4}\right]$ cluster [76]. The most common protein ligand is cysteine, but also histidine, serine and arginine can form a bond [74].

In yeast, $\mathrm{Fe} / \mathrm{S}$ clusters synthesis takes place exclusively in mitochondria, but an $\mathrm{Fe}-$ $\mathrm{S}$ cluster can also be exported from mitochondria by a specific $\mathrm{ABC}$ transporter in the inner mitochondrial membrane [77]. The central actor of the synthesis pathway found in eukaryotic mitochondria is known as iron-sulfur cluster assembly enzyme (ISCU), which acts as a scaffold for the initial synthesis of a [2Fe-2S] cluster. This cluster will be the basis for the formation of both mitochondrial and cytosolic Fe/S groups. The sulfide ions used in this process are obtained from cysteine side chains, thanks to the activity of enzymes called cysteine desulfurases [78], while it is not clear how iron is delivered to the ISCU, although frataxin may be involved [79].

\section{The Electron Transport Chain}

The enzymatic machinery performing cellular respiration, the electron transport chain (ETC), is composed of four protein complexes embedded in the IMM and two mobile electron carriers (ubiquinone, or coenzyme $\mathrm{Q}$, and cytochrome $c$ ) (Figure 5). Electrons are transported from electron carriers reduced during glycolysis and the Krebs cycle (NADH and $\mathrm{FADH}_{2}$ ) to coenzyme $\mathrm{Q}$ and cytochrome $c$ and eventually transferred to $\mathrm{O}_{2}$, forming $\mathrm{H}_{2} \mathrm{O}$. The energy liberated by this chain of redox reactions leads to the generation of an electrochemical proton gradient across the IMM, which is used by complex $V$ or $F_{1} F_{o}$ ATP synthase to generate ATP $[80,81]$. 


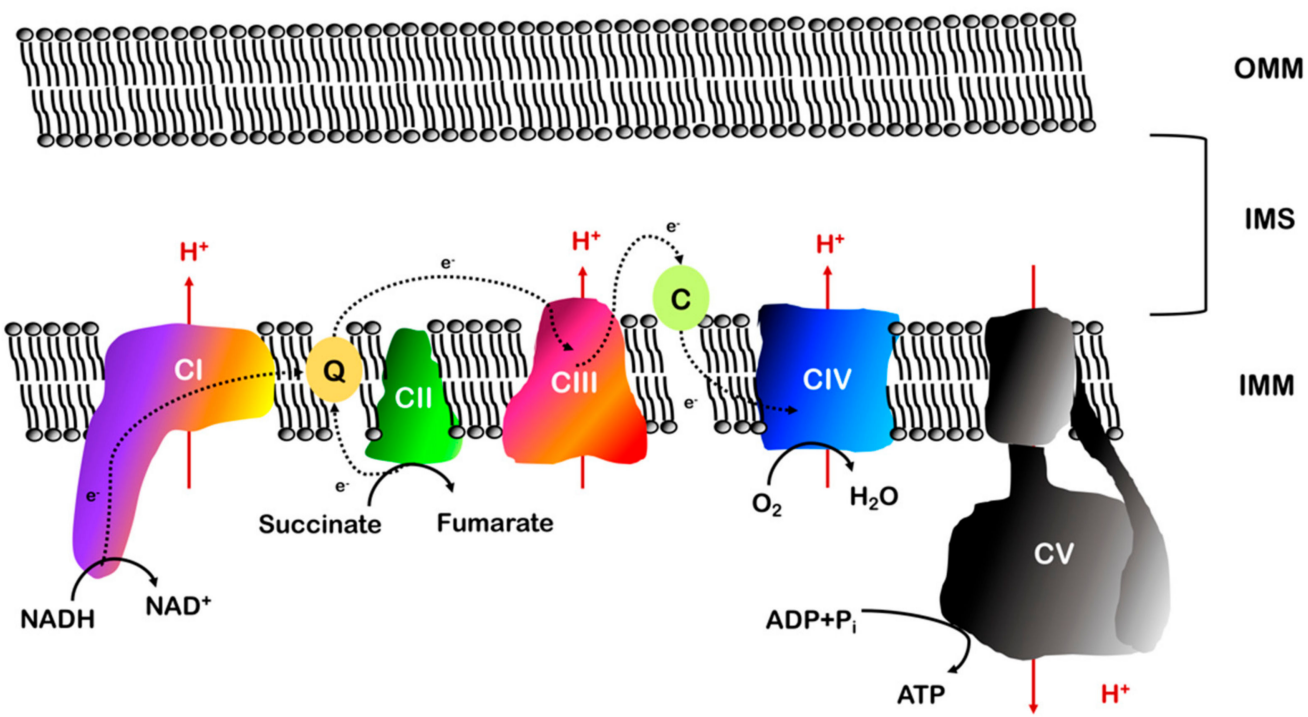

Figure 5. Cartoon representation of the oxidative phosphorylation (OXPHOS) machinery. NADH and FADH2 molecules generated during glycolysis and the Krebs cycle are oxidized by complex I (CI) and complex II (CII), respectively. Electrons are then passed to ubiquinone (Q), which transfers them to complex III (CIII). Here, they are transferred to cytochrome c (C) and to complex IV (CIV), where they are used to reduce $\mathrm{O}_{2}$ to $\mathrm{H}_{2} \mathrm{O}$. Coupled to electron transfer, protons are pumped from the matrix (red arrows) to the intermembrane space (IMS) and the proton motive force generated is used by complex V (CV) to produce ATP.

\subsection{Proton Gradient and Proton Motive Force}

The formation of the electrochemical gradient is made possible by the nature of the phospholipidic bilayer that forms the IMM. Indeed, the membrane is impermeable to the passage of protons, which require protein transporters to cross it. These transporters are part of complexes I, III and IV and the energy necessary for the proton pumping and the generation of the electrochemical gradient derives from the transport of electrons.

This gradient produces the proton motive force (PMF or $\Delta \mathrm{p}$ ), which can be described as a measure of the potential energy stored across the IMM. Since protons are electrically charged particles, the PMF has both chemical and electric components. The electric component corresponds to the voltage difference across the membrane and the free energy is calculated as $\Delta \mathrm{G}=-\mathrm{F} \Delta \Psi$ ( $\mathrm{F}=$ Faraday constant; $\Delta \Psi=$ membrane potential $)$. The chemical component, instead, has a free energy calculated as $\Delta \mathrm{G}=\mathrm{RT} \ln \left(\left[\mathrm{H}^{+}\right]_{\mathrm{i}} /\left[\mathrm{H}^{+}\right]_{\mathrm{o}}\right)$, where $\left[\mathrm{H}^{+}\right]_{\mathrm{i}}$ and $\left[\mathrm{H}^{+}\right]_{\mathrm{o}}$ refer to the proton concentrations inside and outside the IMM, respectively, $R$ is the gas constant of $1.987 \mathrm{cal} /($ degree $\cdot \mathrm{mol}$ ), and $T$ is the temperature (in degrees Kelvin). Combining these two components, the PMF is calculated as $\Delta p=\Delta \Psi-(\mathrm{RT} / \mathrm{F})$ * $\ln \left(\left[\mathrm{H}^{+}\right]_{\mathrm{i}} /\left[\mathrm{H}^{+}\right]_{\mathrm{o}}\right)$. Under physiological conditions, the magnitude of the PMF is about $-220 \mathrm{mV}$ [71]. As a consequence of the difference in protons concentration, the matrix side of the inner mitochondrial membrane is negatively charged and slightly alkaline $(\mathrm{pH}=8)$.

\subsection{Electron Transport and Oxidative Phosphorylation}

The first actors in the electron transport chain are $\mathrm{NADH}$ and $\mathrm{FADH}_{2}$ (Figure 6). $\mathrm{NAD}^{+}$and $\mathrm{FAD}^{+}$are reduced to $\mathrm{NADH}$ and $\mathrm{FADH}_{2}$, respectively, during glycolysis or beta oxidation of fatty acids and the citric acid (Krebs) cycle. A 1:1 mixture of NADH and $\mathrm{NAD}^{+}$has a redox potential of $-320 \mathrm{mV}$, while the midpoint redox potential of $\mathrm{FADH}_{2}$ is around $-220 \mathrm{mV}$. This means that both these molecules have a strong tendency to donate electrons [54]. The $\Delta \mathrm{G}^{\circ \prime}$ values for these strongly exergonic reactions are $-52.6 \mathrm{kcal} / \mathrm{mol}$ $(\mathrm{NADH})$ and $-43.4 \mathrm{kcal} / \mathrm{mol}\left(\mathrm{FADH}_{2}\right)$ [71]. 


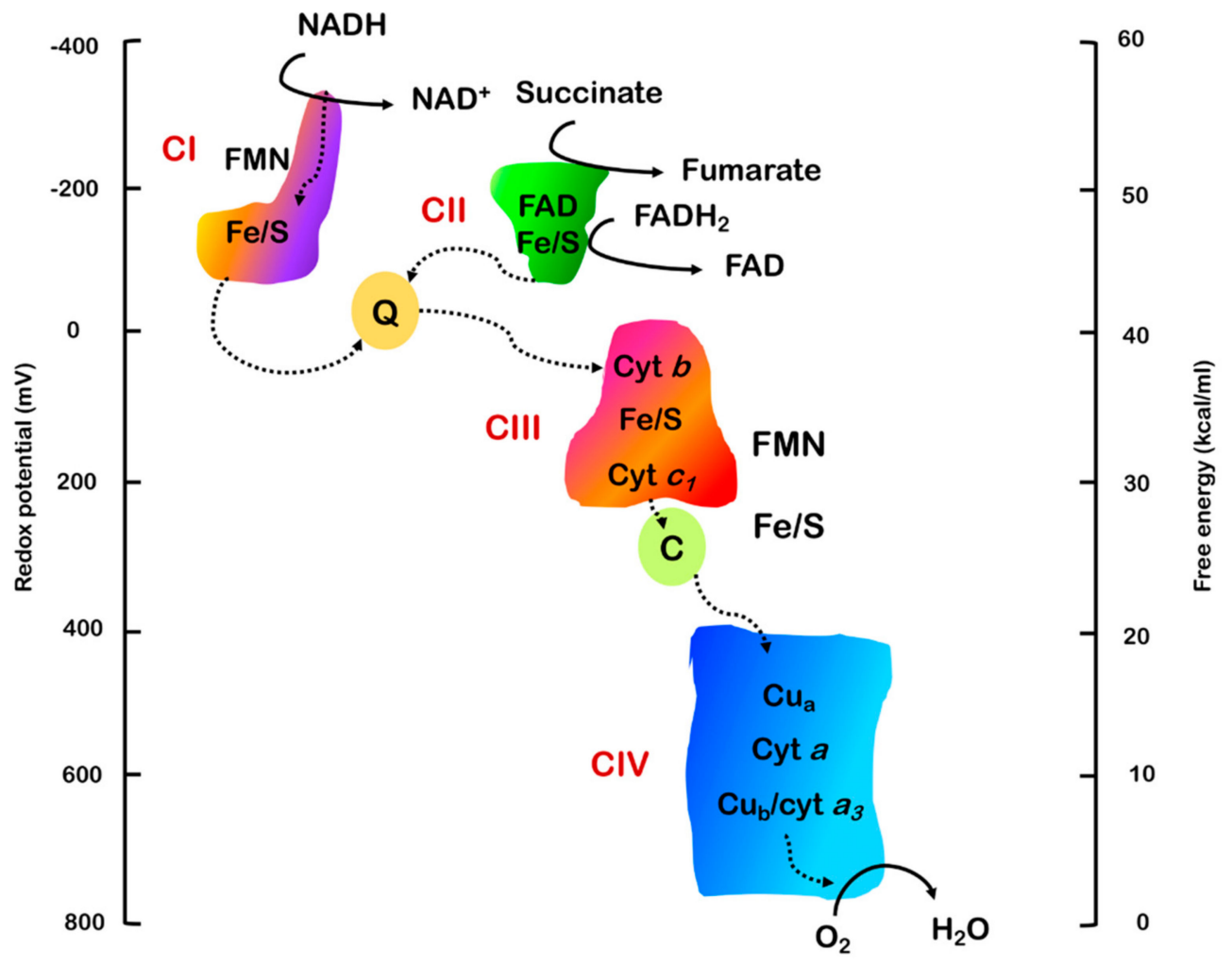

Figure 6. Graphic representation of electrons flow through the electron transport chain (ETC) from $\mathrm{NADH}$, succinate and $\mathrm{FADH}_{2}$ to $\mathrm{O}_{2}$ (dotted arrows). The catalytic centers of the four electron transport chain complexes are represented. Electrons pass in sequence from carriers with a lower reduction potential to those with a higher potential. The energy released from the passage of electrons through the chain is coupled with the pumping of protons across the inner membrane, establishing the proton motive force (PMF). Adapted from Molecular Cell Biology, 4th edition. W. H. Freeman, New York.

NADH binds to complex I (CI, NADH dehydrogenase) and is oxidized to $\mathrm{NAD}^{+}$, donating two electrons to a flavin mononucleotide (FMN) (Figure 6), inserted in CI subunit NDUFV1. Electrons are then passed to a chain of eight iron-sulfur $(\mathrm{Fe} / \mathrm{S})$ clusters, in order to be eventually transferred to the oxidized form of coenzyme $Q$ or ubiquinone $(\mathrm{Q})$, which uptakes two protons to form ubiquinol $\left(\mathrm{QH}_{2}\right)$. As the electrons are transferred from one redox center to the other, four protons are pumped through $\mathrm{CI}$ out of the matrix. Despite the numerous biochemical and structural studies on $\mathrm{CI}$, a definitive model of redoxcoupled proton pumping does not exist yet. Many models have been proposed: the first hypotheses suggested conformational changes in antiporter-like subunits in the P-module, allowed by the energy produced during electron transport [82,83], or transient hydration changes able to generate water-gated pathways for proton transfer between conserved ionizable residues along the membrane domain [84]. The energy necessary for the proton translocation could be provided by two processes: a two-stroke mechanism where the pumping is coupled with $\mathrm{N}_{2}$ (the terminal cluster in the Fe/S chain) reduction/re-oxidation, which occurs twice for every NADH oxidized, assuming the transfer of one electron at a time, or a single-stroke mechanism, where all four protons are translocated together after the reduction of coenzyme Q [85-87]. More recent analyses of the X-ray structure of the Y. lipolytica enzyme, instead, led to the hypothesis that proton pumping is linked to the coordinated conformational rearrangement of three loops in subunits ND1, NDUFS2 and ND3, triggered by the binding of negatively charged ubiquinone [88].

$\mathrm{FADH}_{2}$ derives from the oxidation of succinate to fumarate by complex II (CII, succinate dehydrogenase) during the Krebs cycle (and the last steps of beta oxidation), a reaction 
that reduces $\mathrm{FAD}^{+}$to $\mathrm{FADH}_{2}$, a cofactor bound to the flavoprotein subunit (SDHA). Then, two electrons are transferred to the Fe/S clusters contained in SDHB, which will eventually pass them to $Q$ (Figure 6). This process results in an increased ubiquinol pool but does not directly influence the proton gradient because $\mathrm{CII}$ is not a proton pump.

Coenzyme $\mathrm{Q}$ is a mobile cofactor that can interact with $\mathrm{CI}$ and $\mathrm{CII}$ and transports the electrons received to complex III (CIII, Q-cytochrome c oxidoreductase). CIII oxidizes $\mathrm{QH}_{2}$ to $\mathrm{Q}$ and passes the electrons to another soluble carrier, cytochrome $c$, during a process known as the Q-cycle (Figure 7). The Q-cycle consists of two parallel reactions, which involve the three prosthetic groups of the enzyme: the heme groups contained in cytochrome $c 1$ and cytochrome $b$ and the $2 \mathrm{Fe} / 2 \mathrm{~S}$ cluster contained in the Rieske protein/UQCRFS1 [89]. The first reaction requires the passage of one electron from $\mathrm{QH}_{2}$ bound to the $\mathrm{Q}_{\mathrm{o}}$ binding site to the iron/sulfur group and then to cytochrome $c 1$, leading to the reduction of cytochrome $c$. Each cytochrome $c$ is able to bind only one electron and, when reduced, moves from CIII to complex IV (CIV, cytochrome $c$ oxidase). The second electron from $\mathrm{QH}_{2}$ is passed to the two heme $b$ groups $\left(b_{\mathrm{L}}\right.$ and $\left.\mathrm{b}_{\mathrm{H}}\right)$ contained in cytochrome $b$ and terminates on a second ubiquinone molecule bound to a different binding site of the enzyme $\left(Q_{i}\right.$ site). This ubiquinone is partially reduced to a semiquinone $\left(\mathrm{Q}^{-} \bullet\right)$ during the first $\mathrm{Q}$-cycle and completely reduced to $\mathrm{QH}_{2}$ following a second catalytic cycle [90-93]. One $\mathrm{QH}_{2}$ molecule is then recycled and two electrons are eventually passed to two cytochrome $c$ molecules. For each $\mathrm{QH}_{2}$ molecule that is oxidized, there is the release of two protons to the intermembrane space. $\mathrm{QH}_{2}$ has a redox potential around $0 \mathrm{mV}$, while CIII centers have a positive potential, allowing the passage of electrons. In order to permit the two branches of the Q-cycle, different centers of CIII must have different redox potentials, ranging between $72.5 \mathrm{mV}$ for cytochrome $b$, low enough to allow the recycling of electrons through semiquinone, and $242 \mathrm{mV}$ for cytochrome $c 1$, which passes the electron to cytochrome $c$ $(251 \mathrm{mV})[94,95]$.

\section{Q-Cycle}

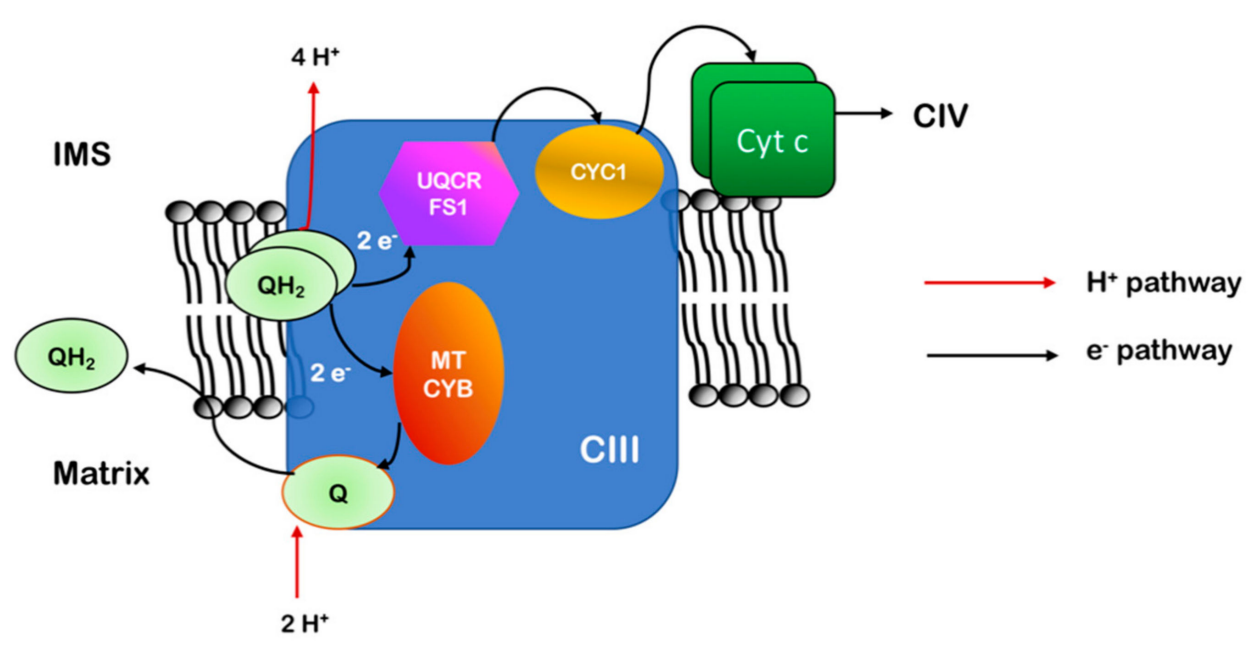

Figure 7. Schematic representation of the Q-cycle.

During the Q-cycle, CoQ is present in three different forms, according to its redox state: ubiquinone $(\mathrm{Q})$, semiquinone $\left(\mathrm{Q}^{-} \bullet\right)$ and ubiquinol $\left(\mathrm{QH}_{2}\right)$. According to the phase of the cycle and the consequent state of the reaction, CoQ molecules can bind CIII in different binding sites: $Q_{0}$, which faces the IMS and catalyzes the oxidation of ubiquinol to ubiquinone, and $\mathrm{Q}_{i}$, which faces the matrix and catalyzes the reduction of ubiquinone to semiquinone and ubiquinol [96]. 
The last steps of oxidative phosphorylation take place in CIV (the terminal oxidase), which allows the passage of electrons from cytochrome $c$ to oxygen (redox potential $=$ $820 \mathrm{mV}$ ), generating water. Since cytochrome $c$ carries only one electron, four molecules are oxidized in order to generate two $\mathrm{H}_{2} \mathrm{O}$ molecules from one molecule of $\mathrm{O}_{2}$. In the meantime, four substrate protons are taken from the matrix to form $\mathrm{H}_{2} \mathrm{O}$ and the other four protons are pumped into the IMS [97,98]. CIV contains two heme groups (cytochromes $a$ and $\left.a_{3}\right)$ and two copper atoms $\left(\mathrm{Cu}_{\mathrm{A}}\right.$ and $\left.\mathrm{Cu}_{\mathrm{B}}\right)$ [99]. Electrons are transferred through the $\mathrm{Cu}_{\mathrm{A}}$ center and heme $a$ to the heme $a_{3} / \mathrm{Cu}_{\mathrm{B}}$ group. When both heme $a_{3}$ and $\mathrm{Cu}_{\mathrm{B}}$ are reduced, one $\mathrm{O}_{2}$ molecule is recruited to form a peroxide bridge between these two prosthetic groups. This bond is broken by the reaction with protons picked up by the mitochondrial matrix and two $\mathrm{H}_{2} \mathrm{O}$ molecules are formed [100].

\subsection{Complex I}

\subsubsection{Structure and Assembly}

NADH dehydrogenase (Complex I, CI) is the first step of the electron transport chain and is composed of 44 different subunits in mammals [101], organized into three structural domains: a membrane arm, or P-module, and two peripheral domains, the $\mathrm{N}$ and the $\mathrm{Q}$ modules, protruding in the mitochondrial matrix. The $\mathrm{N}$ module contains the FMN cofactor and is responsible for the binding and the oxidation of $\mathrm{NADH}$, while the $\mathrm{Q}$ module contains the ubiquinone binding site. The passage of electrons between these two extremities occurs in Fe/S clusters in both the $\mathrm{N}$ and the $\mathrm{Q}$ modules. The peripheral arm is composed of nuclear-encoded proteins, 7 "core" subunits (NDUFV1, NDUFV2, NDUFS1, NDUFS2, NDUFS3, NDUFS7 and NDUFS8) and 30 accessory subunits necessary to stabilize the enzyme and to protect it from reactive oxygen species (ROS) damage [102]. The P-module, instead, is deputed to the proton pumping activity and contains seven mtDNA-encoded proteins: ND1, ND2, ND3, ND4, ND4L, ND5 and ND6. ND1 forms the reduction site for ubiquinone, while ND2, ND4 and ND5 have been found to share a similar structure to sodium and potassium antiporters and may be involved in proton pumping [103]. The mammalian CI structure is represented in Figure 8.

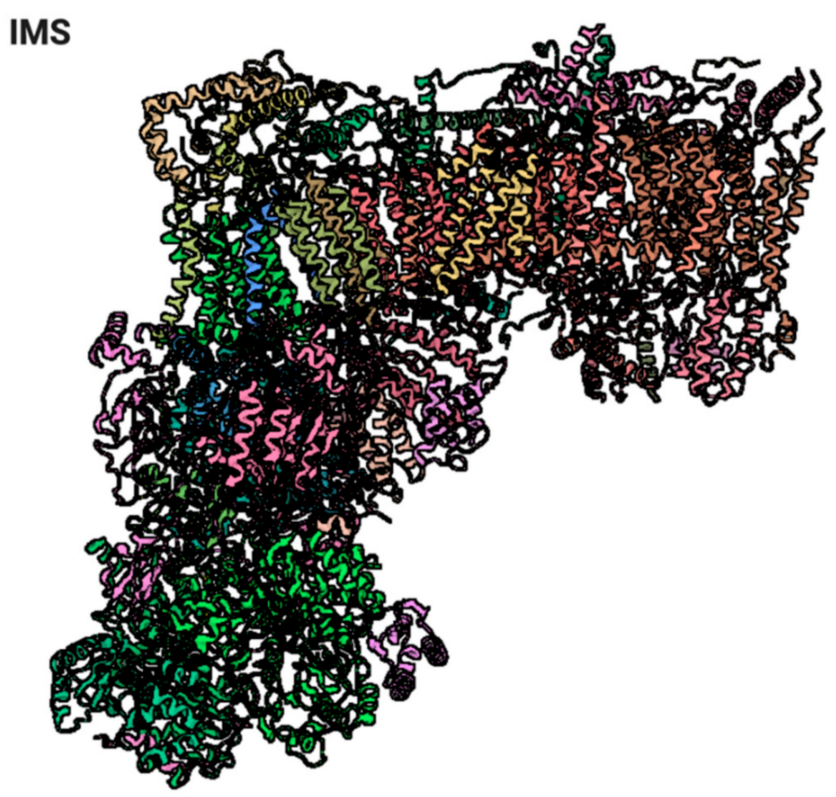

\section{Matrix}

Figure 8. Representation of $\mathrm{CI}$ structure. Image has been created with BioRender.com using the structural data retrieved from PDB (5LC5). 
Due to the large number of subunits forming CI, the assembly pathway of this enzyme is particularly complex and requires the involvement of many assembly factors. The first stage is the synthesis of the various subunits, both inside mitochondria and in the cytoplasm, coupled with the import in the organelle of the nuclear-encoded components. Most CI subunits have N-terminal mitochondrial targeting sequences (MTS), while 11 are imported into the organelle thanks to uncharacterized internal signals within the mature protein [104]. Several core subunits need further maturation and the insertion of the prosthetic groups. However, it is difficult to identify assembly factors with this role using traditional proteomic analysis, probably because of the transient and labile interaction between them and the forming enzyme [105]. The only assembly factor known to be involved in the incorporation of $4 \mathrm{Fe} / 4 \mathrm{~S}$ clusters in the peripheral arm is NUBPL, a member of the Mrp/NBP35 ATP-binding protein family $[106,107]$. Moreover, it is not clear if the insertion of the iron/sulfur clusters happens before or after the incorporation of the single subunit into the subcomplex.

The second step of CI assembly is the formation of six independent modules, N, Q, $\mathrm{ND} 1 / \mathrm{P}_{\mathrm{P}}-\mathrm{a}, \mathrm{ND} 2 / \mathrm{P}_{\mathrm{P}}-\mathrm{b}, \mathrm{ND} 4 / \mathrm{P}_{\mathrm{D}}$ and $\mathrm{ND} 5 / \mathrm{P}_{\mathrm{D}-\mathrm{b}}$, and the incorporation of each of them in a specific order [108]. All the known CI assembly factors are summarized in Table 1.

The ND2 module is the first detectable after inhibition of mitochondrial protein biosynthesis [109]. This subassembly binds to numerous assembly factors: ACAD9, ECSIT, TMEM126B, NDUFAF1, COA1 and the putative assembly factor TMEM186, which form the mitochondrial complex I intermediate assembly (MCIA) [110]. Moreover, TMEM186 was found to strongly interact with the newly synthesized MT-ND3, which is added to the intermediate together with MT-ND6 and MT-ND4L, forming a $385 \mathrm{kDa}$ structure.

In parallel to this, an intermediate of the $\mathrm{Q}$ module starts forming, binding to NDUFAF3 and NDUFAF4 and generating a $170 \mathrm{kDa}$ structure. This submodule will then bind to the assembly factor TIMMDC1 and the subunits ND1, NDUFA3, NDUFA8 and NDUFA13, to yield a $283 \mathrm{kDa}$ complex [109].

The ND4 module, instead, involves the subunits NDUFB1, NDUFB4, NDUFB5, NDUFB6, NDUFB10 and NDUFB11, together with the assembly factors FOXRED1, ATP5SL and TMEM70. This $230 \mathrm{kDa}$ module binds initially to the $\mathrm{N} 2$ module and then to the ND1/Q module intermediate [109].

The ND5 module, which forms the distal extremity of the membrane arm, is the second to last intermediate inserted into the forming enzyme. It is composed of the subunits NDUFB2, NDUFB3, NDUFB7, NDUFB8, NDUFB9 and NDUFAB1, and it is known to bind one assembly factor: DMAC1/TMEM261 [111]. This late intermediate lacking the $\mathrm{N}$ module is stabilized by NDUFAF2/NDUFA12L/B17.2L.

Finally, the N module, composed of NDUFV1, NDUFV2, NDUFS1 and NDUFA2, forming a $160 \mathrm{kDa}$ assembly, is incorporated [109]. This last passage completes the assembly of the enzyme, which loses the interaction with the assembly factors and stabilizes as a $\sim 1000$ kDa complex.

Table 1. CI assembly factors. Adapted from Giachin, 2016 [112], and Sanchez-Caballero et al., 2016 [105].

\begin{tabular}{|c|c|c|c|}
\hline Assembly Factor & Function & CI Interacting Module & References \\
\hline ACAD9 & Binding of ND2 module & $\mathrm{ND} 2 / \mathrm{P}_{\mathrm{P}}-\mathrm{b}$ module & {$[113,114]$} \\
\hline ECSIT & Insertion of ND2 & $\mathrm{ND} 2 / \mathrm{P}_{\mathrm{P}}-\mathrm{b}$ module & [115] \\
\hline FOXRED1 & In a complex with AIFM1 and ACAD9 & $\mathrm{ND} 4 / \mathrm{P}_{\mathrm{D}}$ module & {$[116,117]$} \\
\hline ATP5SL & Binding of ND4 module & $\mathrm{ND} 4 / \mathrm{P}_{\mathrm{D}}$ module & [118] \\
\hline TMEM70 & Binding of ND4 module & $\mathrm{ND} 4 / \mathrm{P}_{\mathrm{D}}$ module & {$[119,120]$} \\
\hline NDUFAF1 & Insertion of ND2 module & N module, ND1 & [121] \\
\hline NDUFAF2 & Binding of $\mathrm{N}$ module & $\mathrm{N}$ module & [122] \\
\hline NDUFAF3 & Binding of $Q$ with $P_{P}-a$ & Q module & [123] \\
\hline NDUFAF4 & Binding of $\mathrm{Q}$ with $\mathrm{P}_{\mathrm{P}}-\mathrm{a}$ & Q module & [124] \\
\hline NDUFAF5 & Methyltransferase activity & Not known & {$[125,126]$} \\
\hline NDUFAF6 & Squalene/phytoene synthase activity & Not known & [127] \\
\hline NDUFAF7 & Methyltransferase activity & Not known & {$[128,129]$} \\
\hline
\end{tabular}


Table 1. Cont.

\begin{tabular}{|c|c|c|c|}
\hline Assembly Factor & Function & CI Interacting Module & References \\
\hline NUBPL & $\begin{array}{l}4 \mathrm{Fe} / 4 \mathrm{~S} \text { clusters insertion. Necessary for the } \\
\text { entire enzyme stability }\end{array}$ & $\begin{array}{l}\text { Supposed to interact with the developing } \\
\mathrm{N} \text { module and possibly Q module }\end{array}$ & {$[106,107,130]$} \\
\hline TIMMDC1 & $\begin{array}{l}\text { Translocase of inner mitochondrial } \\
\text { membrane domain-containing protein } 1\end{array}$ & $\mathrm{ND} 1 / \mathrm{P}_{\mathrm{P}}-\mathrm{a}$ & {$[118,131]$} \\
\hline TMEM126B & Required for formation of the ND2 module & $\mathrm{ND} 2 / \mathrm{P}_{\mathrm{P}}-\mathrm{b}$ module & [132] \\
\hline TMEM186 & Not known & $\mathrm{ND} 2 / \mathrm{P}_{\mathrm{P}}-\mathrm{b}$ module & [109] \\
\hline DMAC1/TMEM261 & Stabilization and/or assembly of ND5 & $\mathrm{ND} 5 / \mathrm{P}_{\mathrm{D}-\mathrm{b}}$ & [111] \\
\hline COA1 & $\begin{array}{l}\text { CIV assembly factor, found bound to CI } \\
\text { assembly intermediates }\end{array}$ & $\mathrm{ND} 2 / \mathrm{P}_{\mathrm{P}}-\mathrm{b}$ module & [109] \\
\hline
\end{tabular}

\subsubsection{Pathologies Associated with Complex I Deficiency}

Mutations affecting CI stability or activity are responsible for a wide range of pathological phenotypes [133]. Missense mutations affecting the mitochondrial-encoded subunits (ND subunits) have been associated with Leber's hereditary optic neuropathy (LHON), mitochondrial encephalomyopathy, lactic acidosis and stroke-like syndrome (MELAS) and Leigh syndrome. Many mutations in nuclear-encoded subunits have been identified in patients with CI deficiency, causing Leigh syndrome, leukoencephalopathy, leukodystrophy, encephalopathy, cardiomyopathy and other neurological defects. In addition, assembly factors and chaperones involved in CI assembly can also be at the origin of the pathogenesis of these diseases [134]. The main pathological mutations found in CI subunits or assembly factors are summarized in Table 2.

Table 2. CI subunits and assembly factors associated with mitochondrial diseases.

\begin{tabular}{|c|c|c|c|}
\hline Gene/Protein & OMIM & Associated Phenotype & Reference \\
\hline \multicolumn{4}{|c|}{ Complex I subunits } \\
\hline MTND1 & 516000 & Leber optic atrophy, MELAS syndrome, dystonia, spasticity and myopathy. & [135-137] \\
\hline MTND2 & 516001 & Leber optic atrophy. & [138] \\
\hline MTND3 & 516002 & Infantile encephalopathy and Leigh syndrome. & [139] \\
\hline MTND4 & 516003 & Leber optic atrophy and MELAS syndrome. & {$[140,141]$} \\
\hline MTND4L & 516004 & Leber optic atrophy. & [142] \\
\hline MTND5 & 516005 & Leber optic atrophy and MELAS syndrome. & {$[143,144]$} \\
\hline MTND6 & 516006 & Leber optic atrophy and MELAS syndrome. & {$[143,145]$} \\
\hline NDUFV1 & 161015 & Severe encephalopathy and neurologic abnormalities. & {$[146,147]$} \\
\hline NDUFV2 & 600532 & Hypertrophic cardiomyopathy, truncal hypotonia and encephalopathy. & [148] \\
\hline NDUFS1 & 157655 & $\begin{array}{c}\text { Growth retardation, axial hypotonia, hepatomegaly, dystonia and persistent } \\
\text { hyperlactatemia. }\end{array}$ & [147] \\
\hline NDUFS2 & 602985 & Neonatal lactic acidosis and hypertrophic cardiomyopathy. & [149] \\
\hline NDUFS3 & 603846 & $\begin{array}{l}\text { Leigh syndrome, severe axial dystonia with oral and pharyngeal motor dysfunction, } \\
\text { dysphagia and a tetraparetic syndrome. }\end{array}$ & [150] \\
\hline NDUFS4 & 602694 & Muscular hypotonia, absence of visual and auditive attention and cardiac defects. & [151] \\
\hline NDUFS6 & 603848 & Fatal infantile lactic acidosis. & [152] \\
\hline NDUFS7 & 601825 & Leigh syndrome, feeding problems, dysarthria and ataxia. & [153] \\
\hline NDUFS8 & 602141 & Leigh syndrome, poor feeding and episodes of apnea and cyanosis. & [154] \\
\hline NDUFA11 & 612638 & $\begin{array}{l}\text { Fatal infantile metabolic acidosis, brain atrophy, no motor development and } \\
\text { hypertrophic cardiomyopathy. }\end{array}$ & [155] \\
\hline NDUFA1 & 300078 & $\begin{array}{c}\text { Leigh syndrome, hypotonia, nystagmus, generalized choreoathetosis and decreased } \\
\text { reflexes. }\end{array}$ & [156] \\
\hline
\end{tabular}


Table 2. Cont.

\begin{tabular}{|c|c|c|c|}
\hline Gene/Protein & OMIM & Associated Phenotype & Reference \\
\hline NDUFA2 & 602137 & Leigh syndrome, hypertrophic cardiomyopathy and developmental delay. & [157] \\
\hline NDUFA6 & 602138 & $\begin{array}{c}\text { Intrauterine growth retardation, respiratory insufficiency, lactic acidosis and } \\
\text { hypoglycemia. }\end{array}$ & [158] \\
\hline NDUFA8 & 603359 & $\begin{array}{c}\text { Severe neonatal hypotonia, dysmorphic features, epilepsy and signs of brainstem } \\
\text { involvement. }\end{array}$ & [159] \\
\hline NDUFA9 & 603834 & Respiratory and metabolic acidosis, hearing loss, apneas and retinitis pigmentosa. & [160] \\
\hline NDUFA10 & 603835 & Leigh syndrome and delayed psychomotor development. & [161] \\
\hline NDUFA12 & 614530 & Leigh syndrome, progressive loss of motor abilities, scoliosis and dystonia. & [162] \\
\hline NDUFA13 & 609435 & $\begin{array}{l}\text { Delayed development, hypotonia, poor eye contact, abnormal eye movements, poor } \\
\text { feeding, encephalopathy and hearing loss. }\end{array}$ & [163] \\
\hline NDUFB3 & 603839 & Encephalopathy, myopathy, hypotonia, developmental delay and lactic acidosis. & [164] \\
\hline NDUFB8 & 602140 & $\begin{array}{l}\text { Leigh syndrome, respiratory failure, seizures, hypotonia, cardiac hypertrophy, failure } \\
\text { to thrive and severely delayed psychomotor development. }\end{array}$ & [165] \\
\hline NDUFB9 & 601445 & Progressive hypotonia associated with increased serum lactate. & [164] \\
\hline NDUFB10 & 603843 & Lethal complex I deficiency. & [166] \\
\hline NDUFB11 & 300403 & $\begin{array}{l}\text { X-linked microphthalmia with linear skin defects (MLS) syndrome, cardiomyopathy } \\
\text { and other congenital anomalies. }\end{array}$ & {$[167,168]$} \\
\hline NDUFC2 & 603845 & Leigh syndrome. & [169] \\
\hline \multicolumn{4}{|c|}{ Complex I assembly factors } \\
\hline ACAD9 & 611103 & $\begin{array}{l}\text { Cardiorespiratory depression, hypertrophic cardiomyopathy, encephalopathy and } \\
\text { severe lactic acidosis. }\end{array}$ & [114] \\
\hline FOXRED1 & 613622 & $\begin{array}{l}\text { Leigh syndrome, congenital lactic acidosis, athetoid movements of the limbs in early } \\
\text { childhood, hypotonia and cerebellar atrophy. }\end{array}$ & [170] \\
\hline NDUFAF1 & 606934 & $\begin{array}{l}\text { Hypertrophic cardiomyopathy, developmental delay, lactic acidosis, hypotonia and } \\
\text { Wolff-Parkinson-White syndrome. }\end{array}$ & [171] \\
\hline NDUFAF2 & 609653 & $\begin{array}{c}\text { Ataxia, lethargy, nystagmus, hypotonia, optic atrophy and episodic respiratory } \\
\text { insufficiency. }\end{array}$ & [122] \\
\hline NDUFAF3 & 612911 & Macrocephaly, weak cry, no eye contact, wide anterior fontanel and axial hypotonia. & [123] \\
\hline NDUFAF4 & 611776 & Severe encephalopathy and antenatal cardiomyopathy. & [124] \\
\hline NDUFAF5 & 612360 & Facial dysmorphism, progressive lactic acidosis and neurological defects. & [125] \\
\hline NDUFAF6 & 612392 & $\begin{array}{l}\text { Focal seizures, decreased movement and strength, ataxia, lactic acidosis and Leigh } \\
\text { syndrome. }\end{array}$ & [172] \\
\hline NDUFAF8 & 618461 & Leigh syndrome. & [173] \\
\hline NUBPL & 613621 & $\begin{array}{l}\text { Infantile-onset hepatopathy, renal tubular acidosis, developmental delay, short stature, } \\
\text { leukoencephalopathy, myopathy, nystagmus and ataxia. }\end{array}$ & {$[106,107,130]$} \\
\hline TIMMDC1 & 615534 & $\begin{array}{c}\text { Infantile-onset hypotonia, failure to thrive, delayed or minimal psychomotor } \\
\text { development, sensorineural deafness, dysmetria, dyskinetic movements, peripheral } \\
\text { neuropathy, nystagmus and Leigh syndrome. }\end{array}$ & [174] \\
\hline TMEM126B & 615533 & $\begin{array}{l}\text { Exercise intolerance, muscle weakness, myalgia, early-onset renal tubular acidosis and } \\
\text { hypertrophic cardiomyopathy. }\end{array}$ & {$[175,176]$} \\
\hline COA7 & 615623 & Autosomal recessive spinocerebellar ataxia with axonal neuropathy-3. & [177] \\
\hline
\end{tabular}

\subsection{Complex II}

\subsubsection{Structure and Assembly}

Succinate dehydrogenase (SDH, complex II, CII) is a $\sim 120 \mathrm{kDa}$ integral membrane complex, involved in both the TCA cycle and the ETC. Indeed, this enzyme catalyzes the 
oxidation of succinate to fumarate, a central step of the citric acid cycle, and reduces FAD to FADH2, which then reduces ubiquinone to ubiquinol [178]. CII is the only complex of the chain that does not pump protons across the membrane and that is entirely encoded by the nuclear DNA.

CII is composed of four subunits, named SDHA-D, forming two domains (Figure 9). The hydrophilic head of CII comprises SDHA and SDHB and is required for the oxidation of succinate. $\mathrm{FAD}^{+}$binds to SDHA and the electrons are transferred to SDHB, containing three $\mathrm{Fe} / \mathrm{S}$ clusters ([2Fe-2S], [4Fe-4S] and [3Fe-4S]) [179]. The hydrophobic membrane domain of the enzyme is composed of SDHC and SDHD and contains a heme broup and two ubiquinone binding sites [180].

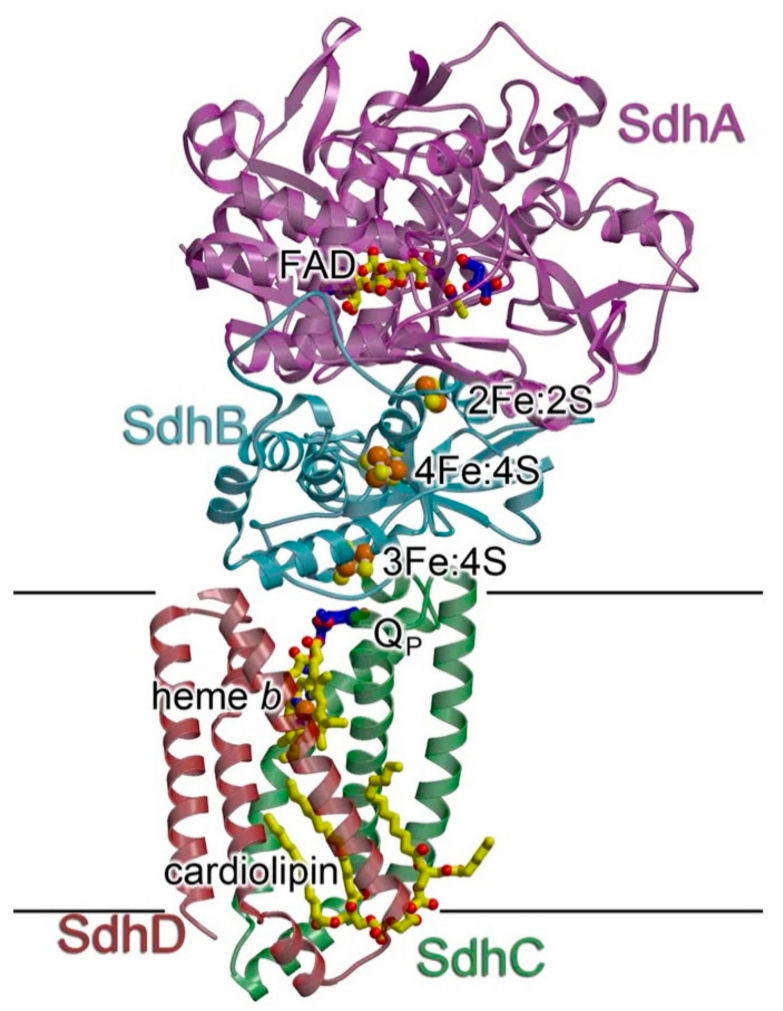

Figure 9. Representation of $E$. coli CII structure. The four subunits forming the complex (SDHA-D) are shown in different colors and labeled with the letters A to D. FAD, Fe-S centers, heme $b$ and the ubiquinone binding site facing the matrix (Qp) are indicated. Source: Iverson, 2013 [181].

The mature forms of SDHA and SDHB are generated independently before the complex assembly, while SDHC and SDHD are able to form an intermediate subcomplex [182]. SDHA is initially imported into the matrix as an apo-protein and the FAD cofactor is inserted thanks to the interaction with the assembly factor SDHAF2/Sdh5 [183]. Then, mature SDHA binds to SDHAF4/Sdh8, a chaperone that protects the subunit from auto-oxidation and facilitates the assembly with SDHB. Mature SDHB contains Fe/S clusters, which are inserted by SDHAF1 $[184,185]$. SDHB stability is then maintained by the association with an LYR motif protein recently identified in yeast, Sdh7 (SDHAF3/ACN9/LYRM10, human ortholog), which shields one or more of the prosthetic centers from oxidants [186]. Mature SDHA and SDHB are then able to assemble together and join SDHC and SDHD and insert into the membrane via a still uncharacterized mechanism.

\subsubsection{Pathologies Associated with Complex II Deficiency}

Patients presenting with a specific CII defect are quite rare, less than $10 \%$ of OXPHOS deficiency cases [187]. Two main phenotypes can originate from mutations in CII subunits or assembly factors. Mutations in SDHAF1 and SDHA lead to encephalomyopathy and leukoencephalopathy $[184,188]$, while variants in SDHA, SDHB, SDHC, SDHD 
and SDHAF2 are responsible for hereditary paraganglioma and pheochromocytomas, rare neuroendocrine tumors [183,189-192]. Moreover, other genes involved in FAD and $\mathrm{Fe} / \mathrm{S}$ cluster synthesis can impair CII activity and stability [193]. The main pathological mutations found in CII subunits or assembly factors are summarized in Table 3.

Table 3. CII subunits and assembly factors associated with mitochondrial diseases.

$\left.\begin{array}{cccc}\hline \text { Gene/Protein } & \text { OMIM } & \text { Associated Phenotype } & \text { Reference } \\ \hline \text { SDHA } & 600857 & \text { Leigh syndrome, neonatal dilated cardiomyopathy, } & \text { [194-196] } \\ \text { SDHB } & 185470 & \text { Paraganglioma, pheochromocytoma, gastrointestinal stromal tumors. } & {[197,198]} \\ \text { SDHC } & 602413 & \text { Paraganglioma, gastric stromal sarcoma. } & {[190,199]} \\ \text { SDHD } & 602690 & \text { Paraganglioma, pheochromocytoma, gastric stromal sarcoma. } & {[191,199]} \\ \text { SDHAF1 } & 612848 & \text { Leukoencephalopathy, spastic quadriplegia, psychomotor regression. } & {[184]} \\ \text { SDHAF2 } & 613019 & & \text { Paraganglioma. }\end{array}\right]$

\subsection{Complex III}

\subsubsection{Structure and Subunits}

The ubiquinol:cytochrome $c$ oxidoreductase (cytochrome $b c_{1}$, complex III, CIII) is the central element of the respiratory chain. In yeast, it is formed of 10 different subunits, while in mammals, an additional subunit was identified, corresponding to the mitochondrial targeting sequence of the Rieske protein/UQCRFS1, which remains anchored to the complex after the proteolytic cleavage [200]. However, recent studies proposed that the latter is not a stoichiometric subunit and that the N-terminal UQCRFS1 peptide needs to be eliminated in order to maintain the functionality of CIII [201,202]. All CIII subunits are encoded by nuclear DNA except cytochrome $b$ (MTCYB), which is mitochondrial-encoded [92,203]. $\mathrm{CIII}$ is always dimeric and high-resolution crystal structures of the bovine, chicken and yeast $b c_{1}$ complexes have been resolved [91,204-206] (Figure 10).

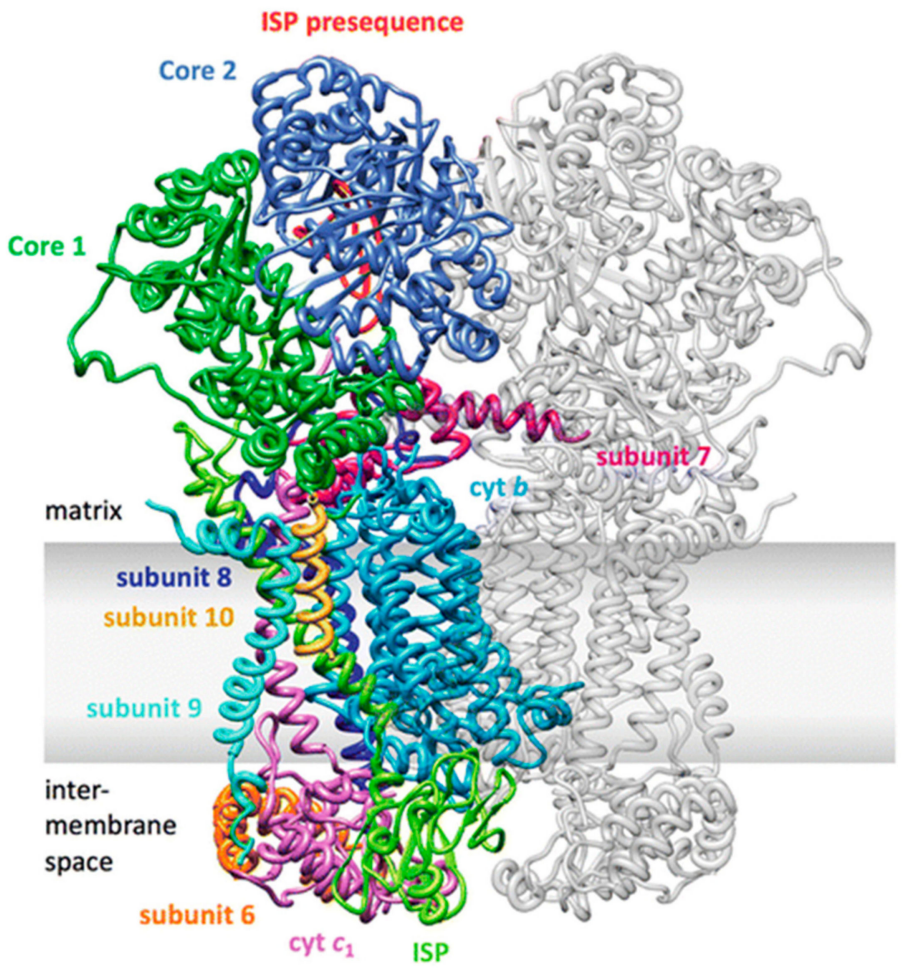

Figure 10. Representation of bovine CIII structure. CIII is shown as a dimer, the only form in which it is found in cells. All the 10 subunits are represented with a different color in one monomer. Source: Sousa et al., 2018 [207]. 
Both in yeast and mammals, CIII contains three protein subunits with redox prosthetic groups: cytochrome $b$, which contains both the high-potential $b_{\mathrm{H}}(b 562)$ and the lowerpotential $b_{\mathrm{L}}$ (b565) heme centers, cytochrome $c 1$ (CYC1), containing the $c$-type heme $c_{1}$, and the Rieske iron-sulfur protein (Rip1 in yeast, UQCRFS1 protein in mammals) with a $2 \mathrm{Fe}-2 \mathrm{~S}$ cluster [208]. The di-heme cytochrome $b$ polypeptide forms eight transmembrane helices and contains two histidine residues in each of the second (helix B) and fourth (helix D), forming the binding site for quinone [209]. The low-potential heme $b_{\mathrm{L}}$ is located on the intermembrane space side of the IMM, while the high-potential heme $b_{\mathrm{H}}$ is positioned in a cavity accessible from the matrix, where it can receive electrons from $b_{\mathrm{L}}$ and pass them to the Qi site, where it reduces one bound ubiquinone to semiquinone [208]. CYC1 has a wedge-like structure containing the heme group and is anchored in the membrane through a C-terminal transmembrane anchor next to helix $\mathrm{E}$ of cytochrome $b$ [93]. The heme group binds a CXXCH domain, highly conserved in c-type cytochromes. UQCRFS1 contacts MTCYB on one of the two CIII heterodecamers with its N-terminal transmembrane domain, where it receives one electron and undergoes a conformational change that makes it reach CYC1 on the other one [210]. The maturation of UQCRFS1 has been studied in detail in simpler organisms, such as Neurospora crassa and Saccharomyces cerevisiae [211]. The newly synthesized protein undergoes two post-translational modifications: the cleavage of a targeting pre-sequence and the insertion of the iron-sulfur cluster into the mitochondrial matrix. Initially, the MTS is cleaved by a mitochondrial matrix protease (MPP), and finally, an extra eight-amino acid-long sequence is removed by a mitochondrial intermediate protease (MIP). Contrary to yeast and birds, mammalian UQCRFS1 maturation generates a 78-amino acid-long fragment, which remains temporally bound to CIII as an eleventh subunit, Subunit 9 (Su9) [200]. This additional subunit localizes between the two core subunits UQCRC1 and UQCRC2 and it has been proposed that these two are responsible for the cleavage of UQCRFS1, due to the conservation of their MPP function [212-214].

The remaining subunits are accessory and their function is mainly to support and stabilize the complex $[215,216]$.

\subsubsection{Assembly}

The CIII assembly pathway has been studied in depth in S. cerevisiae [217-221], while the human CIII assembly model has been initially constructed by homology, as some of the steps have been shown to be analogous to yeast [222], and recently updated following our study on CIII-deficient cybrids [223].

The first step of CIII assembly, both in yeast and in mammals, is the synthesis and the insertion into the IMM of cytochrome $b$. Yeast cytochrome $b$ contains introns and requires processing [224], while mammalian MTCYB is transcribed as a polycistronic segment. MtDNA is organized so that mRNAs coding for proteins are divided by tRNAs, which assume a specific secondary structure, and function as punctuation marks between the genes. tRNAs are then cleaved by mitochondrial RNase $\mathrm{P}$ at the $5^{\prime}$ ends and by RNase $\mathrm{Z}$ at the $3^{\prime}$ ends, and mRNAs are then translated [225]. Moreover, studies in mice suggested the involvement of PTCD2 (pentatricopeptide repeat domain protein 2) in processing the pre-processed ND5-CYTB RNA transcript [226].

The transcription and translation of cytochrome $b$ must be coordinated with the synthesis of nuclear-encoded proteins. This mitochondrial-nuclear communication is possible thanks to a group of proteins called translational activators. These nuclear-encoded factors regulate the expression of mitochondrial genes and their own expression in relation to the OXPHOS activity, in order to limit the accumulation of unused subunits, which can have toxic effects on the organelle. In yeast, four translational activators of COB have been identified: Cbp1, Cbs1, Cbs2 and the complex Cbp3/Cbp6 [220]. These factors interact with mitochondrial ribosomes and the mitochondrial organization of gene expression (MIOREX) complex [227]. The primary role of $\mathrm{Cbp} 1$ is to protect $C O B$ mRNAs and to transfer them to the translational apparatus [228]. Cbs1 and Cbs2 have been found associated in the same high-molecular weight complex with mitochondrial ribosomes, but they might also 
form other subcomplexes including those with different activator proteins, such as COXspecific activators $[229,230]$. Recent studies on Cbs1 determined that this protein binds to a segment of the $5^{\prime}$ UTR of $C O B$ mRNA, sequestering it and repressing the translation. Cbs1 is then replaced by the complex $\mathrm{Cbp} 3 / \mathrm{Cbp} 6$ liberated during assembly, which activates the translation [231]. These proteins, necessary for the stability of COB mRNA and its translation, do not have orthologs in mammals [220].

The Cbp3-Cbp6 complex, instead, plays a role in the second phase of translation, binding the nascent polypeptide exiting the ribosome, and it does not leave the protein until the incorporation of the $b_{L}$ heme group [232,233]. This complex has orthologs in mammals named ubiquinol-cytochrome $c$ reductase complex assembly factors 1 and 2 (UQCC1 and UQCC2), with the same function [234]. Cbp3 interacts directly with Cbp4 (human ortholog: UQCC3), an assembly factor anchored in the IMM and protruding into the intermembrane space. Cbp4 is not necessary for complete translation and release from ribosomes of cytochrome $b$, but it has a role in the stabilization of the semihemylated intermediate that contains $b_{\mathrm{L}}[232,233]$. Together, Cbp3-Cbp6, Cbp4 and cytochrome $b$ compose intermediate I. In yeast, the now mature cytochrome $b$ forms a subcomplex with the subunits Qcr7 and Qcr8, called intermediate II. Deletion of any of the genes encoding cytochrome b, Qcr7 or Qcr8 leads to the almost complete loss of the other two subunits and Qcr6, while the other subunits are only partially reduced [235]. Similarly, the mammalian orthologs UQCRB and UQCRQ are incorporated in the early stages of CIII assembly, provoking the release of the UQCC1-UQCC2 complex.

The following steps of CIII assembly, instead, have been proposed to differ between yeasts and mammals. The order of incorporation in S. cerevisiae was determined by generating yeast mutants for single CIII subunits and studying the stability of the remaining components of the complex [217-219]. The third intermediate step involves the insertion of four subunits: Qcr6 (UQCRH in humans), the two large structural core subunits Cor1 and Cor2 (UQCRC1 and UQCRC2), and cytochrome $c 1$ (Cyt1). At this stage, dimerization occurs by joining assembly intermediate II and the Cor1/2 modules [236]. Interestingly, Cor1, Cor2 and cytochrome $c 1$ were found associated in a subassembly module, even if the contacts between the core proteins and the catalytic subunits in the fully assembled enzyme are minimal [217]. Surprisingly, the complex Cor1/Cor2 was detected in various subcomplexes in two-dimensional electrophoresis. This behavior might be due to the association of these subunits with other proteins or ETC complexes in the IMM or to the formation of Cor1/Cor2 aggregates. However, these subassemblies were detectable only in mutant strains and disappeared when the complex was assembled correctly; therefore, they might not represent a physiological intermediate. The last assembly factor that might have a role in the early or intermediate phases of CIII assembly is Bca1, an inner membrane protein found only in fungi [237]. However, its function is not clear yet.

Taking advantage of CIII-deficient transmitochondrial cybrids carrying a mutation in $M T C Y B$, however, we recently highlighted two important differences between these steps of CIII biogenesis in yeasts and in humans [223]. Firstly, we observed the formation of subassemblies containing CYC1, UQCR10 and potentially UQCRH, while our data did not suggest any interaction of CYC1 with the core subunits UQCRC1 and UQCRC2. Secondly, we identified CIV subunits, mainly belonging to the MTCO2 module, consistently interacting with this intermediate in the CIII-mutant cells. These results suggest that CIII might use CIV or CIV modules as a structural scaffold in a physiological context, or sequester CIV-specific subunits or intermediates when supercomplex formation is impaired, as a control mechanism to inhibit the complete biogenesis of the enzyme. The yeasts-based and the updated CIII assembly models are shown in Figure 11.

A requirement for the generation of intermediate III is the synthesis, the import and the maturation of Cyt1. Cyt1 contains a single heme center and is anchored to the IMM via a single transmembrane segment near its C-terminus [91]. The precursor of this subunit is translated in the cytosol and transported through TOM and TIM complexes into the mitochondria. The cytochrome $c_{1}$ precursor protein contains an $\mathrm{N}$-terminal cleavable 
bipartite pre-sequence [238]. The first of the two independent sequences, a strongly basic region of 35 amino acids, is a mitochondrial targeting signal and it is proteolytically removed by MPP in the matrix. The second sequence is a hydrophobic sorting sequence, which targets Cyt1 to the IMM. However, two models have been proposed to explain this process. The first one proposes that the whole protein, and therefore both the targeting sequences, reach the mitochondrial matrix and that only later is the second sequence relocated into the membrane, allowing the proteolytic cleavages [239]. Instead, in the second model, only the first segment reaches the mitochondrial matrix, while the second internal hydrophobic sequence remains anchored in the membrane, stopping the import. In the matrix, the positive-charged mitochondrial targeting sequence is cleaved by MPP. At the same time, the C-terminal alpha-helix gets inserted into the membrane and the heme center is attached to the protein. The hemylation is mediated by holocytochrome $c_{1}$ synthetase (Cyt2 or HCCS1 in mammals) [240]. This modification provokes a conformational change that allows the exposure and the cleavage of the second targeting sequence by $\operatorname{Imp} 2$ (inner membrane peptidase 2), leaving the $\mathrm{N}$-terminus of the mature Cyt1 soluble in the intermembrane space [241].

The late assembly stages involve the incorporation of Qcr9 (mammalian UQCR10) in yeasts, and Qcr10 (UQCR11) and Rip1 (UQCRFS1) both in yeasts and mammals. Firstly, Qcr9 is inserted [242]. This small (7.3 kDa) accessory subunit is necessary for the functionality of the complex and its deletion results in the formation of a nearly inactive enzyme. Indeed, it has been observed that, lacking Qcr9, the conformation of Rip1 is altered and the Fe/S cluster is not incorporated correctly [243]. The last two proteins to be inserted are Qcr10 and Rip1. Qcr10 is an $8.5 \mathrm{kDa}$ supernumerary subunit incorporated before Rip1 and required for its stabilization. However, it is not clear yet how and when it is recruited [244]. Many studies, instead, have been published about the maturation and insertion of the Rieske protein both in yeast and mammals.

Prior to the insertion, Rip1 is imported into mitochondria and receives its $2 \mathrm{Fe} / 2 \mathrm{~S}$ center, likely by the resident iron-sulfur cluster (ISC) system. In yeast, the import is followed by two proteolytic steps that eliminate the N-terminal MTS. The precursor form is first processed by a matrix MPP protease into an intermediate form [245]. The second cleavage generates the mature form of the protein and is catalyzed by the mitochondrial intermediate peptidase (MIP). At this point, Rip1 is transported back across the IMM into the intermembrane space, where it is assembled in the complex. In mammals, however, the UQCRFS1 N-terminal import signal is cleaved in a single step when the protein is already incorporated in the complex and the cleaved segment remains attached to the enzyme [200].

Two assembly factors are necessary for the Rieske protein assembly in both mammals and yeast: Bcs1 (BCS1L in mammals) and Mzm1 (LYRM7). Bcs1 is a 456 amino acid protein formed by three different domains: a positively charged 126 amino acid $\mathrm{N}$-terminal targeting signal [246], a central Bcs1p-specific domain and a highly conserved C-terminal AAA-ATPase domain [247]. It has been initially proposed that Bcs1p might have a role in $\mathrm{Fe} / \mathrm{S}$ cluster insertion, act as a chaperone [248] or bind to the partially formed CIII in an ATP-dependent manner, keeping it in a state that allows the incorporation of the Rieske protein [249]. The most recent theory is that Bcs1 is responsible for the export of the Rieske Fe/S domain from the matrix into the intermembrane space [250]. Bcs1, indeed, is able to recognize the correctly folded Rieske protein and act as a protein translocase. This model has been confirmed by the determination of the cryogenic electron microscopy (cryo-EM) structure of Bcs1 in yeast [251] and mice [252], which suggested an airlock-like mechanism for Rip1/UQCRFS1 translocation. Bcs1, indeed, seems to form two large aqueous vestibules, a bigger one on the matrix side and a smaller one in the inner membrane, through which the Rieske protein is transported.

Mzm1 is a $14 \mathrm{kDa}$ protein located in the mitochondrial matrix. It was initially thought to be involved in the modulation of the zinc pool and to this function it owes its name (mitochondrial zinc maintenance 1) [253]. However, in addition to the reduced zinc pool, cells lacking Mzm1 have a defect in CIII due to faulty insertion of Rip1 [254]. Its role is 
to stabilize Rip1 in the matrix before the translocation to the IMM. The same function is shared by the human ortholog, LYRM7 or MZM1L [255].

Finally, the third factor necessary for UQCRFS1 metabolism, which does not have a yeast ortholog, is TTC19 [256]. TTC19 binds to CIII after the incorporation of UQCRFS1 and is involved in the clearance of UQCRFS1 fragments, a process that is necessary to keep the complex in a functionally competent state [201]. A complete list of CIII subunits is indicated in Table 4 and the latest model of the CIII biogenesis pathway is represented in Figure 11.
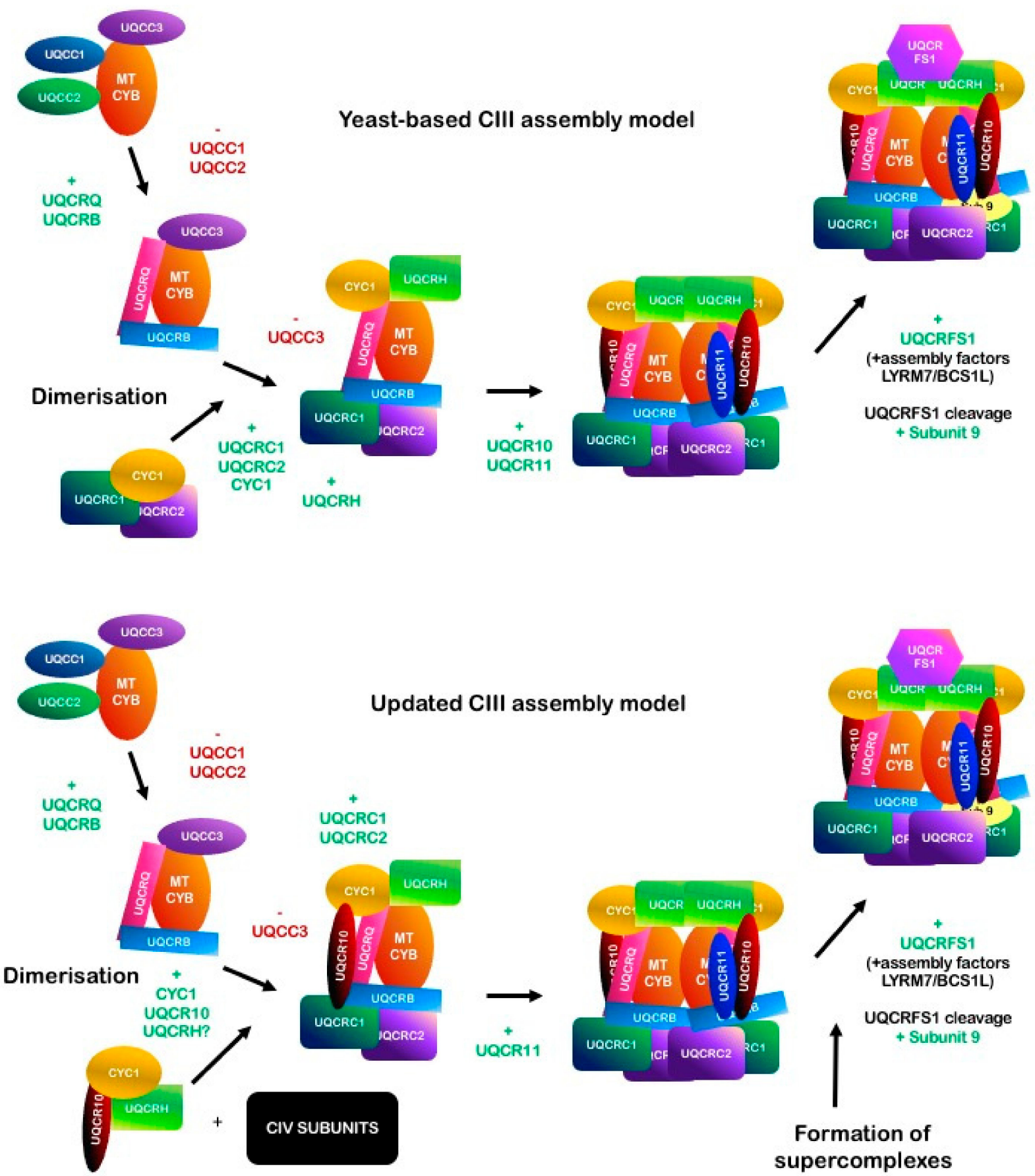

\section{Formation of supercomplexes}

Figure 11. Schematic representation of human CIII assembly model based on the homology with the available data for $S$. cerevisiae [217-219,221,232,233,236,250,254,257], and of our updated model [220]. 
Table 4. List of CIII subunits and factors involved in CIII assembly, both in S. cerevisiae and humans.

\begin{tabular}{|c|c|c|c|c|c|}
\hline \multicolumn{2}{|c|}{ S. cerevisiae } & \multicolumn{2}{|c|}{ Homo sapiens } & & \multirow[b]{2}{*}{$\begin{array}{l}\text { Reference } \\
\text { (ID Yeast) }\end{array}$} \\
\hline Gene & Protein & Gene & Protein & & \\
\hline \multicolumn{6}{|c|}{ Complex III subunits } \\
\hline COR1 & Cor1 & UQCRC1 & UQCRC1 & & [258] \\
\hline COR2 & Cor2 & UQCRC2 & UQ̄CRC2 & & [259] \\
\hline $\mathrm{COB}$ & Cytb & $M T-C Y B$ & Cytochrome $b$ & & [260] \\
\hline CYT1 & Cytc1 & CYC1 & CYC1 & & [238] \\
\hline RIP1 & Rip1 & UOCRFS1 & UOCRFS1 & & [261] \\
\hline QCR6 & Qcr6 & UQCRH & UQCRH & & [262] \\
\hline QCR7 & Qcr7 & $U \widetilde{Q C R B}$ & UQCRB & & [263] \\
\hline QCR8 & Qcr8 & $U \widetilde{Q C R Q}$ & UQCRQ & & [264] \\
\hline QCR9 & Qcr9 & UQCR10 & UQCR10 & & [242] \\
\hline QCR10 & Qcr10 & UQCR11 & UQCR11 & & [244] \\
\hline- & - & UQCRFS1 & UQCRFS1 & & - \\
\hline \multicolumn{4}{|c|}{ Translation factors } & Function & Reference \\
\hline CBP1 & Cbp1 & - & - & Translational activator of COB mRNA & [265] \\
\hline CBS1 & Cbs1 & - & - & Translational activator of COB mRNA & [266] \\
\hline CBS2 & Cbs2 & - & - & Translational activator of COB mRNA & [266] \\
\hline CBP3 & Cbp3 & UQCC1 & UQCC1 & Translational activator of $\mathrm{COB}$ & [267] \\
\hline CBP6 & Cbp6 & UQ̄CC2 & UQ̄CC2 & Translational activator of $\mathrm{COB}$ & [268] \\
\hline \multicolumn{6}{|c|}{ Assembly factors } \\
\hline CBP3 & Cbp3 & UQCC1 & UQCC1 & Cytochrome $b$ assembly factor & [267] \\
\hline CBP6 & Cbp6 & UQCC2 & UQCC2 & Cytochrome $b$ assembly factor & [268] \\
\hline CBP4 & Cbp4 & UQCC3 & UQCC3 & Cytochrome $b$ assembly factor & {$[269,270]$} \\
\hline FMP25 & Bca1 & $\alpha$ & - & $\begin{array}{l}\text { Early/intermediate stages assembly } \\
\text { factor in fungi }\end{array}$ & [237] \\
\hline CYT2 & Cyt2 & VPS53 & HCCS1 & Heme lyase (Cytochrome $c 1$ ) & [240] \\
\hline CYC2 & Сус2 & - & - & $\begin{array}{c}\text { Cytochrome } c 1 \text { and cytochrome } c \\
\text { assembly factor }\end{array}$ & [271] \\
\hline BCS1 & Bcs1 & $B C S 1 L$ & BCS1L & $\begin{array}{l}\text { AAA-ATPase involved in Rieske } \\
\text { protein incorporation }\end{array}$ & $\begin{array}{c}{[248-} \\
250,272]\end{array}$ \\
\hline MZM1 & Mzm1 & LYRM7 & LYRM7 & $\begin{array}{l}\text { Matrix protein involved in Rieske } \\
\text { protein incorporation }\end{array}$ & {$[253,255,257]$} \\
\hline- & - & TTC19 & TTC19 & Rieske protein metabolism & [256] \\
\hline
\end{tabular}

\subsubsection{Pathologies Associated with Complex III Deficiency}

Pathologies due to deficiencies in CIII activity are relatively infrequent and most of them derive from mutations in $M T C Y B$, the only mtDNA-encoded subunit. Mutations in this protein are generally associated with myopathy and exercise intolerance [193]. Defects in nuclear-encoded subunits are rarer, but a handful of mutations have been found in several patients (Table 5). The majority of the pathological variants associated with mitochondrial CIII deficiency of nuclear origin are found in BCS1L [273]. The genes found mutated in patients with CIII deficiency and the relative clinical phenotypes are summarized in Table 5.

Table 5. CIII subunits and assembly factors associated with mitochondrial diseases.

\begin{tabular}{|c|c|c|c|}
\hline Gene/Protein & OMIM & Associated Phenotype & Reference \\
\hline \multicolumn{4}{|c|}{ Complex III subunits } \\
\hline UQCRC2 & 191329 & Hypoglycemia, lactic acidosis, ketosis and hyperammonemia. & [274] \\
\hline MTCYB & 516020 & $\begin{array}{c}\text { Leber optic atrophy, exercise intolerance, encephalomyopathy, cardiomyopathy and } \\
\text { multisystemic disorder. }\end{array}$ & [275-279] \\
\hline CYC1 & 123980 & $\begin{array}{c}\text { Neurologic deterioration, insulin-responsive hyperglycemia, ketoacidosis with increased serum } \\
\text { lactate, liver failure and hyperammonemia. }\end{array}$ & [280] \\
\hline UQCRB & 191330 & $\begin{array}{c}\text { Gastroenteritis, liver enlargement, hypoglycemia and metabolic acidosis but normal } \\
\text { psychomotor development at age } 4 \text {. }\end{array}$ & [216] \\
\hline UQCRQ & 612080 & Severe neurologic phenotype. & [215] \\
\hline UQCRFS1 & 191327 & Cardiomyopathy and alopecia totalis. & [281] \\
\hline
\end{tabular}


Table 5. Cont.

\begin{tabular}{ccccc}
\hline Gene/Protein & OMIM & Associated Phenotype & Reference \\
\hline \multicolumn{5}{c}{ Complex III assembly factors } \\
\hline BCS1L & 603647 & GRACILE Syndrome, Bjornstad Syndrome, myopathy, encephalopathy, proximal tubulopathy & [272,273,282-288] \\
TTC19 & 613814 & Pnd liver failure. & Progressive encephalopathy, ataxia, spastic paraparesis and psychiatric phenotype. & {$[256,289-292]$} \\
LYRM7 & 615831 & Neurological decompensation and regression, leukoencephalopathy and liver failure. & {$[293,294]$} \\
UQCC2 & 614461 & Intrauterine growth retardation, neonatal lactic acidosis and renal tubular dysfunction. & {$[234,295]$} & [270] \\
UQCC3 & 616097 & Lactic acidosis, hypoglycemia, hypotonia and delayed development. & \\
\hline
\end{tabular}

\subsection{Complex IV}

\subsubsection{Structure and Subunits}

Cytochrome $c$ oxidase (COX, complex IV, CIV) is the terminal step of the ETC. The enzyme has a molecular mass of about $200 \mathrm{kDa}$ and in mammals it is composed of 13 subunits, 10 nuclear-encoded and 3 encoded by the mtDNA (MTCO1, MTCO2 and MTCO3), which form the functional core of the complex [296] (Figure 12). However, recently a 14th subunit, NDUFA4, previously attributed to CI, has been described [297,298] and was found to be incorporated in the structure of monomeric human CIV [299].

MTCO1 contains three prosthetic groups: cytochrome $a_{3}$ and $\mathrm{Cu}_{\mathrm{B}}$, which form the bi-nuclear center that binds oxygen, and cytochrome $a$. MTCO2 incorporates the $\mathrm{Cu}_{\mathrm{A}}$ center [300] and MTCO3 does not have catalytic activity. The remaining subunits (COX4, 5A, $5 \mathrm{~B}, 6 \mathrm{~A}, 6 \mathrm{~B}, 6 \mathrm{C}, 7 \mathrm{~A}, 7 \mathrm{~B}, 7 \mathrm{C}, 8 \mathrm{~A}$ ) are thought to have a structural role in the stabilization of the complex. Interestingly, $\mathrm{CIV}$ is the only ETC complex that evolved tissue-, developmentaland species-specific isoforms for COX subunits 4, 6A, 6B, 7A, 7B and 8A [301], probably in order to regulate ATP and energy production in different conditions [302].

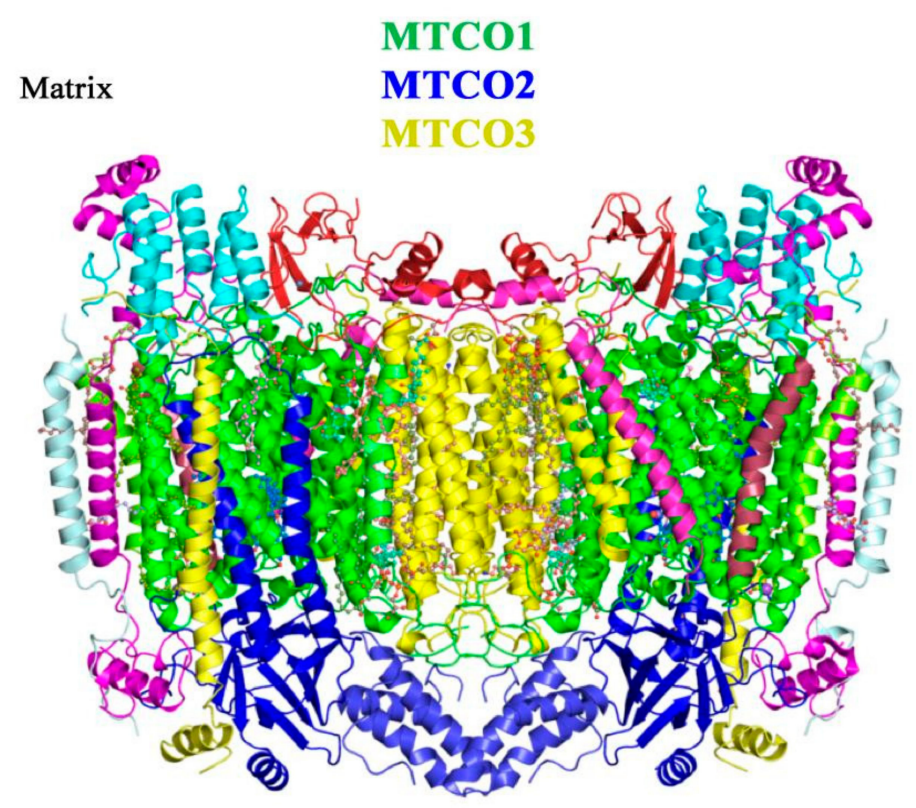

Intermembrane Space

Figure 12. Representation of bovine CIV dimeric structure, obtained from X-ray crystallography (SFX). The functional core of the complex is composed of the mitochondrial-encoded subunits MTCO1 (green), MTCO2 (dark blue) and MTCO3 (yellow). Source: adapted from Ishigami et al., 2017 [303].

\subsubsection{Assembly}

CIV assembly is now understood as a modular process. MTCO1 was classically considered the "seed" around which the rest of the complex assembles [304,305]. However, 
recent evidence indicates that the first CIV subassembly is formed by the association between two nuclear-encoded subunits, COX4I1 and COX5A [306]. This module contains also HIGD1A, a protein initially proposed to be involved in the regulation of CIV activity during hypoxia [307].

In parallel, the MTCO1 module, also known as "MITRAC" (MItochondrial TRanslation Regulation Assembly intermediate of Cytochrome $c$ oxidase) [308,309], is formed, composed of the CIV subunit and a series of assembly factors necessary for its maturation and stabilization. The first level of regulation of this module is translational, with the activity of the mitochondrial RNA-binding protein LRPPRC [310] and the translational activator TACO1 [311]. After translation, the newly synthesized protein has to be inserted in the IMM. The first factors binding MTCO1 are COX14/C12ORF62 and COA3/CCDC56/MITRAC12 [308,312-314]. These two chaperones assist MTCO1 during and after its insertion in the membrane and avoid the aggregation of MTCO1 subunits. The transient complex MTCO1/COX14/COA3 is stabilized by another assembly factor, CMC1 [315].

At this point of the pathway, MTCO1 needs the incorporation of the three prosthetic groups. Heme $a$ biosynthesis is carried out by COX10 and COX15 catalyzing the conversion of heme $b$ to heme $o$, and then heme $o$ to heme $a[316,317]$. On the other hand, the assembly factor SURF1 has been proposed to participate in its delivery [305]. In addition, PET117 might also have a role in this process because it was found interacting with COX15 in yeast, but its involvement still has to be shown in mammals [318]. $\mathrm{Cu}_{\mathrm{B}}$ incorporation is mediated by the metallochaperone COX11 [319], which is maintained in the correct redox state by COX19 [320]. The coppers are donated by COX17 [321].

MTCO2 requires binding with COX18 in order to be inserted in the IMM [322] and with COX20/FAM36A and TMEM177 for stabilization $[323,324]$. Secondly, the $\mathrm{Cu}_{\mathrm{A}}$ center must be inserted in MTCO2. This process is regulated by the copper-binding proteins COX17, SCO1 and SCO2 [325-327], together with COA6 [328,329] and COX16 [330,331]. The MTCO2 module (MTCO2 + COX5B + COX6C + COX7C + COX8A and, most probably, COX7B) is incorporated in intermediate steps of the assembly process by joining the COX4I1-COX5A and the MTCO1 modules, forming the "S3" intermediary. This intermediary binds three assembly factors, PET100 [332], PET117 [318] and MR-1S [306]. MR-1S is a vertebrate-specific chaperone that interacts with the highly conserved factors PET100 and PET117. An additional assembly factor, APOPT1 or COA8, was proposed to have a role in the intermediate steps of CIV assembly in mouse and human mitochondria (Signes et al., 2019). Finally, the MTCO3 module (MTCO3 + COX6A1 + COX6B1 + COX7A2) is incorporated [306], followed by NDUFA4 initially described as a CI subunit and later assigned to CIV [305]. All known CIV assembly factors are summarized in Table 6.

Table 6. Factors involved in mammals CIV assembly. When present, the yeast orthologue is indicated.

\begin{tabular}{|c|c|c|c|c|}
\hline $\begin{array}{c}\text { Assembly } \\
\text { Factor (Yeast) }\end{array}$ & $\begin{array}{l}\text { Assembly Factor } \\
\text { (Mammals) }\end{array}$ & Function & $\begin{array}{l}\text { CIV Interacting } \\
\text { Module }\end{array}$ & References \\
\hline \multicolumn{5}{|c|}{ RNA stability and translation } \\
\hline- & TACO1 & \multirow{3}{*}{$\begin{array}{l}\text { Translational activator of mitochondria-encoded MTCO1. } \\
\text { Mitochondrial mRNA stability. } \\
\text { Involved in post-transcriptional RNA maturation, ribosome biogenesis and } \\
\text { translation. }\end{array}$} & MTCO1-translation & [311] \\
\hline- & LRPPRC & & - & [310] \\
\hline- & FASTKD2 & & - & [333] \\
\hline \multicolumn{5}{|c|}{ Heme a biosynthesis and insertion } \\
\hline Cox10 & COX10 & Heme $a$ synthesis (conversion of heme $b$ into heme $o$ ). & MTCO1 module & {$[316,334]$} \\
\hline Cox15 & COX15 & Heme $a$ synthesis (conversion of heme $o$ into heme $a$ ). & MTCO1 module & {$[335,336]$} \\
\hline Shy1 & SURF1 & Involved in the insertion or stabilization of heme $a_{3}$. & $\begin{array}{l}\text { Early MTCO1 } \\
\text { subcomplexes }\end{array}$ & [337] \\
\hline \multicolumn{5}{|c|}{ Copper metabolism and insertion } \\
\hline Coa6 & COA6 & Copper homeostasis and transport to CIV. & MTCO2 module & {$[328,338]$} \\
\hline Sco1 & SCO1 & Incorporation of copper atoms. & MTCO2 module & {$[327,339]$} \\
\hline- & $\mathrm{SCO} 2$ & Incorporation of copper atoms. & MTCO2 module & [340] \\
\hline Cox11 & COX11 & Copper chaperone. & MTCO1 module & {$[319,341]$} \\
\hline Cox16 & COX16 & MTCO2 maturation. & MTCO2 module & {$[331,342]$} \\
\hline Cox17 & COX17 & Copper transfer. & MTCO1 module & [321] \\
\hline
\end{tabular}


Table 6. Cont.

\begin{tabular}{|c|c|c|c|c|}
\hline $\begin{array}{c}\text { Assembly } \\
\text { Factor (Yeast) }\end{array}$ & $\begin{array}{l}\text { Assembly Factor } \\
\text { (Mammals) }\end{array}$ & Function & $\begin{array}{l}\text { CIV Interacting } \\
\text { Module }\end{array}$ & References \\
\hline Cox19 & COX19 & Stabilization of COX11. & MTCO1 module & {$[320,343]$} \\
\hline \multicolumn{5}{|c|}{ Assembly } \\
\hline Coa3 & COA3/MITRAC12 & $\begin{array}{l}\text { Required for MTCO1 stability and assembly. Involved in translational regulation } \\
\text { of MTCO1 and prevention of MTCO1 aggregation before assembly. }\end{array}$ & MTCO1 module & {$[313,314]$} \\
\hline- & COA7 & Unknown. & Unknown & [177] \\
\hline Cox14 & COX14/c12orf62 & MTCO1 stability and assembly; avoids MTCO1 aggregation. & MTCO1 module & {$[312,344]$} \\
\hline Cmc1 & CMC1 & Stabilizes the interaction between MTCO1, COX14 and COA3. & MTCO1 module & [315] \\
\hline- & COX20/FAM36A & MTCO2 chaperone for copper metalation. & MTCO2 module & [345] \\
\hline Pet100 & PET100 & Assembly factor. & S3 intermediary & [346-348] \\
\hline Pet117 & PET117 & Assembly factor; possible role in Cox15 oligomerization and function. & S3 intermediary & {$[318,349,350]$} \\
\hline- & MR-1S & Interacts with PET117 and PET100. & S3 intermediary & [306] \\
\hline- & APOPT1/COA8 & Intermediate assembly steps. Putative role in CIV protection from ROS damage. & Unknown & [351] \\
\hline Cox18 & COX18 & Promotes the translocation of MTCO2 globular domain through the IMM. & MTCO2 & {$[352,353]$} \\
\hline
\end{tabular}

\subsubsection{Pathologies Associated with Complex IV Deficiency}

After CI-related pathologies, defects in CIV are the most common OXPHOS defects associated with mitochondrial disease [193]. The most frequent clinical phenotypes associated with CIV deficiencies are myopathy, affecting the skeletal muscles, and systemic pathologies, such as Leigh's disease and multiorgan failure (https://rarediseases.org/ rare-diseases / cytochrome-c-oxidase-deficiency/). As in most of the mitochondrial diseases, symptoms can be very heterogeneous and the severity of the pathology can vary greatly [354]. While most of the pathological mutations found in patients are associated with assembly factors of the enzyme or with mitochondrial tRNAs (mutations in tRNA ${ }^{\text {Lys }}$,

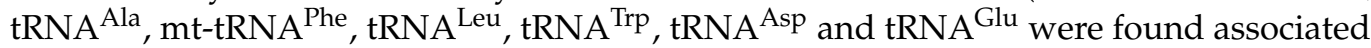
with COX deficiency [354], only few cases of mutations in CIV structural subunits have been reported. This observation suggests that mutations in CIV subunits might be incompatible with life. The genes found mutated in patients with CIV deficiency and the relative clinical phenotypes are summarized in Table 7.

Table 7. CIV subunits and assembly factors associated with mitochondrial diseases.

\begin{tabular}{|c|c|c|c|}
\hline Gene/Protein & OMIM & Associated Phenotype & Reference \\
\hline \multicolumn{4}{|c|}{ Complex IV subunits } \\
\hline MTCO1 & 516030 & $\begin{array}{l}\text { MELAS syndrome, myopathy, myoglobinuria, motor neurone disease, exercise intolerance, epilepsy, } \\
\text { multisystem disorders, deafness, LHON or mitochondrial sensorineural hearing loss. }\end{array}$ & {$[355-359]$} \\
\hline MTCO2 & 516040 & Encephalomyopathy, LHON, myopathy, hypertrophic cardiomyopathy. & [360-363] \\
\hline MTCO3 & 516050 & $\begin{array}{l}\text { MIDD, LHON, myopathy, Leigh disease, myoglobinuria, sporadic bilateral optic neuropathy, } \\
\text { rhabdomyolysis, encephalopathy. }\end{array}$ & {$[364-369]$} \\
\hline COX4I1 & 123864 & Short stature, poor weight gain, mild dysmorphic features, Fanconi anemia. & [370] \\
\hline COX4I2 & 607976 & Exocrine pancreatic insufficiency, dyserythropoietic anemia, calvarial hyperostosis. & {$[371]$} \\
\hline COX5A & 603773 & Early-onset pulmonary arterial hypertension, lactic acidemia, failure to thrive. & [372] \\
\hline COX6A1 & 602072 & Charcot-Marie-Tooth disease. & [373] \\
\hline COX6A2 & 602009 & Muscle weakness and hypotonia, cardiomyopathy. & [374] \\
\hline COX6B1 & 124089 & Severe infantile encephalomyopathy. & [375] \\
\hline COX7A1 & 123995 & Failure to thrive, encephalopathy, hypotonia. & [376] \\
\hline COX7B & 300885 & Microphthalmia with linear skin lesions. & [377] \\
\hline COX8A & 123870 & Leigh-like syndrome presenting with leukodystrophy and severe epilepsy. & [378] \\
\hline NDUFA4 & 603833 & Leigh syndrome. & [298] \\
\hline \multicolumn{4}{|c|}{ Complex IV assembly factors } \\
\hline SURF1 & 185620 & Leigh syndrome, Charcot-Marie-Tooth disease. & {$[379,380]$} \\
\hline COA3/MITRAC12 & 614775 & Mild phenotype, exercise intolerance, peripheral neuropathy, obesity and short stature. & [308] \\
\hline COA7 & 615623 & Ataxia and peripheral neuropathy, cognitive impairments, leukodystrophy. & [177] \\
\hline COX14/c12orf62 & 614478 & Severe lactic acidosis and dysmorphic features. & [344] \\
\hline COX20/FAM36A & 614698 & Growth delay, hypotonia, cerebellar ataxia. & [381] \\
\hline PET100 & 614770 & Early-onset psychomotor delay, seizures, hypotonia, Leigh syndrome. & {$[347,348]$} \\
\hline PET117 & 614771 & Neurodevelopmental regression. & [350] \\
\hline APOPT1/COA8 & 616003 & Leukodystrophy, neurological signs. & [382] \\
\hline SCO1/SCO2 & $603644 / 604272$ & $\begin{array}{c}\text { Cardioencephalomyopathy, Leigh syndrome-like symptoms, spinal muscular atrophy-like presentations, } \\
\text { Charcot-Marie-Tooth disease type } 4 .\end{array}$ & {$[383,384]$} \\
\hline COX10/COX15 & $602125 / 603646$ & Leigh syndrome, encephalopathy, cardiomyopathy, sensorineural deafness and metabolic acidosis. & {$[316,336]$} \\
\hline COA6/C1orf31 & 614772 & Fatal infantile cardioencephalopathy. & [385] \\
\hline TACO1 & 612958 & Leigh syndrome. & [311] \\
\hline COA5 & 613920 & Fatal infantile cardioencephalomyopathy. & [386] \\
\hline FASTKD2 & 612322 & $\begin{array}{c}\text { Brain atrophy, epilepsy, delayed psychomotor development, bilateral optic atrophy, spastic hemiparesis, } \\
\text { cardiomyopathy. }\end{array}$ & {$[387,388]$} \\
\hline LRPPRC & 607544 & French Canadian type of Leigh syndrome. & [389] \\
\hline
\end{tabular}




\subsection{Complex $V$}

\subsubsection{Structure and Assembly}

ATP synthase (Complex V, CV) is the enzyme that catalyzes the synthesis of ATP from $\mathrm{ADP}$ and phosphate. It is composed of two distinct domains: the $\mathrm{F}_{1}$ domain, which faces the mitochondrial matrix, and the $F_{o}$ domain, located in the IMM $[390,391]$. The human $\mathrm{CV}$ is composed of 29 proteins of $18 \mathrm{kinds}$, only two of which are encoded by the mtDNA (ATP6 and ATP8) [392]. A schematic representation of the main domains of CV is shown in Figure 13. The $F_{1}$ domain is composed of three copies of subunits $\alpha$ and $\beta$, and one copy of subunits $\gamma, \delta$ and $\varepsilon . \gamma, \delta$ and $\varepsilon$ subunits form the central stalk of the complex, while $\alpha$ and $\beta$ are the subunits that physically interact with the ADP and ATP molecules [390]. $\mathrm{F}_{\mathrm{o}}$, instead, is composed of a ring of $\mathrm{c}$ subunits and one copy each of subunits $\mathrm{a}, \mathrm{b}, \mathrm{d}, \mathrm{F}_{6}$ and the oligomycin sensitivity-conferring protein (OSCP). The c-ring stoichiometry is not constant, but can vary, ranging from 8 copies in vertebrates to 15 in photosynthetic organisms [393].

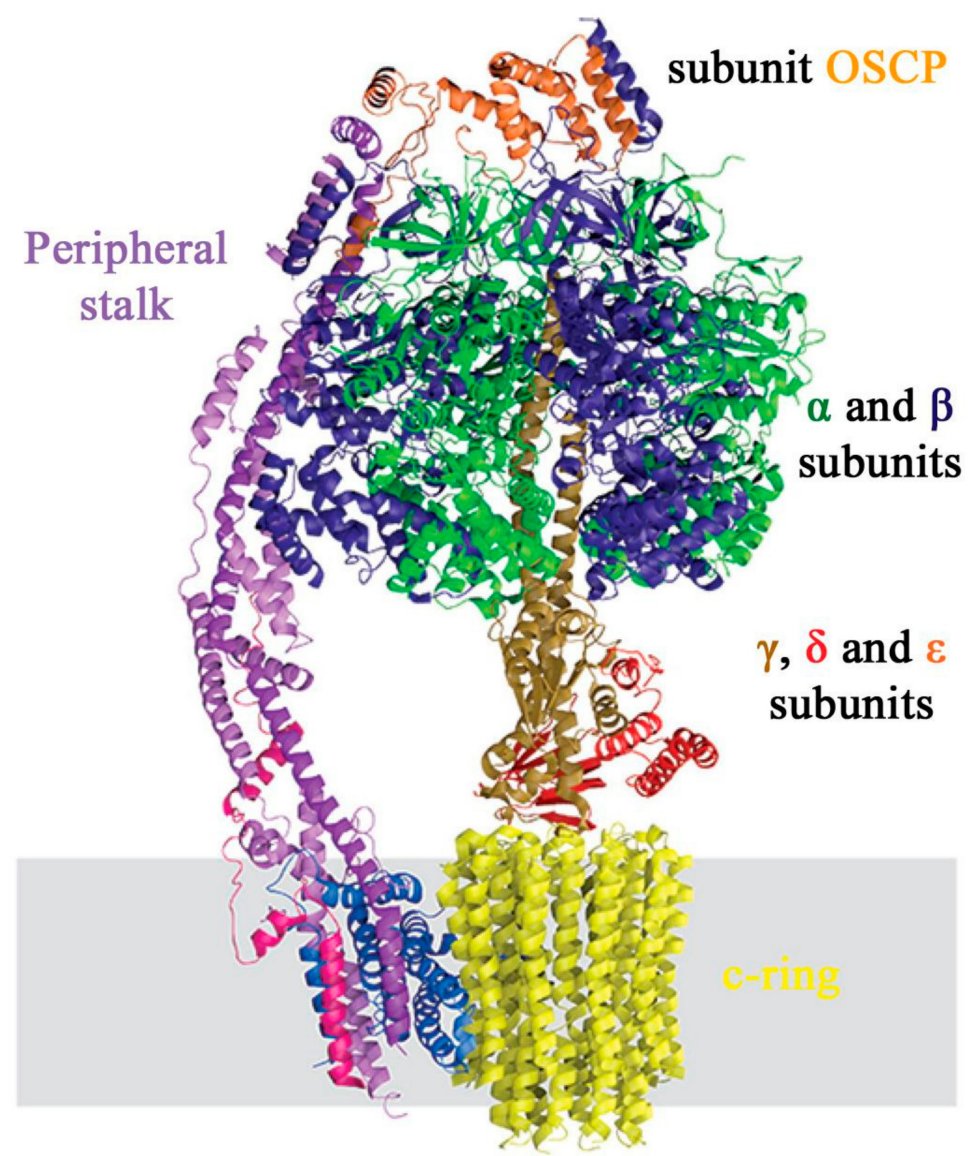

Figure 13. Representation of S. cerevisiae CV structure. The main subunits of the enzyme are indicated and shown in different colors. Source: adapted from Kuhlbrandt, 2019 [394].

Each c subunit is able to bind one proton in the IMS, which interacts with a conserved carboxylate group from a glutamate or aspartate side chain. The protonation of these subunits provokes the rotation of the c-ring, until the final dissociation of the proton at the matrix side favored by the positive charge on a conserved arginine residue (A210) of subunit a [56]. The c-ring is structurally linked to the $\gamma$ and $\epsilon$ subunits and its rotation provokes the turn of these subunits inside the $\alpha_{3} \beta_{3}$ hexamer unit of $F_{1}$. On the external side, the $\alpha_{3} \beta_{3}$ hexamer is prevented from rotating by the peripheral stalk formed by the two $\mathrm{b}$ chains and the $\mathrm{d}$ subunit. The result of the proton transport, therefore, is first the rotation of the c-ring, followed by the rotation of the $\gamma$ subunit, and the consequent synthesis of ATP through the binding change mechanism of $\alpha_{3} \beta_{3}$. The binding change mechanism is 
based on the fact that the interactions between the $\gamma$ subunit and the three $\beta$ subunits are not identical. The result is three different conformations for the three $\beta$ subunits: $\mathrm{T}$ (tight), $\mathrm{L}$ (loose) and $\mathrm{O}$ (open). The subunit in T conformation binds ATP very strongly and its affinity for the molecule is so high that it will induce the conversion of ADP $+P_{i}$ into ATP. The subunit in the L conformation, instead, is able to bind ADP and $P_{i}$ but it cannot release the nucleotides. Finally, the $\mathrm{O}$ conformation allows the release of the formed ATP. The result of the $\gamma$ subunit rotation is the change in these subunit conformations allowing the passage through all the stages and the generation of ATP [56].

As for the other complexes described, the CV assembly is also modular. Three subassemblies are formed individually and then put together: the $F_{1}$ module, the c-ring and the peripheral stalk [395]. The $\mathrm{F}_{1}$ subcomplex formation requires the activity of the chaperones ATPAF1/ATP11 and ATPAF2/ATP12, which bind ATP5B and ATP5A1, respectively [396]. Initially, the $\mathrm{F}_{1}$ and the c-ring modules assemble. The peripheral stalk, instead, is incorporated in two additional steps: the incorporation of b/ATP5F1, d/ATPH, $\mathrm{F}_{6}$ / ATP5J and OSCP/ATP5O first and the addition of e/ATP5I, g/ATP5L and f/ATPJ2 in a second step $[397,398]$. Different assembly factors involved in this process have been identified in yeasts. Atp25 stimulates the synthesis and assembly of subunit c of the cring [399], while the protease Atp23 processes and stabilizes the membrane-inserted yeast Atp6, unprocessed in mammals [400]. Finally, the inner membrane assembly complex (INAC), composed of Ina17 and Ina22 [401], binds and stabilizes two distinct assembly intermediates of the yeast ATP synthase: the newly assembled c-ring and an assembly intermediate composed of the $\mathrm{F}_{1}$ domain and the peripheral stalk.

\subsubsection{Pathologies Associated with Complex V Deficiency}

Patients presenting with CV defects are rare and generally associated with neonatalonset hypotonia and hypertrophic cardiomyopathy, lactic acidosis and 3-methylglutaconic aciduria [193]. Only few pathological mutations in CV subunits or assembly factors have been found in patients so far. The majority of these mutations were identified in MT-ATP6, responsible for neurogenic muscle weakness and ataxia and retinitis pigmentosa (NARP) syndrome [402,403], and MT-ATP8 [404], while rarer cases were found in ATP5E, ATP5A1, ATPAF2 and TMEM70 [404-409]. The CV subunits or assembly factors found mutated in patients with $\mathrm{CV}$ deficiency and the relative clinical phenotypes are summarized in Table 8 .

Table 8. CV subunits and assembly factors associated with mitochondrial diseases.

\begin{tabular}{|c|c|c|c|}
\hline Gene/Protein & OMIM & Associated Phenotype & Reference \\
\hline MT-ATP6 & 516060 & $\begin{array}{l}\text { Neuropathy, ataxia and retinitis pigmentosa (NARP), maternally inherited } \\
\text { Leigh's syndrome (MILS), mental retardation, ataxia, cardiomyopathy. }\end{array}$ & {$[402,403,410,411]$} \\
\hline MT-ATP8 & 516070 & Hypertrophic cardiomyopathy and neuropathy. & [404] \\
\hline ATP5E & 614053 & $\begin{array}{l}\text { Neonatal-onset lactic acidosis, 3-methylglutaconic aciduria, mental } \\
\text { retardation, hypertrophic cardiomyopathy and peripheral neuropathy. }\end{array}$ & [405] \\
\hline ATP5A1 & 615228 & Fatal infantile encephalopathy. & [408] \\
\hline ATPAF2 & 608918 & Degenerative encephalopathy, elevated lactate levels, developmental delay. & [412] \\
\hline ATP5F1A & 164360 & Fatal infantile mitochondrial encephalopathy & {$[408,413]$} \\
\hline ATP5F1D & 603150 & $\begin{array}{l}\text { Metabolic decompensation with lactic acidosis, hypoglycemia, } \\
\text { hyperammonemia, 3-methylglutaconic aciduria, encephalopathy. }\end{array}$ & [414] \\
\hline ATP5F1E & 606153 & $\begin{array}{l}\text { Neonatal-onset lactic acidosis, 3-methylglutaconic aciduria, mild mental } \\
\text { retardation, hypertrophic cardiomyopathy, peripheral neuropathy. }\end{array}$ & [405] \\
\hline TMEM70 & 612418 & Neonatal mitochondrial encephalocardiomyopathy. & [119] \\
\hline
\end{tabular}




\subsection{Localization of the OXPHOS Machinery in the IMM}

The OXPHOS machinery is embedded in the IMM, together with a variety of other mitochondrial proteins. Indeed, the IMM is one of the most protein-rich lipid bilayers in biological systems, with a protein/lipid mass ratio of $\sim 75: 25$ [415]. Many protein complexes which localize in this compartment are not distributed randomly, but tend to cluster in specific regions, according to their individual function. As discussed previously, the IMM can be divided into two subdomains: the inner boundary membrane (IBM), opposite to the $\mathrm{OMM}$, and the cristae membrane (CM), the alias for invaginations of the membrane in the matrix, connected by the cristae junctions.

Results obtained with quantitative immunogold-EM on mammalian mitochondria and yeast cells demonstrated that the preferential location of OXPHOS complexes is the CM, but that both subcompartments are dynamic and the distribution of mitochondrial proteins can change according to the physiological state of the cell [416,417]. In particular, it has been observed that OXPHOS enzymes - or intermediates of them-might localize in different regions of the membrane in different stages of maturation. With the only exception of CII, the respiratory chain enzymes are composed of both nuclear- and mitochondrial-encoded subunits, and their biogenesis is the result of the coordination between two temporally and spatially separated protein synthesis machineries. Consequently, it was proposed that, while proteins synthesized in the matrix are translated and inserted directly in the cristae, subunits that must be imported from the cytosol are preferentially inserted in the IBM [417]. More recent analyses by super-resolution microscopy and quantitative cryoimmunogold-EM have helped to determine where specifically CIII, CIV and CV subunits are translated and inserted in the yeast inner membrane [418]. This study confirmed that, under steady-state conditions, the mature forms of CIII, CIV and CV localize mainly in the $\mathrm{CM}$, while early stages of assembly are more enriched in the IBM. Indeed, mitoribosomes translating $C O B$ mRNA (the very first step of CIII assembly) and Cbp3 and Cbp6 (markers for the early assembly of the enzyme) were found more present in the IBM, while Cbp4 (a marker of the early-to-mid-assembly phase) was already less enriched in this subcompartment. Conversely, the integration of the Rieske protein, the last step of maturation, which takes place after CIII dimerization, happened predominantly in the CM. Similarly, Stoldt and colleagues investigated the localization of markers of the early (Pnt1, Cox18, Coa1 and Cox20) and the late (Pet100) phases of CIV assembly, finding the earliest stages of maturation enriched in the IBM and the late phases in the CM. By contrast, the entire assembly pathway of CV seems to occur mainly in the CM [418].

\subsection{Supercomplexes}

The picture of the OXPHOS machinery as individual enzymes sitting in the IMM is a simplified vision of what happens in the mitochondria of living cells. A second level of complexity is added by the formation of supercomplexes (SC), stable structures composed of the association of the respiratory chain enzymes.

The development of blue native PAGE techniques [419] allowed the separation and detection of both the individual complexes and the supercomplexes, composed of different combinations of $\mathrm{CI}, \mathrm{CIII}_{2}$ and $\mathrm{CIV}$. However, many questions remained open in the field. Firstly, it was necessary to characterize the type and strength of these inter-complex interactions, in order to hypothesize a realistic model of IMM organization. Secondly, it was necessary to attempt to explain the biological and physiological function of these structures. This second aspect will be one of the central questions of this thesis.

\subsubsection{Existing Models}

The models to explain the organization of the respiratory chain enzymes have changed over time. The first proposal, known as the "fluid state" model, describes the mitochondrial complexes as individual and independent units that float in the inner membrane and collide randomly with each other, allowing the passage of electrons. According to this theory, cytochrome $c$ would be diffusing in three dimensions, in order to transport electrons 
between complexes, and this transient and casual formation of each SC species by collision would allow the cell to adapt to different energy demands. This model was the most accepted one during the 1980s, following the presentation of the random collision model of Hackenbrock [420]. The fluid model is supported by the very high protein-to-lipid ratio in the membrane, which allows the frequent interaction of the enzymes, and by scanning calorimetry [421] and freeze-fracture electron microscopy [422] studies showing that the intramembrane particles are randomly distributed in the IMM. Moreover, independent studies showed that CoQ is a mobile carrier [423,424], confirming an essential part of this theory. On the other hand, however, both blue native PAGE and electron microscopy experiments in different systems, such as mammals, bacteria, yeasts and plants, suggest more stable interactions between these particles [425-429]. In the original experiments, it was necessary to solubilize the membranes with a strong detergent in order to isolate the single enzyme, while milder detergents such as digitonin used in blue native studies preserve the various species of SC intact.

The second and opposite model proposed was the "solid state" model, which supported the vision that the different activities and redox centers were contained in an undissociated protein matrix. These structures were also thought to contain $\mathrm{Q}$ and cyt $c[430,431]$. This view, however, was challenged by the observation that the isolated complexes were functional and that they could diffuse within the lipid bilayer, as well as activity rate values being compatible with a mechanism of random collision [432]. The "solid state" model remained the most accepted view until the development of the native electrophoretic techniques described above, which showed the co-existence of supercomplexes of different sizes and the individual respiratory chain complexes. From a functional point of view, the proximity of the enzymes and the molecular carriers involved would increase the interactions and prevent the intermediates from escaping or being sequestered by other enzymes for use in secondary metabolic pathways [433]. Indeed, in the model in which the different supramolecular species coexist and trap the mobile electron carriers, the association of CI, III and IV and, on the other side, CIII and IV would define two different functional $C o Q$ populations: $C o Q$ dedicated to transferring electrons originating from NADH (CoQ $\left.\mathrm{Q}_{\mathrm{NDH}}\right)$, which is trapped in $\mathrm{SC}$ containing $\mathrm{CI}$, and free $\mathrm{CoQ}$ in the inner mitochondrial membrane for use by $\mathrm{CII}$ and other enzymes that use FAD (CoQ $\left.\mathrm{FAD}_{\mathrm{F}}\right)$ [434]. However, this system is not compatible with the kinetics of the CoQ pool, and recent additional studies indicated that cytochrome $c$ diffuses freely in the IMS in yeast [433] and that only one CoQ and cytochrome $c$ pools are present, accessible to all the enzymes [435]. An additional interesting analysis has been proposed after inserting AOX (an alternative oxidase) in vitro, a cyanide-insensitive quinol oxidase originally from Trypanosoma brucei, in bovine heart mitochondria [436]. AOX receives electrons from ubiquinone, bypassing CIII and CIV. In the case of two separate pools of ubiquinone, the "respirasome pool" should continue to provide a substantial flux of electrons through the supercomplex. Instead, a competition between respirasomes and AOX was observed in increasing the AOX supplement, confirming the theory that ubiquinone is not channeled but can move freely in the IMM.

In conclusion, putting together the information available today, the most realistic proposal is a middle-ground and more dynamic model in which various species of supercomplexes and free respiratory complexes coexist. For now, the model that explains this phenomenon is the so-called "dynamic aggregate" or "plasticity" model, which proposes a dynamic interchange of the complexes in their "free" and associated states into SC in response to varying energetic demands. A premise for the model is that the complexes are pre-assembled individually before associating with each other $[437,438]$.

\subsubsection{Species of Supercomplexes and Complex-Complex Interactions}

Structures of the $\mathrm{I}_{1} \mathrm{III}_{2} \mathrm{IV}$ and $\mathrm{I}_{1} \mathrm{III}_{2} \mathrm{SC}$ from mammals and plants have been resolved by single-particle electron cryo-EM [439-442] and by electron cryo-tomography (cryo- 
ET) $[443,444]$. The yeast Saccharomyces cerevisiae lacks CI, and complexes III and IV form two SC species $\mathrm{III}_{2} \mathrm{IV}_{1}$ and $\mathrm{III}_{2} \mathrm{IV}_{2}$, the structures of which have been recently solved $[445,446]$. In mammals, the main supercomplex species are $\mathrm{III}_{2} \mathrm{IV}_{1}, \mathrm{I}_{1} \mathrm{III}_{2}$ and the respirasomes $\mathrm{I}_{1} \mathrm{III}_{2} \mathrm{IV}_{1-\mathrm{n}}$. The existence of a "Megacomplex" with a $\mathrm{I}_{2} \mathrm{III}_{2} \mathrm{IV}_{2}$ stoichiometry, which might also bind CII, was reported in cultured human cells [441]. Additionally, CIV and CV can form homodimers and CIV is involved in the formation of other high-molecular weight structures not yet identified, but visible in blue native PAGE experiments $[395,447,448]$. "Megacomplexes" containing also CII have been proposed as well, but their existence is debated.

Since Saccharomyces cerevisiae lacks CI [449], yeast-based studies of the respirasomes have been conducted in Yarrowia lipolytica [444]. In this model, CI and CIII interactions are comparable to what has been observed in mammals, while CIV was found in various positions around $\mathrm{CIII}_{2}$, but not in the position most commonly observed in the porcine heart respirasomes, contacting the ND5 module of CI (Figure 14).

In plants, on the other hand, CIV was never observed in the respirasomes and the only apparent supercomplex was $\mathrm{I}_{1} \mathrm{III}_{2}$. Interestingly, supercomplexes are not universal and simpler organisms such as Escherichia coli, which express CI, CII and CV homologues, but not CIII, do not present such structures [450]. In these bacteria, the different complexes have been shown to not co-localize together and to not sub-localize in specific domains over the membrane surface [451].

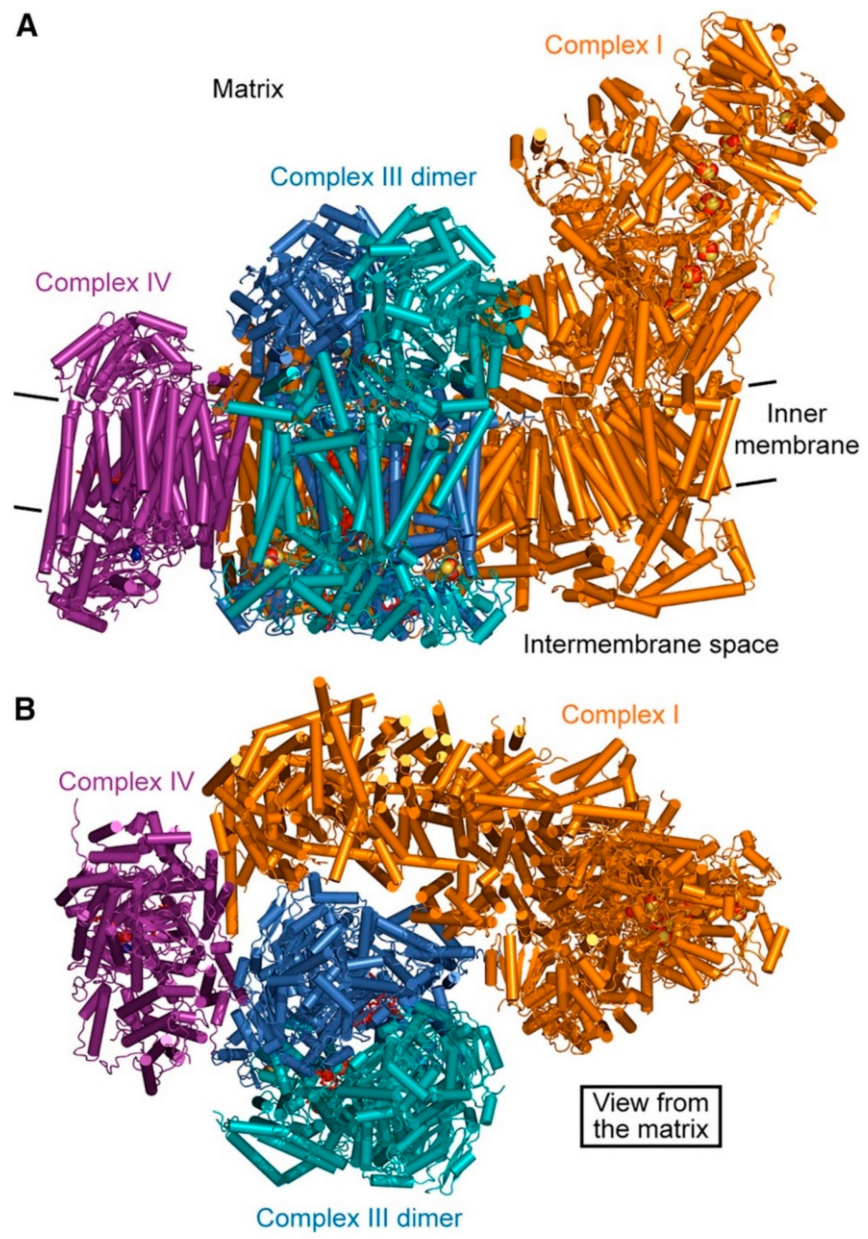

Figure 14. Overall structure of porcine respirasome $\left(\mathrm{I}_{1} \mathrm{III}_{2} \mathrm{IV}_{1}\right)$. Source: adapted from Milenkovic et al., 2017 [452].

Interestingly, the percentage of free complexes vs. SC varies largely between different species. In bovine heart mitochondria, electron cryo-tomography indicated that only $56 \%$ of 
CI was associated with other complexes [444]. However, BN-PAGE-based quantifications of the same cell type estimated that only $14-16 \%$ of free CI was present [426]. On the other hand, blue native-PAGE experiments using human mitochondria show a minimal part of CI ( $10 \%$ at the most, in the presence of digitonin) migrating as an individual complex [453]. In any case, there seems to be more of "free" CI in mitochondria from different tissues in mammalian organisms such as sheep, pigs or mice than in humans $[437,454]$. These differences might be due to various reasons, including artefacts introduced during the sample preparation or actual differences in the regulation of energy demands between different organisms.

In addition, in the same organism, not all the complexes engage in the formation of SC in the same proportion. Indeed, in humans, it has been estimated that while $85 \%-100 \%$ of $\mathrm{CI}$ is inserted in a supercomplex structure, only $55 \%-65 \%$ of $\mathrm{CIII}$ and $15 \%-25 \%$ of CIV are found in SC [426,453,455,456].

Structural analyses have also been important to define which subunits are involved in the complex-complex interaction. The association between CI and CIV seems to involve subunit COX7A of CIV, and ND5 and NDUFA9 of CI (Letts et al., 2016). COX7A, together with COX8B, could be involved also in the interaction with CIII, through binding of UQCRC1, UQCRQ, UQCR10 or UQCR11 (Letts et al., 2016) [440,444]. Concerning the connection between CI and CIII, subunit NDUFA11 of CI seems to face and contact the transmembrane region of CIII, close to UQCRB and UQCRQ [440] (Letts et al., 2016). Other CI subunits that might be involved in the interaction are NDUFAB1 and NDUFB9, contacting UQCRC1 of CIII.

\subsubsection{Possible Functional Roles of Supercomplexes}

The biological function of SC is still highly debated and various hypotheses have been proposed. The first theory proposes that their role is substrate channeling, increasing OXPHOS efficiency due to the physical proximity of all the machinery components [457]. The second possible function of SC might be to minimize ROS production. ROS are generated by the reduction of oxygen by electrons leaked from the ETC and are physiologically used as a signaling molecule [458]. However, if there is an imbalance between the excessive formation of ROS and limited antioxidant defenses, ROS can become deleterious and damage mtDNA, lipids and proteins. In this case, the formation of supra-structures might decrease electron or proton leakages during respiration. This theory is supported by two studies. In the first one, ROS production by $\mathrm{CI}$ has been shown to increase in two experimental conditions that inhibit the formation of $\mathrm{CI}$ and $\mathrm{CIII}$ interactions: treating bovine heart mitochondria or liposome-reconstituted supercomplex I-III with dodecyl maltoside, and reconstructing CI and CIII at a high phospholipid/protein ratio [459]. In the second study, the difference in SC formation in astrocytes and neurons was analyzed, showing how astrocytes, which present a higher percentage of free CI, are characterized by poorer mitochondrial respiration but higher ROS production [460].

The last hypothesis, which will be the basis of the first project presented in this thesis, is that the formation of SC is necessary for the assembly and/or stability of the single enzymes. This theory is supported by the observation that defects in one enzyme can lead to multi-complex deficiencies. Indeed, mutations in MTCYB, fundamental for CIII assembly, also induce CI deficiencies [461-463]. Similarly, patients presenting with mutations in CIII assembly factors, such as BCS1L, can display defects in both CI and CIV [464], while the suppression of CIV in mouse fibroblasts affects CI assembly or stability [465]. An explanation for this phenomenon was that $\mathrm{CI}$ was destabilized after its complete assembly by an active oxidative stress-triggered degradation [466-468]. However, a multistep model for SC assembly that sees CI intermediates binding CIII and CIV subunits before the completion of the mature enzyme was proposed [469]. In the same study, UQCRFS1 was shown to insert preferentially within the $\mathrm{III}_{2}+\mathrm{IV}$ supercomplex, instead of dimeric $\mathrm{CIII}_{2}$.

Finally, an additional role of SC is reserved to the ATP synthase. CV does not seem to interact with the rest of the respiratory chain, but it is able to form dimers and more 
complex supra-structures such as tetramers and hexamers [470]. These supercomplexes localize specifically at the bottom of the cristae, where they appear to enforce a strong local curvature on the inner membrane, necessary for the formation of the invagination [471].

\subsubsection{Assembly of Supercomplexes}

Being that the assembly of the monomeric forms of the OXPHOS enzymes requires the participation of a number of assembly factors, it has been proposed that additional proteins should be involved in the formation of supercomplexes.

The first proposed assembly factor was COX7A2L or SCAF1 (supercomplex assembly factor 1), an isoform of the CIV subunit COX7A, described originally to have a role in the inclusion of CIV in $\mathrm{III}_{2}+\mathrm{IV}$ and I $+\mathrm{III}_{2}+\mathrm{IV}_{1-4}$ [434]. However, following studies showed that the lack of COX7A2L affects the formation of the SC III $2+\mathrm{IV}$, but not of respirasomes [453,472-474]. Pérez-Pérez data also showed how COX7A2L binds to $\mathrm{CIII}_{2}$ early during its assembly, indicating a preferential interaction with this complex [472]. Thus, it might possess a role in the establishment of a checkpoint for the regulation of $\mathrm{CIII}_{2}$ levels and its incorporation into SC [453].

Another study showed how the incorporation of different COX7A isoforms might determine which CIV-containing species (monomer, dimer or respirasome) is formed [13]. Thus, the CIV subunit COX7A2 is replaced by COX7A2L in supercomplexes with both CIV and CIII, and by COX7A1 in CIV dimers. Moreover, other CIV tissue-specific subunit isoforms might play a role in this, as well as dimers, which appeared to be stabilized by the COX6A2 isoform rather than COX6A1. COX6A subunits are localized at the interface between the two monomers, a position that would favor the regulation of the dimerization. COX7A2 and COX6A1, instead, would favor the free CIV form.

Analyses conducted in Saccharomyces cerevisiae suggested the participation of Rcf1 and Rcf 2 in the formation of respirasomes [448]. In yeast, the loss of Rcf1 affects CIV function and the correct insertion of Cox13 (equivalent to human COX6A). These data showed also deficiency in SC formation, but recent reports point to this being an indirect effect due to CIV defects [475-477]. While Rcf2 is specific to yeast, two orthologs of Rcf1 have been identified in humans: RCF1a/HIGD1A and RCF1b/HIGD2A. HIGD1A has been confirmed to bind CIV and it has been suggested to affect the interaction between CIV and cytochrome $c$, or to act in a still unclear way on the heme centers [306,307]. Another study found HIGD1A directly involved in CIII biogenesis, promoting the final incorporation of UQCRFS1, and suggested its participation in the formation of CIII-containing SC [478]. Concerning HIGD2A, instead, two independent groups demonstrated that the knockdown of this protein leads to impaired SC formation by the release of CIV from respirasomes [479,480]. However, HIGD2A was identified as a MTCO3 module assembly factor and it is possible that its impact on SC is a pleotropic effect due to impaired CIV biogenesis $[478,481]$.

Concerning oligomerization of CV, the role of post-translational modifications in Atp20 has been investigated [482]. Specifically, the molecular mechanism seems to revolve around the phosphorylation of serine 62 , which inhibits the dimerization of the ATP synthase.

Finally, also the lipid composition of the IMM and, in particular, the level of cardiolipin are important for the stabilization of SC. In yeast lacking Taz1, the acyltransferases involved in the remodeling of cardiolipin and CIII and CIV associations are destabilized [483]. In Barth syndrome patients, harboring mutations in Tafazzin (the human ortholog of Taz1), the assembly and stability of CIV and its SC forms are affected, with a secondary effect also on CI + III associations [484].

\subsubsection{Conclusive Remarks}

Mitochondria fulfil a variety of functions in the cell, including the well-known energy production via oxidative phosphorylation. For this reason, the failure of mitochondria to operate correctly is associated with a wide spectrum of genetic disorders. In this review, we have analyzed, in detail, the structure, the assembly pathway and the organization in 
supercomplexes of each component of the OXPHOS machinery and how defects in these enzymes are linked to diseases in humans.

Our review aimed to show the heterogeneity and the complexity behind the still growing group of pathologies normally identified as "mitochondrial diseases", the pathophysiology of which is still often poorly understood. During the past decade, big advancements in genetic screening and in the study of mitochondrial biology and physiology have been made. However, the diagnosis of mitochondrial disorders is limited to about half of the suspected cases, the genotype-phenotype correlation is not always comprehended and effective therapies are still missing.

Future research will need to continue investigating the biology of this organelle, in order to better understand the molecular and cellular basis of mitochondrial diseases, and identify possible targets for new treatments.

Funding: This research received no external funding.

Institutional Review Board Statement: UK Medical Research Council core grant (MC_UU_00015/5) and European Research Council (erc.europa.eu) Advanced Grant FP7-322424, NRJ-Institut de France, Fondazione Renato Comini ONLUS, and Fondazione Telethon Italy grant GGP19007.

Informed Consent Statement: All the investigations on human beings mentioned in the paper were obtained upon signed informed consent of the patients or tutors according to the ethical committee of each institution.

Data Availability Statement: The data reported in this review are taken from publicly available, peer-reviewed scientific papers.

Acknowledgments: This work was funded by the UK Medical Research Council core grant (MC_UU_ 00015/5) and the European Research Council (erc.europa.eu) Advanced Grant FP7-322424, NRJInstitut de France, Fondazione Renato Comini ONLUS, and Telethon Italy grant GGP19007 to M.Z.

Conflicts of Interest: The authors declare no conflict of interest.

\section{References}

1. Margulis, L. Origin of Eukaryotic Cells: Evidence and Research Implications for a Theory of the Origin and Evolution of Microbial, Plant, and Animal Cells on the Precambrian Earth; Yale University Press: London, UK, 1970.

2. Cavalier-Smith, T. Origin of mitochondria by intracellular enslavement of a photosynthetic purple bacterium. Proc. Biol. Sci. 2006, 273, 1943-1952. [CrossRef]

3. Chinnery, P.F.; Hudson, G. Mitochondrial genetics. Br. Med. Bull. 2013, 106, 135-159. [CrossRef]

4. Gustafsson, C.M.; Falkenberg, M.; Larsson, N.G. Maintenance and Expression of Mammalian Mitochondrial DNA. Annu. Rev. Biochem. 2016, 85, 133-160. [CrossRef]

5. Giles, R.E.; Blanc, H.; Cann, H.M.; Wallace, D.C. Maternal inheritance of human mitochondrial DNA. Proc. Natl. Acad. Sci. USA 1980, 77, 6715-6719. [CrossRef]

6. Hoffmann, A.; Spengler, D. The Mitochondrion as Potential Interface in Early-Life Stress Brain Programming. Front. Behav. Neurosci. 2018, 12, 306. [CrossRef]

7. Kuhlbrandt, W. Structure and function of mitochondrial membrane protein complexes. BMC Biol. 2015, 13, 89. [CrossRef]

8. Ernster, L.; Schatz, G. Mitochondria: A historical review. J. Cell Biol. 1981, 91, 227-255.

9. Palade, G.E. An electron microscope study of the mitochondrial structure. J. Histochem. Cytochem. Off. J. Histochem. Soc. 1953, 1, 188-211. [CrossRef]

10. Colombini, M. Voltage gating in the mitochondrial channel, VDAC. J. Membr. Biol. 1989, 111, $103-111$.

11. Nicholls, D.G. The influence of respiration and ATP hydrolysis on the proton-electrochemical gradient across the inner membrane of rat-liver mitochondria as determined by ion distribution. Eur. J. Biochem. 1974, 50, 305-315. [CrossRef]

12. De Stefani, D.; Raffaello, A.; Teardo, E.; Szabo, I.; Rizzuto, R. A forty-kilodalton protein of the inner membrane is the mitochondrial calcium uniporter. Nature 2011, 476, 336-340. [CrossRef]

13. Cogliati, S.; Calvo, E.; Loureiro, M.; Guaras, A.M.; Nieto-Arellano, R.; Garcia-Poyatos, C.; Ezkurdia, I.; Mercader, N.; Vazquez, J.; Enriquez, J.A. Mechanism of super-assembly of respiratory complexes III and IV. Nature 2016, 539, 579-582. [CrossRef]

14. Cogliati, S.; Enriquez, J.A.; Scorrano, L. Mitochondrial Cristae: Where Beauty Meets Functionality. Trends Biochem. Sci. 2016, 41, 261-273. [CrossRef]

15. Pfanner, N.; van der Laan, M.; Amati, P.; Capaldi, R.A.; Caudy, A.A.; Chacinska, A.; Darshi, M.; Deckers, M.; Hoppins, S.; Icho, T.; et al. Uniform nomenclature for the mitochondrial contact site and cristae organizing system. J. Cell Biol. 2014, 204, 1083-1086. [CrossRef] 
16. An, J.; Shi, J.; He, Q.; Lui, K.; Liu, Y.; Huang, Y.; Sheikh, M.S. CHCM1/CHCHD6, novel mitochondrial protein linked to regulation of mitofilin and mitochondrial cristae morphology. J. Biol. Chem. 2012, 287, 7411-7426. [CrossRef]

17. Guarani, V.; McNeill, E.M.; Paulo, J.A.; Huttlin, E.L.; Frohlich, F.; Gygi, S.P.; Van Vactor, D.; Harper, J.W. QIL1 is a novel mitochondrial protein required for MICOS complex stability and cristae morphology. Elife 2015, 4. [CrossRef]

18. Rampelt, H.; Zerbes, R.M.; van der Laan, M.; Pfanner, N. Role of the mitochondrial contact site and cristae organizing system in membrane architecture and dynamics. Biochim. Biophys. Acta Mol. Cell Res. 2017, 1864, 737-746.

19. Barbot, M.J.D.; Schulz, C.; Denkert, N.; Kroppen, B.; Hoppert, M.; Jakobs, S.; Meinecke, M. Mic10 Oligomerizes to Bend Mitochondrial Inner Membranes at Cristae Junctions. Cell Metab. 2015, 21, 756-763.

20. Darshi, M.; Mendiola, V.L.; Mackey, M.R.; Murphy, A.N.; Koller, A.; Perkins, G.A.; Ellisman, M.H.; Taylor, S.S. ChChd3, an inner mitochondrial membrane protein, is essential for maintaining crista integrity and mitochondrial function. J. Biol. Chem. 2011, 286, 2918-2932. [CrossRef]

21. Huynen, M.A.; Mühlmeister, M.; Gotthardt, K.; Guerrero-Castillo, S.; Brandt, U. Evolution and structural organization of the mitochondrial contact site (MICOS) complex and the mitochondrial intermembrane space bridging (MIB) complex. Biochim. Biophys. Acta 2016, 1863, 91-101. [CrossRef]

22. Scharwey, M.; Tatsuta, T.; Langer, T. Mitochondrial lipid transport at a glance. J. Cell Sci. 2013, 126, 5317-5323. [CrossRef]

23. Cipolat, S.; Martins de Brito, O.; Dal Zilio, B.; Scorrano, L. OPA1 requires mitofusin 1 to promote mitochondrial fusion. Proc. Natl. Acad. Sci. USA 2004, 101, 15927-15932. [CrossRef]

24. Frezza, C.; Cipolat, S.; Martins de Brito, O.; Micaroni, M.; Beznoussenko, G.V.; Rudka, T.; Bartoli, D.; Polishuck, R.S.; Danial, N.N.; De Strooper, B.; et al. OPA1 controls apoptotic cristae remodeling independently from mitochondrial fusion. Cell 2006, 126, 177-189. [CrossRef]

25. Glytsou, C.; Calvo, E.; Cogliati, S.; Mehrotra, A.; Anastasia, I.; Rigoni, G.; Raimondi, A.; Shintani, N.; Loureiro, M.; Vazquez, J.; et al. Optic Atrophy 1 Is Epistatic to the Core MICOS Component MIC60 in Mitochondrial Cristae Shape Control. Cell Rep. 2016, 17, 3024-3034. [CrossRef]

26. Paumard, P.; Vaillier, J.; Coulary, B.; Schaeffer, J.; Soubannier, V.; Mueller, D.M.; Brethes, D.; di Rago, J.P.; Velours, J. The ATP synthase is involved in generating mitochondrial cristae morphology. EMBO J. 2002, 21, 221-230. [CrossRef]

27. Palmieri, F.P.C. Mitochondrial metabolite transport. Essays Biochem. 2010, 47, 37-52.

28. Sickmann, A.; Reinders, J.; Wagner, Y.; Joppich, C.; Zahedi, R.; Meyer, H.E.; Schonfisch, B.; Perschil, I.; Chacinska, A.; Guiard, B.; et al. The proteome of Saccharomyces cerevisiae mitochondria. Proc. Natl. Acad. Sci. USA 2003, 100, 13207-13212. [CrossRef]

29. Neupert, W. Protein import into mitochondria. Annu. Rev. Biochem. 1997, 66, 863-917.

30. Mori, M.; Terada, K. Mitochondrial protein import in animals. Biochim. Biophys. Acta 1998, 1403, $12-27$.

31. Wiedemann, N.; Kozjak, V.; Chacinska, A.; Schönfisch, B.; Rospert, S.; Ryan, M.T.; Pfanner, N.; Meisinger, C. Machinery for protein sorting and assembly in the mitochondrial outer membrane. Nature 2003, 424, 565-571.

32. Stroud, D.; Becker, T.; Qiu, J.; Stojanovski, D.; Pfannschmidt, S.; Wirth, C.; Hunte, C.; Guiard, B.; Meisinger, C.; Pfanner, N.; et al. Biogenesis of mitochondrial $\beta$-barrel proteins: The POTRA domain is involved in precursor release from the SAM complex. Mol. Biol. Cell. 2011, 22, 2823-2833.

33. Mordas, A.; Tokatlidis, K. The MIA pathway: A key regulator of mitochondrial oxidative protein folding and biogenesis. Acc. Chem. Res. 2015, 48, 2191-2199. [CrossRef]

34. Fox, T. Mitochondrial Protein Synthesis, Import, and Assembly. Genetics 2012, 192, 1203-1234.

35. Sirrenberg, C.; Bauer, M.F.; Guiard, B.; Neupert, W.; Brunner, M. Import of carrier proteins into the mitochondrial inner membrane mediated by Tim22. Nature 1996, 384, 582-585.

36. Rehling, P.; Model, K.; Brandner, K.; Kovermann, P.; Sickmann, A.; Meyer, H.E.; Kühlbrandt, W.; Wagner, R.; Truscott, K.N.; Pfanner, N. Protein insertion into the mitochondrial inner membrane by a twin-pore translocase. Science (N. Y.) 2003, 299, 1747-1751.

37. Krüger, V.; Deckers, M.; Hildenbeutel, M.; van der Laan, M.; Hellmers, M.; Dreker, C.; Preuss, M.; Herrmann, J.M.; Rehling, P.; Wagner, R.; et al. The mitochondrial oxidase assembly protein1 (Oxa1) insertase forms a membrane pore in lipid bilayers. J. Biol. Chem. 2012, 287, 33314-33326. [CrossRef]

38. Demishtein-Zohary, K.A.A. The TIM23 mitochondrial protein import complex: Function and dysfunction. Cell Tissue Res. 2017, 367, 33-41.

39. Tilokani, L.; Nagashima, S.; Paupe, V.; Prudent, J. Mitochondrial dynamics: Overview of molecular mechanisms. Essays Biochem. 2018, 62, 341-360. [CrossRef]

40. Pickles, S.; Vigie, P.; Youle, R.J. Mitophagy and Quality Control Mechanisms in Mitochondrial Maintenance. Curr. Biol. CB 2018, 28, R170-R185. [CrossRef]

41. Kraus, F.; Ryan, M.T. The constriction and scission machineries involved in mitochondrial fission. J. Cell Sci. 2017, 130, 2953-2960. [CrossRef]

42. Waterham, H.R.; Koster, J.; van Roermund, C.W.; Mooyer, P.A.; Wanders, R.J.; Leonard, J.V. A lethal defect of mitochondrial and peroxisomal fission. N. Engl. J. Med. 2007, 356, 1736-1741. [CrossRef]

43. Gerber, S.; Charif, M.; Chevrollier, A.; Chaumette, T.; Angebault, C.; Kane, M.S.; Paris, A.; Alban, J.; Quiles, M.; Delettre, C.; et al. Mutations in DNM1L, as in OPA1, result in dominant optic atrophy despite opposite effects on mitochondrial fusion and fission. Brain J. Neurol. 2017, 140, 2586-2596. [CrossRef] 
44. Züchner, S.; Mersiyanova, I.V.; Muglia, M.; Bissar-Tadmouri, N.; Rochelle, J.; Dadali, E.L.; Zappia, M.; Nelis, E.; Patitucci, A.; Senderek, J.; et al. Mutations in the mitochondrial GTPase mitofusin 2 cause Charcot-Marie-Tooth neuropathy type 2A. Nat. Genet. 2004, 36, 449-451. [CrossRef]

45. Pesch, U.E.; Leo-Kottler, B.; Mayer, S.; Jurklies, B.; Kellner, U.; Apfelstedt-Sylla, E.; Zrenner, E.; Alexander, C.; Wissinger, B. OPA1 mutations in patients with autosomal dominant optic atrophy and evidence for semi-dominant inheritance. Hum. Mol. Genet. 2001, 10, 1359-1368. [CrossRef]

46. Toomes, C.; Marchbank, N.J.; Mackey, D.A.; Craig, J.E.; Newbury-Ecob, R.A.; Bennett, C.P.; Vize, C.J.; Desai, S.P.; Black, G.C.; Patel, N.; et al. Spectrum, frequency and penetrance of OPA1 mutations in dominant optic atrophy. Hum. Mol. Genet. 2001, 10, 1369-1378. [CrossRef]

47. Delettre, C.; Griffoin, J.M.; Kaplan, J.; Dollfus, H.; Lorenz, B.; Faivre, L.; Lenaers, G.; Belenguer, P.; Hamel, C.P. Mutation spectrum and splicing variants in the OPA1 gene. Hum. Genet. 2001, 109, 584-591. [CrossRef]

48. Barboni, P.; Carbonelli, M.; Savini, G.; Foscarini, B.; Parisi, V.; Valentino, M.L.; Carta, A.; De Negri, A.; Sadun, F.; Zeviani, M.; et al. OPA1 mutations associated with dominant optic atrophy influence optic nerve head size. Ophthalmology 2010, 117, 1547-1553. [CrossRef]

49. Cogliati, S.; Frezza, C.; Soriano, M.E.; Varanita, T.; Quintana-Cabrera, R.; Corrado, M.; Cipolat, S.; Costa, V.; Casarin, A.; Gomes, L.C.; et al. Mitochondrial cristae shape determines respiratory chain supercomplexes assembly and respiratory efficiency. Cell 2013, 155, 160-171. [CrossRef]

50. Civiletto, G.; Varanita, T.; Cerutti, R.; Gorletta, T.; Barbaro, S.; Marchet, S.; Lamperti, C.; Viscomi, C.; Scorrano, L.; Zeviani, M. Opa1 overexpression ameliorates the phenotype of two mitochondrial disease mouse models. Cell Metab. 2015, 21, 845-854. [CrossRef]

51. Frederick, R.L.; Shaw, J.M. Moving mitochondria: Establishing distribution of an essential organelle. Traffic (Cph. Den.) 2007, 8, 1668-1675. [CrossRef]

52. Hollenbeck, P.J.; Saxton, W.M. The axonal transport of mitochondria. J. Cell Sci. 2005, 118, 5411-5419. [CrossRef]

53. Zheng, Y.R.; Zhang, X.N.; Chen, Z. Mitochondrial transport serves as a mitochondrial quality control strategy in axons: Implications for central nervous system disorders. CNS Neurosci. Ther. 2019, 25, 876-886. [CrossRef]

54. Alberts, B.; Johnson, A.; Lewis, J.; Raff, M.; Roberts, K.; Walter, P. Molecular Biology of the Cell, 4th ed.; Garland Science: New York, NY, USA, 2002.

55. Herzig, S.; Raemy, E.; Montessuit, S.; Veuthey, J.L.; Zamboni, N.; Westermann, B.; Kunji, E.R.; Martinou, J.C. Identification and functional expression of the mitochondrial pyruvate carrier. Science (N. Y.) 2012, 337, 93-96. [CrossRef]

56. Berg, J.M.; Tymoczko, J.L.; Stryer, L. Biochemistry, 5th ed.; W. H. Freeman: New York, NY, USA, 2002.

57. Adeva-Andany, M.M.; Carneiro-Freire, N.; Seco-Filgueira, M.; Fernández-Fernández, C.; Mouriño-Bayolo, D. Mitochondrial $\beta$-oxidation of saturated fatty acids in humans. Mitochondrion 2019, 46, 73-90. [CrossRef]

58. Elmore, S. Apoptosis: A Review of Programmed Cell Death. Toxicol. Pathol. 2007, 35, 495-516.

59. Igney, F.H.; Krammer, P.H. Death and anti-death: Tumour resistance to apoptosis. Nat. Rev. Cancer 2002, 2, 277-288. [CrossRef]

60. Große, L.; Wurm, C.A.; Brüser, C.; Neumann, D.; Jans, D.C.; Jakobs, S. Bax assembles into large ring-like structures remodeling the mitochondrial outer membrane in apoptosis. EMBO J. 2016, 35, 402-413. [CrossRef]

61. Salvador-Gallego, R.; Mund, M.; Cosentino, K.; Schneider, J.; Unsay, J.; Schraermeyer, U.; Engelhardt, J.; Ries, J.; García-Sáez, A.J Bax assembly into rings and arcs in apoptotic mitochondria is linked to membrane pores. EMBO J. 2016, 35, 389-401. [CrossRef]

62. Tait, S.W.; Green, D.R. Mitochondrial regulation of cell death. Cold Spring Harb. Perspect. Biol. 2013, 5. [CrossRef]

63. Chinnaiyan, A.M. The apoptosome: Heart and soul of the cell death machine. Neoplasia (N. Y.) 1999, 1, 5-15. [CrossRef]

64. Hill, M.M.; Adrain, C.; Duriez, P.J.; Creagh, E.M.; Martin, S.J. Analysis of the composition, assembly kinetics and activity of native Apaf-1 apoptosomes. EMBO J. 2004, 23, 2134-2145. [CrossRef]

65. Modjtahedi, N.; Giordanetto, F.; Madeo, F.; Kroemer, G. Apoptosis-inducing factor: Vital and lethal. Trends Cell Biol. 2006, 16, 264-272. [CrossRef]

66. Ghezzi, D.; Sevrioukova, I.; Invernizzi, F.; Lamperti, C.; Mora, M.; D’Adamo, P.; Novara, F.; Zuffardi, O.; Uziel, G.; Zeviani, M. Severe X-linked mitochondrial encephalomyopathy associated with a mutation in apoptosis-inducing factor. Am. J. Hum. Genet. 2010, 86, 639-649. [CrossRef]

67. Pozzan, T.; Rizzuto, R. The renaissance of mitochondrial calcium transport. Eur. J. Biochem. 2000, 267, 5269-5273. [CrossRef]

68. Colombini, M. Structure and mode of action of a voltage dependent anion-selective channel (VDAC) located in the outer mitochondrial membrane. Ann. N. Y. Acad. Sci. 1980, 341, 552-563. [CrossRef]

69. Giorgi, C.; Agnoletto, C.; Bononi, A.; Bonora, M.; De Marchi, E.; Marchi, S.; Missiroli, S.; Patergnani, S.; Poletti, F.; Rimessi, A.; et al. Mitochondrial calcium homeostasis as potential target for mitochondrial medicine. Mitochondrion 2012, 12, 77-85. [CrossRef]

70. Chiabrando, D.; Vinchi, F.; Fiorito, V.; Mercurio, S.; Tolosano, E. Heme in pathophysiology: A matter of scavenging, metabolism and trafficking across cell membranes. Front. Pharmacol. 2014, 5, 61. [CrossRef]

71. Lodish, H.; Berk, A.; Zipursky, S.L.; Matsudaira, P.; Baltimore, D.; Darnell, J. Molecular Cell Biology, 4th ed.; W. H. Freeman: New York, NY, USA, 2000.

72. Ogun, A.S.V.M. Biochemistry, Heme Synthesis; StatPearls Publishing: Petersbur, FL, USA, 2019.

73. Ajioka, R.S.; Phillips, J.D.; Kushner, J.P. Biosynthesis of heme in mammals. Biochim. Biophys. Acta 2006, 1763, 723-736. [CrossRef] 
74. Maio, N.; Rouault, T.A. Iron-sulfur cluster biogenesis in mammalian cells: New insights into the molecular mechanisms of cluster delivery. Biochim. Biophys. Acta (BBA) Bioenerg. 2015, 6, 1493-1512.

75. Imlay, J. Iron-sulphur clusters and the problem with oxygen. Mol. Microbiol. 2006, 59, 1073-1082.

76. Beinert, H.H.R.; Münck, E. Iron-sulfur clusters: Nature's modular, multipurpose structures. Science (N. Y.) 1997, $277,653-659$.

77. Ye, H.R.T. Erythropoiesis and iron sulfur cluster biogenesis. Adv. Hematol. 2010. [CrossRef]

78. Roche, B.; Aussel, L.; Ezraty, B.; Mandin, P.; Py, B.; Barras, F. Iron/sulfur proteins biogenesis in prokaryotes: Formation, regulation and diversity. Biochim. Biophys. Acta 2013, 1827, 455-469. [CrossRef]

79. Dean, D.R.; Dos Santos, P.C. Trading Places-Switching Frataxin Function by a Single Amino Acid Substitution within the [Fe-S] Cluster Assembly Scaffold. PLoS Genet. 2015, 11, e1005192. [CrossRef]

80. Reid, R.A.; Moyle, J.; Mitchell, P. Synthesis of adenosine triphosphate by a protonmotive force in rat liver mitochondria. Nature 1966, 212, 257-258. [CrossRef]

81. Capaldi, R.A.; Aggeler, R. Mechanism of the F(1)F(0)-type ATP synthase, a biological rotary motor. Trends Biochem. Sci. 2002, 27, 154-160. [CrossRef]

82. Hunte, C.; Zickermann, V.; Brandt, U. Functional modules and structural basis of conformational coupling in mitochondrial complex I. Science (N. Y.) 2010, 329, 448-451. [CrossRef]

83. Efremov, R.G.; Sazanov, L.A. Structure of the membrane domain of respiratory complex I. Nature 2011, 476, 414-420. [CrossRef]

84. Kaila, V.R.; Wikström, M.; Hummer, G. Electrostatics, hydration, and proton transfer dynamics in the membrane domain of respiratory complex I. Proc. Natl. Acad. Sci. USA 2014, 111, 6988-6993. [CrossRef]

85. Verkhovsky, M.; Bloch, D.A.; Verkhovskaya, M. Tightly-bound ubiquinone in the Escherichia coli respiratory complex I. Biochim. Biophys. Acta 2012, 1817, 1550-1556. [CrossRef]

86. Brandt, U. A two-state stabilization-change mechanism for proton-pumping complex I. Biochim. Biophys. Acta 2011, 1807, 1364-1369. [CrossRef]

87. Hirst, J.; Roessler, M.M. Energy conversion, redox catalysis and generation of reactive oxygen species by respiratory complex I. Biochim. Biophys. Acta 2016, 1857, 872-883. [CrossRef]

88. Cabrera-Orefice, A.; Yoga, E.G.; Wirth, C.; Siegmund, K.; Zwicker, K.; Guerrero-Castillo, S.; Zickermann, V.; Hunte, C.; Brandt, U. Locking loop movement in the ubiquinone pocket of complex I disengages the proton pumps. Nat. Commun. 2018, 9, 4500. [CrossRef]

89. Mitchell, P. Possible molecular mechanisms of the protonmotive function of cytochrome systems. J. Theor. Biol. 1976, 62, 327-367. [CrossRef]

90. Trumpower, B.L. The protonmotive Q cycle. Energy transduction by coupling of proton translocation to electron transfer by the cytochrome bc1 complex. J. Biol. Chem. 1990, 265, 11409-11412.

91. Xia, D.; Yu, C.A.; Kim, H.; Xia, J.Z.; Kachurin, A.M.; Zhang, L.; Yu, L.; Deisenhofer, J. Crystal structure of the cytochrome bc1 complex from bovine heart mitochondria. Science (N. Y.) 1997, 277, 60-66.

92. Iwata, S.; Lee, J.W.; Okada, K.; Lee, J.K.; Iwata, M.; Rasmussen, B.; Link, T.A.; Ramaswamy, S.; Jap, B.K. Complete structure of the 11-subunit bovine mitochondrial cytochrome bc1 complex. Science (N. Y.) 1998, 281, 64-71.

93. Zhang, Z.H.L.; Shulmeister, V.M.; Chi, Y.; Kim, K.K.; Hung, L.; Crofts, A.R.; Berry, E.A.; Kim, S. Electron transfer by domain movement in cytochrome bc1. Nature 1998, 392, 677-684.

94. Urban, P.F.; Klingenberg, M. On the redox potentials of ubiquinone and cytochrome b in the respiratory chain. Eur. J. Biochem. 1969, 9, 519-525. [CrossRef]

95. Peters, J.W.; Beratan, D.N.; Bothner, B.; Dyer, R.B.; Harwood, C.S.; Heiden, Z.M.; Hille, R.; Jones, A.K.; King, P.W.; Lu, Y.; et al. A new era for electron bifurcation. Curr. Opin. Chem. Biol. 2018, 47, 32-38. [CrossRef]

96. Saraste, M. Oxidative phosphorylation at the fin de siecle. Science (N. Y.) 1999, 283, 1488-1493. [CrossRef]

97. Michel, H. Proton pumping by cytochrome c oxidase. Nature 1999, 402, 602-603. [CrossRef]

98. Wikstrom, M. Cytochrome c oxidase: 25 years of the elusive proton pump. Biochim. Biophys. Acta 2004, 1655, 241-247. [CrossRef]

99. Pilet, E.; Jasaitis, A.; Liebl, U.; Vos, M.H. Electron transfer between hemes in mammalian cytochrome c oxidase. Proc. Natl. Acad. Sci. USA 2004, 101, 16198-16203. [CrossRef]

100. Yoshikawa, S.; Shimada, A. Reaction mechanism of cytochrome c oxidase. Chem. Rev. 2015, 115, 1936-1989. [CrossRef]

101. Vinothkumar, K.R.; Zhu, J.; Hirst, J. Architecture of mammalian respiratory complex I. Nature 2014, 515, 80-84. [CrossRef]

102. Vartak, R.S.; Semwal, M.K.; Bai, Y. An update on complex I assembly: The assembly of players. J. Bioenerg. Biomembr. 2014, 46, 323-328. [CrossRef]

103. Carroll, J.; Ding, S.; Fearnley, I.M.; Walker, J.E. Post-translational modifications near the quinone binding site of mammalian complex I. J. Biol. Chem. 2013, 288, 24799-24808. [CrossRef]

104. Claros, M.G.; Vincens, P. Computational method to predict mitochondrially imported proteins and their targeting sequences. Eur. J. Biochem. 1996, 241, 779-786. [CrossRef]

105. Sanchez-Caballero, L.; Guerrero-Castillo, S.; Nijtmans, L. Unraveling the complexity of mitochondrial complex I assembly: A dynamic process. Biochim. Biophys. Acta 2016, 1857, 980-990. [CrossRef]

106. Sheftel, A.D.; Stehling, O.; Pierik, A.J.; Netz, D.J.; Kerscher, S.; Elsasser, H.P.; Wittig, I.; Balk, J.; Brandt, U.; Lill, R. Human ind1, an iron-sulfur cluster assembly factor for respiratory complex I. Mol. Cell Biol. 2009, 29, 6059-6073. [CrossRef] 
107. Bych, K.; Kerscher, S.; Netz, D.J.; Pierik, A.J.; Zwicker, K.; Huynen, M.A.; Lill, R.; Brandt, U.; Balk, J. The iron-sulphur protein Ind1 is required for effective complex I assembly. EMBO J. 2008, 27, 1736-1746. [CrossRef]

108. Signes, A.; Fernandez-Vizarra, E. Assembly of mammalian oxidative phosphorylation complexes I-V and supercomplexes. Essays Biochem. 2018, 62, 255-270. [CrossRef]

109. Guerrero-Castillo, S.; Baertling, F.; Kownatzki, D.; Wessels, H.J.; Arnold, S.; Brandt, U.; Nijtmans, L. The Assembly Pathway of Mitochondrial Respiratory Chain Complex I. Cell Metab. 2017, 25, 128-139. [CrossRef]

110. Formosa, L.E.; Muellner-Wong, L.; Reljic, B.; Sharpe, A.J.; Jackson, T.D.; Beilharz, T.H.; Stojanovski, D.; Lazarou, M.; Stroud, D.A.; Ryan, M.T. Dissecting the Roles of Mitochondrial Complex I Intermediate Assembly Complex Factors in the Biogenesis of Complex I. Cell Rep. 2020, 31, 107541. [CrossRef]

111. Stroud, D.A.; Surgenor, E.E.; Formosa, L.E.; Reljic, B.; Frazier, A.E.; Dibley, M.G.; Osellame, L.D.; Stait, T.; Beilharz, T.H.; Thorburn, D.R.; et al. Accessory subunits are integral for assembly and function of human mitochondrial complex I. Nature 2016, 538, 123-126. [CrossRef]

112. Giachin, G.; Bouverot, R.; Acajjaoui, S.; Pantalone, S.; Soler-López, M. Dynamics of Human Mitochondrial Complex I Assembly: Implications for Neurodegenerative Diseases. Front. Mol. Biosci. 2016, 3, 43.

113. Nouws, J.; Nijtmans, L.; Houten, S.M.; van den Brand, M.; Huynen, M.; Venselaar, H.; Hoefs, S.; Gloerich, J.; Kronick, J.; Hutchin, T.; et al. Acyl-CoA dehydrogenase 9 is required for the biogenesis of oxidative phosphorylation complex I. Cell Metab. 2010, 12, 283-294. [CrossRef]

114. Haack, T.B.; Danhauser, K.; Haberberger, B.; Hoser, J.; Strecker, V.; Boehm, D.; Uziel, G.; Lamantea, E.; Invernizzi, F.; Poulton, J.; et al. Exome sequencing identifies ACAD9 mutations as a cause of complex I deficiency. Nat. Genet. 2010, 42, 1131-1134. [CrossRef]

115. Vogel, R.O.; Janssen, R.J.; van den Brand, M.A.; Dieteren, C.E.; Verkaart, S.; Koopman, W.J.; Willems, P.H.; Pluk, W.; van den Heuvel, L.P.; Smeitink, J.A.; et al. Cytosolic signaling protein Ecsit also localizes to mitochondria where it interacts with chaperone NDUFAF1 and functions in complex I assembly. Genes Dev. 2007, 21, 615-624. [CrossRef]

116. Formosa, L.E.; Mimaki, M.; Frazier, A.E.; McKenzie, M.; Stait, T.L.; Thorburn, D.R.; Stroud, D.A.; Ryan, M.T. Characterization of mitochondrial FOXRED1 in the assembly of respiratory chain complex I. Hum. Mol. Genet. 2015, 24, 2952-2965. [CrossRef]

117. Rendón, O.; Antonicka, H.; Horvath, R.; Shoubridge, E.A. A mutation in the FAD-dependent oxidoreductase FOXRED1 results in cell-type specific assembly defects in oxidative phosphorylation complexes I and II. Mol. Cell. Biol. 2016, 36, $2132-2140$.

118. Andrews, B.; Carroll, J.; Ding, S.; Fearnley, I.M.; Walker, J.E. Assembly factors for the membrane arm of human complex I. Proc. Natl. Acad. Sci. USA 2013, 110, 18934-18939. [CrossRef]

119. Cizkova, A.; Stranecky, V.; Mayr, J.A.; Tesarova, M.; Havlickova, V.; Paul, J.; Ivanek, R.; Kuss, A.W.; Hansikova, H.; Kaplanova, V.; et al. TMEM70 mutations cause isolated ATP synthase deficiency and neonatal mitochondrial encephalocardiomyopathy. Nat. Genet. 2008, 40, 1288-1290. [CrossRef]

120. Sánchez-Caballero, L.; Elurbe, D.M.; Baertling, F.; Guerrero-Castillo, S.; van den Brand, M.; van Strien, J.; van Dam, T.J.P.; Rodenburg, R.; Brandt, U.; Huynen, M.A.; et al. TMEM70 functions in the assembly of complexes I and V. Biochim. Biophys. Acta. Bioenerg. 2020, 1861, 148202. [CrossRef]

121. Vogel, R.O.; Janssen, R.J.; Ugalde, C.; Grovenstein, M.; Huijbens, R.J.; Visch, H.J.; van den Heuvel, L.P.; Willems, P.H.; Zeviani, M.; Smeitink, J.A.; et al. Human mitochondrial complex I assembly is mediated by NDUFAF1. FEBS J. 2005, 272, 5317-5326. [CrossRef]

122. Ogilvie, I.; Kennaway, N.G.; Shoubridge, E.A. A molecular chaperone for mitochondrial complex I assembly is mutated in a progressive encephalopathy. J. Clin. Investig. 2005, 115, 2784-2792. [CrossRef]

123. Saada, A.; Vogel, R.O.; Hoefs, S.J.; van den Brand, M.A.; Wessels, H.J.; Willems, P.H.; Venselaar, H.; Shaag, A.; Barghuti, F.; Reish, O; i et al. Mutations in NDUFAF3 (C3ORF60), encoding an NDUFAF4 (C6ORF66)-interacting complex I assembly protein, cause fatal neonatal mitochondrial disease. Am. J. Hum. Genet. 2009, 84, 718-727. [CrossRef]

124. Saada, A.; Edvardson, S.; Rapoport, M.; Shaag, A.; Amry, K.; Miller, C.; Lorberboum-Galski, H.; Elpeleg, O. C6ORF66 is an assembly factor of mitochondrial complex I. Am. J. Hum. Genet. 2008, 82, 32-38. [CrossRef]

125. Sugiana, C.; Pagliarini, D.J.; McKenzie, M.; Kirby, D.M.; Salemi, R.; Abu-Amero, K.K.; Dahl, H.H.; Hutchison, W.M.; Vascotto, K.A.; Smith, S.M.; et al. Mutation of C20orf7 disrupts complex I assembly and causes lethal neonatal mitochondrial disease. Am. J. Hum. Genet. 2008, 83, 468-478. [CrossRef]

126. Rhein, V.F.; Carroll, J.; Ding, S.; Fearnley, I.M.; Walker, J.E. NDUFAF5 Hydroxylates NDUFS7 at an Early Stage in the Assembly of Human Complex I. J. Biol. Chem. 2016, 291, 14851-14860. [CrossRef]

127. McKenzie, M.; Tucker, E.J.; Compton, A.G.; Lazarou, M.; George, C.; Thorburn, D.R.; Ryan, M.T. Mutations in the gene encoding C8orf38 block complex I assembly by inhibiting production of the mitochondria-encoded subunit ND1. J. Mol. Biol. 2011, 414, 413-426. [CrossRef]

128. Carilla-Latorre, S.; Gallardo, M.E.; Annesley, S.J.; Calvo-Garrido, J.; Grana, O.; Accari, S.L.; Smith, P.K.; Valencia, A.; Garesse, R.; Fisher, P.R.; et al. MidA is a putative methyltransferase that is required for mitochondrial complex I function. J. Cell Sci. 2010, 123, 1674-1683. [CrossRef]

129. Rhein, V.F.; Carroll, J.; Ding, S.; Fearnley, I.M.; Walker, J.E. NDUFAF7 methylates arginine 85 in the NDUFS2 subunit of human complex I. J. Biol. Chem. 2013, 288, 33016-33026. [CrossRef] 
130. Protasoni, M.; Bruno, C.; Donati, M.A.; Mohamoud, K.; Severino, M.; Allegri, A.; Robinson, A.J.; Reyes, A.; Zeviani, M.; Garone, C. Novel compound heterozygous pathogenic variants in nucleotide-binding protein like protein (NUBPL) cause leukoencephalopathy with multi-systemic involvement. Mol. Genet. Metab. 2020, 129, 26-34. [CrossRef]

131. Guarani, V.; Paulo, J.; Zhai, B.; Huttlin, E.L.; Gygi, S.P.; Harper, J.W. TIMMDC1/C3orf1 functions as a membrane-embedded mitochondrial complex I assembly factor through association with the MCIA complex. Mol. Cell Biol. 2014, 34, 847-861. [CrossRef]

132. Heide, H.; Bleier, L.; Steger, M.; Ackermann, J.; Drose, S.; Schwamb, B.; Zornig, M.; Reichert, A.S.; Koch, I.; Wittig, I.; et al. Complexome profiling identifies TMEM126B as a component of the mitochondrial complex I assembly complex. Cell Metab. 2012, 16, 538-549. [CrossRef]

133. Janssen, R.J.; Nijtmans, L.G.; van den Heuvel, L.P.; Smeitink, J.A. Mitochondrial complex I: Structure, function and pathology. J. Inherit. Metab. Dis. 2006, 29, 499-515. [CrossRef]

134. Scheffler, I.E. Mitochondrial disease associated with complex I (NADH-CoQ oxidoreductase) deficiency. J. Inherit. Metab. Dis. 2015, 38, 405-415. [CrossRef]

135. Simon, D.K.; Friedman, J.; Breakefield, X.O.; Jankovic, J.; Brin, M.F.; Provias, J.; Bressman, S.B.; Charness, M.E.; Tarsy, D.; Johns, D.R.; et al. A heteroplasmic mitochondrial complex I gene mutation in adult-onset dystonia. Neurogenetics 2003, 4, 199-205. [CrossRef]

136. Kirby, D.M.; McFarland, R.; Ohtake, A.; Dunning, C.; Ryan, M.T.; Wilson, C.; Ketteridge, D.; Turnbull, D.M.; Thorburn, D.R.; Taylor, R.W. Mutations of the mitochondrial ND1 gene as a cause of MELAS. J. Med. Genet. 2004, 41, 784-789. [CrossRef]

137. Howell, N.; Bindoff, L.A.; McCullough, D.A.; Kubacka, I.; Poulton, J.; Mackey, D.; Taylor, L.; Turnbull, D.M. Leber hereditary optic neuropathy: Identification of the same mitochondrial ND1 mutation in six pedigrees. Am. J. Hum. Genet. 1991, 49, 939-950.

138. Johns, D.R.; Berman, J. Alternative, simultaneous complex I mitochondrial DNA mutations in Leber's hereditary optic neuropathy. Biochem. Biophys. Res. Commun. 1991, 174, 1324-1330. [CrossRef]

139. McFarland, R.; Kirby, D.M.; Fowler, K.J.; Ohtake, A.; Ryan, M.T.; Amor, D.J.; Fletcher, J.M.; Dixon, J.W.; Collins, F.A.; Turnbull, D.M.; et al. De novo mutations in the mitochondrial ND3 gene as a cause of infantile mitochondrial encephalopathy and complex I deficiency. Ann. Neurol. 2004, 55, 58-64. [CrossRef]

140. Torroni, A.; Petrozzi, M.; D’Urbano, L.; Sellitto, D.; Zeviani, M.; Carrara, F.; Carducci, C.; Leuzzi, V.; Carelli, V.; Barboni, P.; et al Haplotype and phylogenetic analyses suggest that one European-specific mtDNA background plays a role in the expression of Leber hereditary optic neuropathy by increasing the penetrance of the primary mutations 11778 and 14484 . Am. J. Hum. Genet. 1997, 60, 1107-1121.

141. Lertrit, P.; Noer, A.S.; Jean-Francois, M.J.; Kapsa, R.; Dennett, X.; Thyagarajan, D.; Lethlean, K.; Byrne, E.; Marzuki, S. A new disease-related mutation for mitochondrial encephalopathy lactic acidosis and strokelike episodes (MELAS) syndrome affects the ND4 subunit of the respiratory complex I. Am. J. Hum. Genet. 1992, 51, 457-468.

142. Brown, M.D.; Starikovskaya, E.; Derbeneva, O.; Hosseini, S.; Allen, J.C.; Mikhailovskaya, I.E.; Sukernik, R.I.; Wallace, D.C. The role of mtDNA background in disease expression: A new primary LHON mutation associated with Western Eurasian haplogroup J. Hum. Genet. 2002, 110, 130-138. [CrossRef]

143. Brown, M.D.; Voljavec, A.S.; Lott, M.T.; MacDonald, I.; Wallace, D.C. Leber's hereditary optic neuropathy: A model for mitochondrial neurodegenerative diseases. FASEB J. Off. Publ. Fed. Am. Soc. Exp. Biol. 1992, 6, 2791-2799. [CrossRef]

144. Liolitsa, D.; Rahman, S.; Benton, S.; Carr, L.J.; Hanna, M.G. Is the mitochondrial complex I ND5 gene a hot-spot for MELAS causing mutations? Ann. Neurol. 2003, 53, 128-132. [CrossRef]

145. Ravn, K.; Wibrand, F.; Hansen, F.J.; Horn, N.; Rosenberg, T.; Schwartz, M. An mtDNA mutation, 14453G->A, in the NADH dehydrogenase subunit 6 associated with severe MELAS syndrome. Eur. J. Hum. Genet. EJHG 2001, 9, 805-809. [CrossRef]

146. Schuelke, M.; Smeitink, J.; Mariman, E.; Loeffen, J.; Plecko, B.; Trijbels, F.; Stöckler-Ipsiroglu, S.; van den Heuvel, L. Mutant NDUFV1 subunit of mitochondrial complex I causes leukodystrophy and myoclonic epilepsy. Nat. Genet. 1999, $21,260-261$. [CrossRef]

147. Bénit, P.; Chretien, D.; Kadhom, N.; de Lonlay-Debeney, P.; Cormier-Daire, V.; Cabral, A.; Peudenier, S.; Rustin, P.; Munnich, A.; Rötig, A. Large-scale deletion and point mutations of the nuclear NDUFV1 and NDUFS1 genes in mitochondrial complex I deficiency. Am. J. Hum. Genet. 2001, 68, 1344-1352. [CrossRef]

148. Bénit, P.; Beugnot, R.; Chretien, D.; Giurgea, I.; De Lonlay-Debeney, P.; Issartel, J.P.; Corral-Debrinski, M.; Kerscher, S.; Rustin, P.; Rötig, A.; et al. Mutant NDUFV2 subunit of mitochondrial complex I causes early onset hypertrophic cardiomyopathy and encephalopathy. Hum. Mutat. 2003, 21, 582-586. [CrossRef]

149. Loeffen, J.; Elpeleg, O.; Smeitink, J.; Smeets, R.; Stöckler-Ipsiroglu, S.; Mandel, H.; Sengers, R.; Trijbels, F.; van den Heuvel, L. Mutations in the complex I NDUFS2 gene of patients with cardiomyopathy and encephalomyopathy. Ann. Neurol. 2001, 49, 195-201. [CrossRef]

150. Bénit, P.; Slama, A.; Cartault, F.; Giurgea, I.; Chretien, D.; Lebon, S.; Marsac, C.; Munnich, A.; Rötig, A.; Rustin, P. Mutant NDUFS3 subunit of mitochondrial complex I causes Leigh syndrome. J. Med. Genet. 2004, 41, 14-17. [CrossRef]

151. Budde, S.M.; van den Heuvel, L.P.; Janssen, A.J.; Smeets, R.J.; Buskens, C.A.; DeMeirleir, L.; Van Coster, R.; Baethmann, M.; Voit, T.; Trijbels, J.M.; et al. Combined enzymatic complex I and III deficiency associated with mutations in the nuclear encoded NDUFS4 gene. Biochem. Biophys. Res. Commun. 2000, 275, 63-68. [CrossRef]

152. Spiegel, R.; Shaag, A.; Mandel, H.; Reich, D.; Penyakov, M.; Hujeirat, Y.; Saada, A.; Elpeleg, O.; Shalev, S.A. Mutated NDUFS6 is the cause of fatal neonatal lactic acidemia in Caucasus Jews. Eur. J. Hum. Genet. EJHG 2009, 17, 1200-1203. [CrossRef] 
153. Smeitink, J.; van den Heuvel, L. Human mitochondrial complex I in health and disease. Am. J. Hum. Genet. 1999, 64, 1505-1510. [CrossRef]

154. Loeffen, J.; Smeitink, J.; Triepels, R.; Smeets, R.; Schuelke, M.; Sengers, R.; Trijbels, F.; Hamel, B.; Mullaart, R.; van den Heuvel, L. The first nuclear-encoded complex I mutation in a patient with Leigh syndrome. Am. J. Hum. Genet. 1998, 63, 1598-1608. [CrossRef]

155. Berger, I.; Hershkovitz, E.; Shaag, A.; Edvardson, S.; Saada, A.; Elpeleg, O. Mitochondrial complex I deficiency caused by a deleterious NDUFA11 mutation. Ann. Neurol. 2008, 63, 405-408. [CrossRef]

156. Fernandez-Moreira, D.; Ugalde, C.; Smeets, R.; Rodenburg, R.J.; Lopez-Laso, E.; Ruiz-Falco, M.L.; Briones, P.; Martin, M.A.; Smeitink, J.A.; Arenas, J. X-linked NDUFA1 gene mutations associated with mitochondrial encephalomyopathy. Ann. Neurol. 2007, 61, 73-83. [CrossRef]

157. Hoefs, S.J.; Dieteren, C.E.; Distelmaier, F.; Janssen, R.J.; Epplen, A.; Swarts, H.G.; Forkink, M.; Rodenburg, R.J.; Nijtmans, L.G.; Willems, P.H.; et al. NDUFA2 complex I mutation leads to Leigh disease. Am. J. Hum. Genet. 2008, 82, 1306-1315. [CrossRef]

158. Alston, C.L.; Heidler, J.; Dibley, M.G.; Kremer, L.S.; Taylor, L.S.; Fratter, C.; French, C.E.; Glasgow, R.I.C.; Feichtinger, R.G.; Delon, I.; et al. Bi-allelic Mutations in NDUFA6 Establish Its Role in Early-Onset Isolated Mitochondrial Complex I Deficiency. Am. J. Hum. Genet. 2018, 103, 592-601. [CrossRef]

159. Bugiani, M.; Invernizzi, F.; Alberio, S.; Briem, E.; Lamantea, E.; Carrara, F.; Moroni, I.; Farina, L.; Spada, M.; Donati, M.A.; et al. Clinical and molecular findings in children with complex I deficiency. Biochim. Biophys. Acta 2004, 1659, 136-147. [CrossRef]

160. van den Bosch, B.J.; Gerards, M.; Sluiter, W.; Stegmann, A.P.; Jongen, E.L.; Hellebrekers, D.M.; Oegema, R.; Lambrichs, E.H.; Prokisch, H.; Danhauser, K.; et al. Defective NDUFA9 as a novel cause of neonatally fatal complex I disease. J. Med. Genet. 2012, 49, 10-15. [CrossRef]

161. Hoefs, S.J.; van Spronsen, F.J.; Lenssen, E.W.; Nijtmans, L.G.; Rodenburg, R.J.; Smeitink, J.A.; van den Heuvel, L.P. NDUFA10 mutations cause complex I deficiency in a patient with Leigh disease. Eur. J. Hum. Genet. EJHG 2011, 19, 270-274. [CrossRef]

162. Ostergaard, E.; Rodenburg, R.J.; van den Brand, M.; Thomsen, L.L.; Duno, M.; Batbayli, M.; Wibrand, F.; Nijtmans, L. Respiratory chain complex I deficiency due to NDUFA12 mutations as a new cause of Leigh syndrome. J. Med. Genet. 2011, 48, 737-740. [CrossRef]

163. Angebault, C.; Charif, M.; Guegen, N.; Piro-Megy, C.; Mousson de Camaret, B.; Procaccio, V.; Guichet, P.O.; Hebrard, M.; Manes, G.; Leboucq, N.; et al. Mutation in NDUFA13/GRIM19 leads to early onset hypotonia, dyskinesia and sensorial deficiencies, and mitochondrial complex I instability. Hum. Mol. Genet. 2015, 24, 3948-3955. [CrossRef]

164. Haack, T.B.; Madignier, F.; Herzer, M.; Lamantea, E.; Danhauser, K.; Invernizzi, F.; Koch, J.; Freitag, M.; Drost, R.; Hillier, I.; et al Mutation screening of 75 candidate genes in 152 complex I deficiency cases identifies pathogenic variants in 16 genes including NDUFB9. J. Med. Genet. 2012, 49, 83-89. [CrossRef]

165. Piekutowska-Abramczuk, D.; Assouline, Z.; Mataković, L.; Feichtinger, R.G.; Koňařiková, E.; Jurkiewicz, E.; Stawiński, P.; Gusic, M.; Koller, A.; Pollak, A.; et al. NDUFB8 Mutations Cause Mitochondrial Complex I Deficiency in Individuals with Leigh-like Encephalomyopathy. Am. J. Hum. Genet. 2018, 102, 460-467. [CrossRef]

166. Friederich, M.W.; Erdogan, A.J.; Coughlin, C.R., 2nd; Elos, M.T.; Jiang, H.; O’Rourke, C.P.; Lovell, M.A.; Wartchow, E.; Gowan, K.; Chatfield, K.C.; et al. Mutations in the accessory subunit NDUFB10 result in isolated complex I deficiency and illustrate the critical role of intermembrane space import for complex I holoenzyme assembly. Hum. Mol. Genet. 2017, 26, 702-716. [CrossRef]

167. van Rahden, V.A.; Fernandez-Vizarra, E.; Alawi, M.; Brand, K.; Fellmann, F.; Horn, D.; Zeviani, M.; Kutsche, K. Mutations in NDUFB11, encoding a complex I component of the mitochondrial respiratory chain, cause microphthalmia with linear skin defects syndrome. Am. J. Hum. Genet. 2015, 96, 640-650. [CrossRef]

168. Reinson, K.; Kovacs-Nagy, R.; Õiglane-Shlik, E.; Pajusalu, S.; Nõukas, M.; Wintjes, L.T.; van den Brandt, F.C.A.; Brink, M.; Acker, T.; Ahting, U.; et al. Diverse phenotype in patients with complex I deficiency due to mutations in NDUFB11. Eur. J. Med. Genet. 2019, 62, 103572. [CrossRef]

169. Alahmad, A.; Nasca, A.; Heidler, J.; Thompson, K.; Oláhová, M.; Legati, A.; Lamantea, E.; Meisterknecht, J.; Spagnolo, M.; He, L.; et al. Bi-allelic pathogenic variants in NDUFC2 cause early-onset Leigh syndrome and stalled biogenesis of complex I. EMBO Mol. Med. 2020, 12, e12619. [CrossRef]

170. Calvo, S.E.; Tucker, E.J.; Compton, A.G.; Kirby, D.M.; Crawford, G.; Burtt, N.P.; Rivas, M.; Guiducci, C.; Bruno, D.L.; Goldberger, O.A.; et al. High-throughput, pooled sequencing identifies mutations in NUBPL and FOXRED1 in human complex I deficiency. Nat. Genet. 2010, 42, 851-858. [CrossRef]

171. Dunning, C.J.; McKenzie, M.; Sugiana, C.; Lazarou, M.; Silke, J.; Connelly, A.; Fletcher, J.M.; Kirby, D.M.; Thorburn, D.R.; Ryan, M.T. Human CIA30 is involved in the early assembly of mitochondrial complex I and mutations in its gene cause disease. EMBO J. 2007, 26, 3227-3237. [CrossRef]

172. Pagliarini, D.J.; Calvo, S.E.; Chang, B.; Sheth, S.A.; Vafai, S.B.; Ong, S.E.; Walford, G.A.; Sugiana, C.; Boneh, A.; Chen, W.K.; et al. A mitochondrial protein compendium elucidates complex I disease biology. Cell 2008, 134, 112-123. [CrossRef]

173. Alston, C.L.; Veling, M.T.; Heidler, J.; Taylor, L.S.; Alaimo, J.T.; Sung, A.Y.; He, L.; Hopton, S.; Broomfield, A.; Pavaine, J.; et al. Pathogenic Bi-allelic Mutations in NDUFAF8 Cause Leigh Syndrome with an Isolated Complex I Deficiency. Am. J. Hum. Genet. 2020, 106, 92-101. [CrossRef]

174. Kremer, L.S.; Bader, D.M.; Mertes, C.; Kopajtich, R.; Pichler, G.; Iuso, A.; Haack, T.B.; Graf, E.; Schwarzmayr, T.; Terrile, C.; et al. Genetic diagnosis of Mendelian disorders via RNA sequencing. Nat. Commun. 2017, 8, 15824. [CrossRef] 
175. Sánchez-Caballero, L.; Ruzzenente, B.; Bianchi, L.; Assouline, Z.; Barcia, G.; Metodiev, M.D.; Rio, M.; Funalot, B.; van den Brand, M.A.; Guerrero-Castillo, S.; et al. Mutations in Complex I Assembly Factor TMEM126B Result in Muscle Weakness and Isolated Complex I Deficiency. Am. J. Hum. Genet. 2016, 99, 208-216. [CrossRef]

176. Alston, C.L.; Compton, A.G.; Formosa, L.E.; Strecker, V.; Oláhová, M.; Haack, T.B.; Smet, J.; Stouffs, K.; Diakumis, P.; Ciara, E.; et al. Biallelic Mutations in TMEM126B Cause Severe Complex I Deficiency with a Variable Clinical Phenotype. Am. J. Hum. Genet. 2016, 99, 217-227. [CrossRef]

177. Martinez Lyons, A.; Reyes, A.; Robinson, A.J.; Moroni, I.; Ghezzi, D.; Fernandez-Vizarra, E.; Zeviani, M. COA7 (C1orf163/RESA1) mutations associated with mitochondrial leukoencephalopathy and cytochrome c oxidase deficiency. J. Med. Genet. 2016, 53, 846-849.

178. Rutter, J.W.D.; Schiffman, J.D. Succinate dehydrogenase-Assembly, regulation and role in human disease. Mitochondrion 2010, 10, 393-401.

179. Cecchini, G. Function and structure of complex II of the respiratory chain. Annu. Rev. Biochem. 2003, 72, 77-109. [CrossRef]

180. Sun, F.; Huo, X.; Zhai, Y.; Wang, A.; Xu, J.; Su, D.; Bartlam, M.; Rao, Z. Crystal structure of mitochondrial respiratory membrane protein complex II. Cell 2005, 121, 1043-1057.

181. Iverson, T.M. Catalytic mechanisms of complex II enzymes: A structural perspective. Biochim. Biophys. Acta 2013, 1827, 648-657. [CrossRef]

182. Van Vranken, J.; Na, U.; Winge, D.R.; Rutter, J. Protein-mediated assembly of succinate dehydrogenase and its cofactors. Crit. Rev. Biochem. Mol. Biol. 2015, 50, 168-180.

183. Hao, H.-X.; Khalimonchuk, O.; Schraders, M.; Dephoure, N.; Bayley, J.-P.; Kunst, H.; Devilee, P.; Cremers CW, R.J.; Schiffman, J.D.; Bentz, B.G.; et al. SDH5, a gene required for flavination of succinate dehydrogenase, is mutated in paraganglioma. Science (N. Y.) 2009, 325, 1139-1142.

184. Ghezzi, D.; Goffrini, P.; Uziel, G.; Horvath, R.; Klopstock, T.; Lochmüller, H.; D'Adamo, P.; Gasparini, P.; Strom, T.M.; Prokisch, H.; et al. SDHAF1, encoding a LYR complex-II specific assembly factor, is mutated in SDH-defective infantile leukoencephalopathy. Nat. Genet. 2009, 41, 654-656.

185. Maio, N.; Ghezzi, D.; Verrigni, D.; Rizza, T.; Bertini, E.; Martinelli, D.; Zeviani, M.; Singh, A.; Carrozzo, R.; Rouault, T.A. DiseaseCausing SDHAF1 Mutations Impair Transfer of Fe-S Clusters to SDHB. Cell Metab. 2016, 23, 292-302.

186. Dwight, T.; Na, U.; Kim, E.; Zhu, Y.; Richardson, A.L.; Robinson, B.G.; Tucker, K.M.; Gill, A.J.; Benn, D.E.; Clifton-Bligh, R.J.; et al. Analysis of SDHAF3 in familial and sporadic pheochromocytoma and paraganglioma. BMC Cancer 2017, $17,497$.

187. Munnich, A.; Rustin, P. Clinical spectrum and diagnosis of mitochondrial disorders. Am. J. Med. Genet. 2001, 106, 4-17.

188. Alston, C.L.; Davison, J.E.; Meloni, F.; van der Westhuizen, F.H.; He, L.; Hornig-Do, H.-T.; Peet, A.C.; Gissen, P.; Goffrini, P.; Ferrero, I.; et al. Recessive germline SDHA and SDHB mutations causing leukodystrophy and isolated mitochondrial complex II deficiency. J. Med. Genet. 2012, 49, 569-577.

189. Skoldberg, F.; Grimelius, L.; Woodward, E.R.; Rorsman, F.; Van Schothorst, E.W.; Winqvist, O.; Karlsson, F.A.; Akerstrom, G.; Kampe, O.; Husebye, E.S. A family with hereditary extra-adrenal paragangliomas without evidence for mutations in the von Hippel-Lindau disease or ret genes. Clin. Endocr. 1998, 48, 11-16.

190. Baysal, B.E.; Willett-Brozick, J.E.; Filho, P.A.A.; Lawrence, E.C.; Myers, E.N.; Ferrell, R.E. An Alu-mediated partial SDHC deletion causes familial and sporadic paraganglioma. J. Med. Genet. 2004, 41, 703-709.

191. Baysal, B.E.; Ferrell, R.E.; Willett-Brozick, J.E.; Lawrence, E.C.; Myssiorek, D.; Bosch, A.; van der May, A.; Taschner, P.E.M.; Rubinstein, W.S.; Myers, E.N.; et al. Mutations in SDHD, a mitochondrial complex II gene, in hereditary paraganglioma. Science (N. Y.) 2000, 287, 848-851.

192. Lussey-Lepoutre, C.; Buffet, A.; Gimenez-Roqueplo, A.P.; Favier, J. Mitochondrial Deficiencies in the Predisposition to Paraganglioma. Metabolites 2017, 7, 17. [CrossRef]

193. Ghezzi, D.; Zeviani, M. Human diseases associated with defects in assembly of OXPHOS complexes. Essays Biochem. 2018, 62, 271-286.

194. Parfait, B.; Chretien, D.; Rötig, A.; Marsac, C.; Munnich, A.; Rustin, P. Compound heterozygous mutations in the flavoprotein gene of the respiratory chain complex II in a patient with Leigh syndrome. Hum. Genet. 2000, 106, 236-243. [CrossRef]

195. Levitas, A.; Muhammad, E.; Harel, G.; Saada, A.; Caspi, V.C.; Manor, E.; Beck, J.C.; Sheffield, V.; Parvari, R. Familial neonatal isolated cardiomyopathy caused by a mutation in the flavoprotein subunit of succinate dehydrogenase. Eur. J. Hum. Genet. EJHG 2010, 18, 1160-1165. [CrossRef]

196. Burnichon, N.; Brière, J.J.; Libé, R.; Vescovo, L.; Rivière, J.; Tissier, F.; Jouanno, E.; Jeunemaitre, X.; Bénit, P.; Tzagoloff, A.; et al. SDHA is a tumor suppressor gene causing paraganglioma. Hum. Mol. Genet. 2010, 19, 3011-3020. [CrossRef]

197. Astuti, D.; Latif, F.; Dallol, A.; Dahia, P.L.; Douglas, F.; George, E.; Sköldberg, F.; Husebye, E.S.; Eng, C.; Maher, E.R. Gene mutations in the succinate dehydrogenase subunit SDHB cause susceptibility to familial pheochromocytoma and to familial paraganglioma. Am. J. Hum. Genet. 2001, 69, 49-54. [CrossRef]

198. Janeway, K.A.; Kim, S.Y.; Lodish, M.; Nosé, V.; Rustin, P.; Gaal, J.; Dahia, P.L.; Liegl, B.; Ball, E.R.; Raygada, M.; et al. Defects in succinate dehydrogenase in gastrointestinal stromal tumors lacking KIT and PDGFRA mutations. Proc. Natl. Acad. Sci. USA 2011, 108, 314-318. [CrossRef]

199. McWhinney, S.R.; Pasini, B.; Stratakis, C.A. Familial gastrointestinal stromal tumors and germ-line mutations. N. Engl. J. Med. 2007, 357, 1054-1056. [CrossRef] 
200. Brandt, U.; Yu, L.; Yu, C.A.; Trumpower, B.L. The mitochondrial targeting presequence of the Rieske iron-sulfur protein is processed in a single step after insertion into the cytochrome bc1 complex in mammals and retained as a subunit in the complex. J. Biol. Chem. 1993, 268, 8387-8390.

201. Bottani, E.; Cerutti, R.; Harbour, M.E.; Ravaglia, S.; Dogan, S.A.; Giordano, C.; Fearnley, I.M.; D'Amati, G.; Viscomi, C.; FernandezVizarra, E.; et al. TTC19 Plays a Husbandry Role on UQCRFS1 Turnover in the Biogenesis of Mitochondrial Respiratory Complex III. Mol. Cell 2017, 67, 96-105.e104. [CrossRef]

202. Fernandez-Vizarra, E.; Zeviani, M. Mitochondrial complex III Rieske Fe-S protein processing and assembly. Cell Cycle (Georget. Tex.) 2018, 17, 681-687. [CrossRef]

203. Schagger, H.; Link, T.A.; Engel, W.D.; von Jagow, G. Isolation of the eleven protein subunits of the bc1 complex from beef heart. Methods Enzymol. 1986, 126, 224-237.

204. Yu, C.; Xia, J.Z.; Kachurin, A.M.; Yu, L.; Xia, D.; Kim, H.; Deisenhofer, J. Crystallization and preliminary structure of beef heart mitochondrial cytochrome-bc1 complex. Biochim. Biophys. Acta 1996, 1275, 47-53.

205. Berry, E.; Huang, L.S.; Zhang, Z.; Kim, S.H. Structure of the avian mitochondrial cytochrome bc1 complex. J. Bioenerg. Biomembr. 1999, 31, 177-190.

206. Lange, C.H.C. Crystal structure of the yeast cytochrome bc1 complex with its bound substrate cytochrome c. Proc. Natl. Acad. Sci. USA 2002, 99, 2800-2805.

207. Sousa, J.S.; Vonck, J. Mitochondrial Respiratory Chain Complexes; Springer: Singapore, 2018; Volume 87.

208. Kim, H.J.; Khalimonchuk, O.; Smith, P.M.; Winge, D.R. Structure, function, and assembly of heme centers in mitochondrial respiratory complexes. Biochim. Biophys. Acta (BBA) Mol. Cell Res. 2012, 1823, 1604-1616.

209. Yun, C.H.; Gennis, R.B. Assignment of the histidine axial ligands to the cytochrome bH and cytochrome bL components of the bc1 complex from Rhodobacter sphaeroides by site-directed mutagenesis. Biochemistry 1991, 30, 6747-6754.

210. Iwata, M.; Bjorkman, J.; Iwata, S. Conformational change of the Rieske [2Fe-2S] protein in cytochrome bc1 complex. J. Bioenerg. Biomembr. 1999, 31, 169-175. [CrossRef]

211. Graham, L.A.; Brandt, U.; Trumpower, B.L. Protease maturation of the Rieske iron-sulphur protein after its insertion into the mitochondrial cytochrome bc1 complex of Saccharomyces cerevisiae. Biochem. Soc. Trans. 1994, 22, 188-191. [CrossRef]

212. Deng, K.; Shenoy, S.K.; Tso, S.C.; Yu, L.; Yu, C.A. Reconstitution of mitochondrial processing peptidase from the core proteins (subunits I and II) of bovine heart mitochondrial cytochrome bc(1) complex. J. Biol. Chem. 2001, 276, 6499-6505. [CrossRef]

213. Deng, K.; Zhang, L.; Kachurin, A.M.; Yu, L.; Xia, D.; Kim, H.; Deisenhofer, J.; Yu, C.A. Activation of a matrix processing peptidase from the crystalline cytochrome bc1 complex of bovine heart mitochondria. J. Biol. Chem. 1998, 273, 20752-20757. [CrossRef]

214. Berry, E.A.; De Bari, H.; Huang, L.S. Unanswered questions about the structure of cytochrome bc1 complexes. Biochim. Biophys. Acta 2013, 1827, 1258-1277. [CrossRef]

215. Barel, O.; Shorer, Z.; Flusser, H.; Ofir, R.; Narkis, G.; Finer, G.; Shalev, H.; Nasasra, A.; Saada, A.; Birk, O.S. Mitochondrial complex III deficiency associated with a homozygous mutation in UQCRQ. Am. J. Hum. Genet. 2008, 82, 1211-1216.

216. Haut, S.; Brivet, M.; Touati, G.; Rustin, P.; Lebon, S.; Garcia-Cazorla, A.; Saudubray, J.M.; Boutron, A.; Legrand, A.; Slama, A. A deletion in the human QP-C gene causes a complex III deficiency resulting in hypoglycaemia and lactic acidosis. Hum. Genet. 2003, 113, 118-122.

217. Zara, V.; Conte, L.; Trumpower, B.L. Identification and characterization of cytochrome bc(1) subcomplexes in mitochondria from yeast with single and double deletions of genes encoding cytochrome bc(1) subunits. FEBS J. 2007, 274, 4526-4539. [CrossRef]

218. Zara, V.; Conte, L.; Trumpower, B.L. Biogenesis of the yeast cytochrome bc1 complex. Biochim. Biophys. Acta 2009, $1793,89-96$. [CrossRef]

219. Zara, V.; Conte, L.; Trumpower, B.L. Evidence that the assembly of the yeast cytochrome bc1 complex involves the formation of a large core structure in the inner mitochondrial membrane. FEBS J. 2009, 276, 1900-1914. [CrossRef]

220. Ndi, M.; Marin-Buera, L.; Salvatori, R.; Singh, A.P.; Ott, M. Biogenesis of the bc1 Complex of the Mitochondrial Respiratory Chain. J. Mol. Biol. 2018, 430, 3892-3905. [CrossRef]

221. Smith, P.M.; Fox, J.L.; Winge, D.R. Biogenesis of the cytochrome bc(1) complex and role of assembly factors. Biochim. Biophys. Acta 2012, 1817, 276-286. [CrossRef]

222. Fernandez-Vizarra, E.; Zeviani, M. Nuclear gene mutations as the cause of mitochondrial complex III deficiency. Front. Genet. 2015, 6, 134. [CrossRef]

223. Protasoni, M.; Pérez-Pérez, R.; Lobo-Jarne, T.; Harbour, M.E.; Ding, S.; Peñas, A.; Diaz, F.; Moraes, C.T.; Fearnley, I.M.; Zeviani, M.; et al. Respiratory supercomplexes act as a platform for complex III-mediated maturation of human mitochondrial complexes I and IV. EMBO J. 2020, 39, e102817. [CrossRef]

224. Christianson, T.; Edwards, J.C.; Mueller, D.M.; Rabinowitz, M. Identification of a single transcriptional initiation site for the glutamic tRNA and COB genes in yeast mitochondria. Proc. Natl. Acad. Sci. USA 1983, 80, 5564-5568.

225. Hallberg, B.; Larsson, N.G. Making proteins in the powerhouse. Cell Metab. 2014, 20, 226-240.

226. Xu, F.; Ackerley, C.; Maj, M.C.; Addis, J.B.; Levandovskiy, V.; Lee, J.; Mackay, N.; Cameron, J.M.; Robinson, B.H. Disruption of a mitochondrial RNA-binding protein gene results in decreased cytochrome b expression and a marked reduction in ubiquinolcytochrome c reductase activity in mouse heart mitochondria. Biochem. J. 2008, 416, 15-26.

227. Kehrein, K.; Schilling, R.; Möller-Hergt, B.V.; Wurm, C.A.; Jakobs, S.; Lamkemeyer, T.; Langer, T.; Ott, M. Organization of mitochondrial gene expression in two distinct ribosome-containing assemblies. Cell Rep. 2015, 10, 843-853. 
228. Islas-Osuna, M.A.E.T.; Mittelmeier, T.M.; Dieckmann, C.L. Suppressor mutations define two regions in the Cbp1 protein important for mitochondrial cytochrome b mRNA stability in Saccharomyces cerevisiae. Curr. Genet. 2003, 43, 327-336.

229. Krause-Buchholz, U.; Lauffer, S.; Rödel, G. Saccharomyces cerevisiae translational activator Cbs1p is associated with translationally active mitochondrial ribosomes. Biol. Chem. 2005, 386, 407-415.

230. Naithani, S.; Saracco, S.A.; Butler, C.A.; Fox, T.D. Interactions among COX1, COX2, and COX3 mRNA-specific translational activator proteins on the inner surface of the mitochondrial inner membrane of Saccharomyces cerevisiae. Mol. Biol. Cell 2003, 14, 324-333.

231. Salvatori, R.; Kehrein, K.; Singh, A.P.; Aftab, W.; Möller-Hergt, B.V.; Forne, I.; Imhof, A.; Ott, M. Molecular Wiring of a Mitochondrial Translational Feedback Loop. Mol. Cell 2020, 77, 887-900.e885. [CrossRef]

232. Gruschke, S.; Kehrein, K.; Römpler, K.; Gröne, K.; Israel, L.; Imhof, A.; Herrmann, J.M.; Ott, M. Cbp3-Cbp6 interacts with the yeast mitochondrial ribosomal tunnel exit and promotes cytochrome b synthesis and assembly. J. Cell Biol. 2011, 193, 101-114.

233. Hildenbeutel, M.; Hegg, E.L.; Stephan, K.; Gruschke, S.; Meunier, B.; Ott, M. Assembly factors monitor sequential hemylation of cytochrome b to regulate mitochondrial translation. J. Cell Biol. 2014, 205, 511-524.

234. Tucker, E.J.; Wanschers, B.F.; Szklarczyk, R.; Mountford, H.S.; Wijeyeratne, X.W.; van den Brand, M.A.; Leenders, A.M.; Rodenburg, R.J.; Reljic, B.; Compton, A.G.; et al. Mutations in the UQCC1-interacting protein, UQCC2, cause human complex III deficiency associated with perturbed cytochrome b protein expression. PLoS Genet. 2013, 9, e1004034. [CrossRef]

235. Zara, V.P.I.; Conte, L.; Trumpower, B.L. Further insights into the assembly of the yeast cytochrome bc1 complex based on analysis of single and double deletion mutants lacking supernumerary subunits and cytochrome b. Eur. J. Biochem. 2004, 271, 1209-1218.

236. Stephan, K.; Ott, M. Timing of dimerization of the bc(1) complex during mitochondrial respiratory chain assembly. Biochim. Biophys. Acta. Bioenerg. 2020, 1861, 148177. [CrossRef]

237. Mathieu, L.; Saint-Georges, Y.; Jacq, C.; Dujardin, G. A transcriptome screen in yeast identifies a novel assembly factor for the mitochondrial complex III. Mitochondrion 2011, 11, 391-396.

238. Sadler, I.; Suda, K.; Schatz, G.; Kaudewitz, F.; Haid, A. Sequencing of the nuclear gene for the yeast cytochrome c1 precursor reveals an unusually complex amino-terminal presequence. EMBO J. 1984, 3, 2137-2143.

239. Arnold, I.; Folsch, H.; Neupert, W.; Stuart, R.A. Two distinct and independent mitochondrial targeting signals function in the sorting of an inner membrane protein, cytochrome c1. J. Biol. Chem. 1998, 273, 1469-1476.

240. Zollner, A.; Haid, A. Molecular cloning and characterization of the Saccharomyces cerevisiae CYT2 gene encoding cytochrome-c1heme lyase. FEBS J. 1992, 207, 1093-1100.

241. van Loon, A.; Brandli, A.W.; Pesold-Hurt, B.; Blank, D.; Schatz, G. Transport of proteins to the mitochondrial intermembrane space: The 'matrix-targeting' and the 'sorting' domains in the cytochrome c1 presequence. EMBO J. 1987, 6, $2433-2439$.

242. Phillips, J.; Schmitt, M.E.; Brown, T.A.; Beckmann, J.D.; Trumpower, B.L. Isolation and characterization of QCR9, a nuclear gene encoding the 7.3-kDa subunit 9 of the Saccharomyces cerevisiae ubiquinol-cytochrome c oxidoreductase complex. An intron-containing gene with a conserved sequence occurring in the intron of COX4. J. Biol. Chem. 1990, 265, $20813-20821$.

243. Phillips, J.; Graham, L.A.; Trumpower, B.L. Subunit 9 of the Saccharomyces cerevisiae cytochrome bc1 complex is required for insertion of EPR-detectable iron-sulfur cluster into the Rieske iron-sulfur protein. J. Biol. Chem. 1993, 268, 11727-11736.

244. Brandt, U.; Uribe, S.; Schägger, H.; Trumpower, B.L. Isolation and characterization of QCR10, the nuclear gene encoding the 8.5-kDa subunit 10 of the Saccharomyces cerevisiae cytochrome bc1 complex. J. Biol. Chem. 1994, 269, 12947-12953.

245. Fu, W.; Japa, S.; Beattie, D.S. Import of the iron-sulfur protein of the cytochrome b.c1 complex into yeast mitochondria. J. Biol. Chem. 1990, 265, 16541-16547.

246. Fölsch, H.; Neupert, W.; Stuart, R.A. Internal targeting signal of the BCS1 protein: A novel mechanism of import into mitochondria. EMBO J. 1996, 15, 479-487.

247. Nouet, C.; Mathieu, L.; Dujardin, G. Functional analysis of yeast bcs1 mutants highlights the role of Bcs1p-specific amino acids in the AAA domain. J. Mol. Biol. 2009, 388, 252-261.

248. Nobrega, F.; Nobrega, M.P.; Tzagoloff, A. BCS1, a novel gene required for the expression of functional Rieske iron-sulfur protein in Saccharomyces cerevisiae. EMBO J. 1992, 11, 3821-3829.

249. Cruciat, C.M.; Fölsch, H.; Neupert, W.; Stuart, R.A. Bcs1p, an AAA-family member, is a chaperone for the assembly of the cytochrome bc1 complex. EMBO J. 1999, 18, 5226-5233.

250. Wagener, N.; Funes, S.; Neupert, W. A pathway of protein translocation in mitochondria mediated by the AAA-ATPase Bcs1. Mol. Cell 2011, 44, 191-202.

251. Kater, L.; Wagener, N.; Berninghausen, O.; Becker, T.; Neupert, W.; Beckmann, R. Structure of the Bcs1 AAA-ATPase suggests an airlock-like translocation mechanism for folded proteins. Nat. Struct. Mol. Biol. 2020, 27, 142-149. [CrossRef]

252. Tang, W.K.; Borgnia, M.J.; Hsu, A.L.; Esser, L.; Fox, T.; de Val, N.; Xia, D. Structures of AAA protein translocase Bcs1 suggest translocation mechanism of a folded protein. Nat. Struct. Mol. Biol. 2020, 27, 202-209. [CrossRef]

253. Atkinson, A.; Khalimonchuk, O.; Smith, P.; Sabic, H.; Eide, D.; Winge, D.R. Mzm1 influences a labile pool of mitochondrial zinc important for respiratory function. J. Biol. Chem. 2010, 285, 19450-19459.

254. Atkinson, A.; Smith, P.; Fox, J.L.; Cui, T.Z.; Khalimonchuk, O.; Winge, D.R. The LYR protein Mzm1 functions in the insertion of the Rieske Fe/S protein in yeast mitochondria. Mol. Cell Biol. 2011, 31, 3988-3996. [CrossRef] 
255. Sanchez, E.; Lobo, T.; Fox, J.L.; Zeviani, M.; Winge, D.R.; Fernandez-Vizarra, E. LYRM7/MZM1L is a UQCRFS1 chaperone involved in the last steps of mitochondrial Complex III assembly in human cells. Biochim. Biophys. Acta 2013, 1827, $285-293$. [CrossRef]

256. Ghezzi, D.; Arzuffi, P.; Zordan, M.; Da Re, C.; Lamperti, C.; Benna, C.; D'Adamo, P.; Diodato, D.; Costa, R.; Mariotti, C.; et al. Mutations in TTC19 cause mitochondrial complex III deficiency and neurological impairment in humans and flies. Nat. Genet. 2011, 43, 259-263.

257. Cui, T.Z.; Smith, P.M.; Fox, J.L.; Khalimonchuk, O.; Winge, D.R. Late-stage maturation of the Rieske Fe/S protein: Mzm1 stabilizes Rip1 but does not facilitate its translocation by the AAA ATPase Bcs1. Mol. Cell Biol. 2012, 32, 4400-4409. [CrossRef]

258. Tzagoloff, A.; Wu, M.A.; Crivellone, M. Assembly of the mitochondrial membrane system. Characterization of COR1, the structural gene for the 44-kilodalton core protein of yeast coenzyme QH2-cytochrome c reductase. J. Biol. Chem. 1986, 261, 17163-17169.

259. Oudshoorn, P.; Van Steeg, H.; Swinkels, B.W.; Schoppink, P.; Grivell, L.A. Subunit II of yeast QH2:cytochrome-c oxidoreductase. Nucleotide sequence of the gene and features of the protein. Eur. J. Biochem. 1987, 163, 97-103. [CrossRef]

260. Nobrega, F.G.; Tzagoloff, A. Assembly of the mitochondrial membrane system. DNA sequence and organization of the cytochrome b gene in Saccharomyces cerevisiae D273-10B. J. Biol. Chem. 1980, 255, 9828-9837.

261. Beckmann, J.D.; Ljungdahl, P.O.; Lopez, J.L.; Trumpower, B.L. Isolation and characterization of the nuclear gene encoding the Rieske iron-sulfur protein (RIP1) from Saccharomyces cerevisiae. J. Biol. Chem. 1987, 262, 8901-8909.

262. Van Loon, A.P.; De Groot, R.J.; De Haan, M.; Dekker, A.; Grivell, L.A. The DNA sequence of the nuclear gene coding for the 17-kd subunit VI of the yeast ubiquinol-cytochrome c reductase: A protein with an extremely high content of acidic amino acids. EMBO J. 1984, 3, 1039-1043.

263. De Haan, M.; van Loon, A.P.; Kreike, J.; Vaessen, R.T.; Grivell, L.A. The biosynthesis of the ubiquinol-cytochrome c reductase complex in yeast. DNA sequence analysis of the nuclear gene coding for the 14-kDa subunit. Eur. J. Biochem. 1984, 138, 169-177. [CrossRef]

264. Maarse, A.C.; Grivell, L.A. Nucleotide sequence of the gene encoding the 11-kDa subunit of the ubiquinol-cytochrome-c oxidoreductase in Saccharomyces cerevisiae. Eur. J. Biochem. 1987, 165, 419-425. [CrossRef]

265. Dieckmann, C.; Pape, L.K.; Tzagoloff, A. Identification and cloning of a yeast nuclear gene (CBP1) involved in expression of mitochondrial cytochrome b. Proc. Natl. Acad. Sci. USA 1982, 79, 1805-1809.

266. Rödel, G.; Michaelis, U.; Forsbach, V.; Kreike, J.; Kaudewitz, F. Molecular cloning of the yeast nuclear genes CBS1 and CBS2. Curr. Genet. 1986, 11, 47-53.

267. Wu, M.T.A. Identification and characterization of a new gene (CBP3) required for the expression of yeast coenzyme QH2cytochrome c reductase. J. Biol. Chem. 1989, 264, 11122-11130.

268. Dieckmann, C.; Tzagoloff, A. Assembly of the mitochondrial membrane system. CBP6, a yeast nuclear gene necessary for synthesis of cytochrome b. J. Biol. Chem. 1985, 260, 1513-1520.

269. Crivellone, M. Characterization of CBP4, a new gene essential for the expression of ubiquinol-cytochrome c reductase in Saccharomyces cerevisiae. J. Biol. Chem. 1994, 269, 21284-21292.

270. Wanschers, B.F.J.; Szklarczyk, R.; van den Brand, M.A.M.; Jonckheere, A.; Suijskens, J.; Smeets, R.; Rodenburg, R.J.; Stephan, K.; Helland, I.B.; Elkamil, A. A mutation in the human CBP4 ortholog UQCC3 impairs complex III assembly, activity and cytochrome b stability. Hum. Mol. Genet. 2014, 23, 6356-6365.

271. Dumont, M.E.; Schlichter, J.B.; Cardillo, T.S.; Hayes, M.K.; Bethlendy, G.; Sherman, F. CYC2 encodes a factor involved in mitochondrial import of yeast cytochrome c. Mol. Cell Biol. 1993, 13, 6442-6451. [CrossRef]

272. Fernandez-Vizarra, E.; Bugiani, M.; Goffrini, P.; Carrara, F.; Farina, L.; Procopio, E.; Donati, A.; Uziel, G.; Ferrero, I.; Zeviani, M. Impaired complex III assembly associated with BCS1L gene mutations in isolated mitochondrial encephalopathy. Hum. Mol. Genet. 2007, 16, 1241-1252. [CrossRef]

273. Baker, R.A.; Priestley, J.R.C.; Wilstermann, A.M.; Reese, K.J.; Mark, P.R. Clinical spectrum of BCS1L Mitopathies and their underlying structural relationships. Am. J. Med. Genetics. Part A 2019, 179, 373-380. [CrossRef]

274. Miyake, N.; Yano, S.; Sakai, C.; Hatakeyama, H.; Matsushima, Y.; Shiina, M.; Watanabe, Y.; Bartley, J.; Abdenur, J.E.; Wang, R.Y.; et al. Mitochondrial Complex III Deficiency Caused by a Homozygous UQCRC2 Mutation Presenting with Neonatal-Onset Recurrent Metabolic Decompensation. Hum. Mutat. 2013, 34, 446-452.

275. Brown, M.D.; Voljavec, A.S.; Lott, M.T.; Torroni, A.; Yang, C.-C.; Wallace, D.C. Mitochondrial DNA complex I and III mutations associated with Leber's hereditary optic neuropathy. Genetics 1992, 130, 163-173.

276. Bouzidi, M.F.; Schagger, H.; Collombet, J.M.; Carrier, H.; Flocard, F.; Quard, S.; Mousson, B.; Godinot, C. Decreased expression of ubiquinol-cytochrome $\mathrm{c}$ reductase subunits in patients exhibiting mitochondrial myopathy with progressive exercise intolerance. Neuromusc. Disord. 1993, 3, 599-604.

277. Keightley, J.A.; Anitori, R.; Burton, M.D.; Quan, F.; Buist, N.R.M.; Kennaway, N.G. Mitochondrial encephalomyopathy and complex III deficiency associated with a stop-codon mutation in the cytochrome b gene. Am. J. Hum. Genet. 2000, 67, 1400-1410.

278. Andreu, A.L.; Checcarelli, N.; Iwata, S.; Shanske, S.; DiMauro, S. A missense mutation in the mitochondrial cytochrome bene in a revisited case with histiocytoid cardiomyopathy. Pediat. Res. 2000, 48, 311-314.

279. Wibrand, F.; Ravn, K.; Schwartz, M.; Rosenberg, T.; Horn, N.; Vissing, J. Multisystem disorder associated with a missense mutation in the mitochondrial cytochrome b gene. Ann. Neurol. 2001, 50, 540-543. 
280. Gaignard, P.; Menezes, M.; Schiff, M.; Bayot, A.; Rak, M.; Ogier de Baulny, H.; Su, C.H.; Gilleron, M.; Lombes, A.; Abida, H.; et al. Mutations in CYC1, encoding cytochrome c1 subunit of respiratory chain complex III, cause insulin-responsive hyperglycemia. Am. J. Hum. Genet. 2013, 93, 384-389.

281. Gusic, M.; Schottmann, G.; Feichtinger, R.G.; Du, C.; Scholz, C.; Wagner, M.; Mayr, J.A.; Lee, C.Y.; Yépez, V.A.; Lorenz, N.; et al. Bi-Allelic UQCRFS1 Variants Are Associated with Mitochondrial Complex III Deficiency, Cardiomyopathy, and Alopecia Totalis. Am. J. Hum. Genet. 2020, 106, 102-111. [CrossRef]

282. Visapaa, I.; Fellman, V.; Varilo, T.; Palotie, A.; Raivio, K.O.; Peltonen, L. Assignment of the locus for a new lethal neonatal metabolic syndrome to 2q33-37. Am. J. Hum. Genet. 1998, 63, 1396-1403.

283. Siddiqi, S.; Siddiq, S.; Mansoor, A.; Oostrik, J.; Ahmad, N.; Kazmi, S.A.; Kremer, H.; Qamar, R.; Schraders, M. Novel mutation in AAA domain of BCS1L causing Bjornstad syndrome. J. Hum. Genet. 2013, 58, 819-821.

284. de Lonlay, P.; Valnot, I.; Barrientos, A.; Gorbatyuk, M.; Tzagoloff, A.; Taanman, J.W.; Benayoun, E.; Chretien, D.; Kadhom, N.; Lombes, A.; et al. A mutant mitochondrial respiratory chain assembly protein causes complex III deficiency in patients with tubulopathy, encephalopathy and liver failure. Nat. Genet. 2001, 29, 57-60. [CrossRef]

285. Hinson, J.T.; Fantin, V.R.; Schonberger, J.; Breivik, N.; Siem, G.; McDonough, B.; Sharma, P.; Keogh, I.; Godinho, R.; Santos, F.; et al. Missense mutations in the BCS1L gene as a cause of the Bjornstad syndrome. N. Engl. J. Med. 2007, 356, 809-819. [CrossRef]

286. Gil-Borlado, M.C.; Gonzalez-Hoyuela, M.; Blazquez, A.; Garcia-Silva, M.T.; Gabaldon, T.; Manzanares, J.; Vara, J.; Martin, M.A.; Seneca, S.; Arenas, J.; et al. Pathogenic mutations in the 5' untranslated region of BCS1L mRNA in mitochondrial complex III deficiency. Mitochondrion 2009, 9, 299-305. [CrossRef]

287. Oláhová, M.; Ceccatelli Berti, C.; Collier, J.J.; Alston, C.L.; Jameson, E.; Jones, S.A.; Edwards, N.; He, L.; Chinnery, P.F.; Horvath, R.; et al. Molecular genetic investigations identify new clinical phenotypes associated with BCS1L-related mitochondrial disease. Hum. Mol. Genet. 2019, 28, 3766-3776. [CrossRef]

288. Blázquez, A.; Gil-Borlado, M.C.; Morán, M.; Verdú, A.; Cazorla-Calleja, M.R.; Martín, M.A.; Arenas, J.; Ugalde, C. Infantile mitochondrial encephalomyopathy with unusual phenotype caused by a novel BCS1L mutation in an isolated complex IIIdeficient patient. Neuromuscul. Disord. NMD 2009, 19, 143-146. [CrossRef]

289. Morino, H.; Miyamoto, R.; Ohnishi, S.; Maruyama, H.; Kawakami, H. Exome sequencing reveals a novel TTC19 mutation in an autosomal recessive spinocerebellar ataxia patient. BMC Neurol. 2014, 14, 1-5.

290. Nogueira, C.; Barros, J.; Sa, M.J.; Azevedo, L.; Taipa, R.; Torraco, A.; Meschini, M.C.; Verrigni, D.; Nesti, C.; Rizza, T.; et al. Novel TTC19 mutation in a family with severe psychiatric manifestations and complex III deficiency. Neurogenetics 2013, 14, 153-160.

291. Habibzadeh, P.; Inaloo, S.; Silawi, M.; Dastsooz, H.; Farazi Fard, M.A.; Sadeghipour, F.; Faghihi, Z.; Rezaeian, M.; Yavarian, M.; Böhm, J.; et al. A Novel TTC19 Mutation in a Patient With Neurological, Psychological, and Gastrointestinal Impairment. Front. Neurol. 2019, 10, 944. [CrossRef]

292. Mordaunt, D.A.; Jolley, A.; Balasubramaniam, S.; Thorburn, D.R.; Mountford, H.S.; Compton, A.G.; Nicholl, J.; Manton, N.; Clark, D.; Bratkovic, D.; et al. Phenotypic variation of TTC19-deficient mitochondrial complex III deficiency: A case report and literature review. Am. J. Med. Genetics. Part A 2015, 167, 1330-1336. [CrossRef]

293. Invernizzi, F.; Tigano, M.; Dallabona, C.; Donnini, C.; Ferrero, I.; Cremonte, M.; Ghezzi, D.; Lamperti, C.; Zeviani, M. A homozygous mutation in LYRM7/MZM1L associated with early onset encephalopathy, lactic acidosis, and severe reduction of mitochondrial complex III activity. Hum. Mutat. 2013, 34, 1619-1622. [CrossRef]

294. Dallabona, C.; Abbink, T.E.; Carrozzo, R.; Torraco, A.; Legati, A.; van Berkel, C.G.; Niceta, M.; Langella, T.; Verrigni, D.; Rizza, T.; et al. LYRM7 mutations cause a multifocal cavitating leukoencephalopathy with distinct MRI appearance. Brain J. Neurol. 2016, 139, 782-794. [CrossRef]

295. Feichtinger, R.G.; Brunner-Krainz, M.; Alhaddad, B.; Wortmann, S.B.; Kovacs-Nagy, R.; Stojakovic, T.; Erwa, W.; Resch, B.; Windischhofer, W.; Verheyen, S.; et al. Combined Respiratory Chain Deficiency and UQCC2 Mutations in Neonatal Encephalomyopathy: Defective Supercomplex Assembly in Complex III Deficiencies. Oxidative Med. Cell. Longev. 2017, 2017, 7202589. [CrossRef]

296. Capaldi, R.A. Structure and function of cytochrome c oxidase. Annu. Rev. Biochem. 1990, 59, 569-596.

297. Balsa, E.M.R.; Perales-Clemente, E.; Szklarczyk, R.; Calvo, E.; Landázuri, M.O.; Enríquez, J.A. NDUFA4 is a subunit of complex IV of the mammalian electron transport chain. Cell Metab. 2012, 16, 378-386.

298. Pitceathly, R.; Rahman, S.; Wedatilake, Y.; Polke, J.M.; Cirak, S.; Foley, A.R.; Sailer, A.; Hurles, M.E.; Stalker, J.; Hargreaves, I.; et al. NDUFA4 mutations underlie dysfunction of a cytochrome c oxidase subunit linked to human neurological disease. Cell Rep. 2013, 3, 1795-1805.

299. Zong, S.; Wu, M.; Gu, J.; Liu, T.; Guo, R.; Yang, M. Structure of the intact 14-subunit human cytochrome c oxidase. Cell Res. 2018, 28, 1026-1034. [CrossRef]

300. Hill, B. The sequence of electron carriers in the reaction of cytochrome c oxidase with oxygen. J. Bioenerg. Biomembr. 1993, 25, 115-120.

301. Sinkler, C.A.; Kalpage, H.; Shay, J.; Lee, I.; Malek, M.H.; Grossman, L.I.; Hüttemann, M. Tissue- and Condition-Specific Isoforms of Mammalian Cytochrome c Oxidase Subunits: From Function to Human Disease. Oxidative Med. Cell. Longev. 2017, 2017, 1534056. [CrossRef]

302. Kadenbach, B.; Huttemann, M. The subunit composition and function of mammalian cytochrome c oxidase. Mitochondrion 2015, $24,64-76$. 
303. Ishigami, I.; Zatsepin, N.A.; Hikita, M.; Conrad, C.E.; Nelson, G.; Coe, J.D.; Basu, S.; Grant, T.D.; Seaberg, M.H.; Sierra, R.G.; et al. Crystal structure of CO-bound cytochrome c oxidase determined by serial femtosecond X-ray crystallography at room temperature. Proc. Natl. Acad. Sci. USA 2017, 114, 8011-8016. [CrossRef]

304. Nijtmans, L.G.; Muijsers, A.O.; Speijer, D.; Van den Bogert, C. Assembly of cytochrome-c oxidase in cultured human cells. Eur. J. Biochem. 1998, 254, 389-394.

305. Timón-Gómez, A.; Abriata, L.A.; Vila, A.J.; Hosler, J.; Barrientos, A. Mitochondrial cytochrome c oxidase biogenesis: Recent developments. Semin. Cell Dev. Biol. 2018, 76, 163-178.

306. Vidoni, S.H.; Guerrero-Castillo, S.; Signes, A.; Ding, S.; Fearnley, I.M.; Taylor, R.W.; Tiranti, V.; Arnold, S.; Fernandez-Vizarra, E.; Zeviani, M. MR-1S Interacts with PET100 and PET117 in Module-Based Assembly of Human Cytochrome c Oxidase. Cell Rep. 2017, 18, 1727-1738.

307. Hayashi, T.; Asano, Y.; Shintani, Y.; Aoyama, H.; Kioka, H.; Tsukamoto, O.; Hikita, M.; Shinzawa-Itoh, K.; Takafuji, K.; Higo, S.; et al. Higd1a is a positive regulator of cytochrome c oxidase. Proc. Natl. Acad. Sci. USA 2015, 112, 1553-1558. [CrossRef]

308. Mick, D.; Dennerlein, S.; Wiese, H.; Reinhold, R.; Pacheu-Grau, D.; Lorenzi, I.; Sasarman, F.; Weraarpachai, W.; Shoubridge, E.A.; Warscheid, B.; et al. MITRAC links mitochondrial protein translocation to respiratory-chain assembly and translational regulation. Cell 2012, 15, 1528-1541.

309. Dennerlein, S.O.S.; Jans, D.; Hellwig, C.; Bareth, B.; Jakobs, S.; Deckers, M.; Warscheid, B.; Rehling, P. MITRAC7 Acts as a COX1-Specific Chaperone and Reveals a Checkpoint during Cytochrome c Oxidase Assembly. Cell Rep. 2015, 12, 1644-1655.

310. Xu, F.; Morin, C.; Mitchell, G.; Ackerley, C.; Robinson, B.H. The role of the LRPPRC (leucine-rich pentatricopeptide repeat cassette) gene in cytochrome oxidase assembly: Mutation causes lowered levels of COX (cytochrome c oxidase) I and COX III mRNA. Biochem. J. 2004, 382, 331-336.

311. Weraarpachai, W.; Antonicka, H.; Sasarman, F.; Seeger, J.; Schrank, B.; Kolesar, J.E.; Lochmüller, H.; Chevrette, M.; Kaufman, B.A.; Horvath, R.; et al. Mutation in TACO1, encoding a translational activator of COX I, results in cytochrome c oxidase deficiency and late-onset Leigh syndrome. Nat. Genet. 2009, 41, 833-837.

312. Szklarczyk, R.W.B.; Cuypers, T.D.; Esseling, J.J.; Riemersma, M.; van den Brand, M.A.; Gloerich, J.; Lasonder, E.; van den Heuvel, L.P.; Nijtmans, L.G.; Huynen, M.A. Iterative orthology prediction uncovers new mitochondrial proteins and identifies C12orf62 as the human ortholog of COX14, a protein involved in the assembly of cytochrome c oxidase. Genome Biol. 2012, 13, R12.

313. Clemente, P.; Peralta, S.; Cruz-Bermudez, A.; Echevarría, L.; Fontanesi, F.; Barrientos, A.; Fernandez-Moreno, M.A.; Garesse, R. hCOA3 stabilizes cytochrome c oxidase 1 (COX1) and promotes cytochrome c oxidase assembly in human mitochondria. J. Biol. Chem. 2013, 288, 8321-8331.

314. Mick, D.; Vukotic, M.; Piechura, H.; Meyer, H.E.; Warscheid, B.; Deckers, M.; Rehling, P. Coa3 and Cox14 are essential for negative feedback regulation of COX1 translation in mitochondria. J. Cell Biol. 2010, 191, 141-154.

315. Bourens, M.; Barrientos, A. A CMC1-knockout reveals translation-independent control of human mitochondrial complex IV biogenesis. EMBO Rep. 2017, 18, 477-494.

316. Antonicka, H.; Leary, S.C.; Guercin, G.H.; Agar, J.N.; Horvath, R.; Kennaway, N.G.; Harding, C.O.; Jaksch, M.; Shoubridge, E.A. Mutations in COX10 result in a defect in mitochondrial heme A biosynthesis and account for multiple, early-onset clinical phenotypes associated with isolated COX deficiency. Hum. Mol. Genet. 2003, 12, 2693-2702.

317. Diaz, F.; Thomas, C.K.; Garcia, S.; Hernandez, D.; Moraes, C.T. Mice lacking COX10 in skeletal muscle recapitulate the phenotype of progressive mitochondrial myopathies associated with cytochrome c oxidase deficiency. Hum. Mol. Genet. 2015, 14, 2737-2748.

318. Taylor, N.G.S.S.; Harris, N.J.; Germany, E.M.; Fox, J.L.; Khalimonchuk, O. The Assembly Factor Pet117 Couples Heme a Synthase Activity to Cytochrome Oxidase Assembly. J. Biol. Chem. 2017, 292, 1815-1825.

319. Hiser, L.D.V.M.; Hamer, A.G.; Hosler, J.P. Cox11p is required for stable formation of the $\mathrm{Cu}(\mathrm{B})$ and magnesium centers of cytochrome c oxidase. J. Biol. Chem. 2000, 275, 619-623.

320. Bode, M.; Woellhaf, M.W.; Bohnert, M.; van der Laan, M.; Sommer, F.; Jung, M.; Zimmermann, R.; Schroda, M.; Herrmann, J.M. Redox-regulated dynamic interplay between Cox19 and the copper-binding protein Cox11 in the intermembrane space of mitochondria facilitates biogenesis of cytochrome c oxidase. Mol. Biol. Cell 2015, 26, 2385-2401.

321. Glerum, D.; Shtanko, A.; Tzagoloff, A. Characterization of COX17, a yeast gene involved in copper metabolism and assembly of cytochrome oxidase. J. Biol. Chem. 1996, 271, 14504-14509.

322. Mansilla, N.; Racca, S.; Gras, D.E.; Gonzalez, D.H.; Welchen, E. The Complexity of Mitochondrial Complex IV: An Update of Cytochrome c Oxidase Biogenesis in Plants. Int. J. Mol. Sci. 2018, 19, 662.

323. Bourens, M.; Boulet, A.; Leary, S.C.; Barrientos, A. Human COX20 cooperates with SCO1 and SCO2 to mature COX2 and promote the assembly of cytochrome c oxidase. Hum. Mol. Genet. 2014, 23, 2901-2913.

324. Lorenzi, I.; Oeljeklaus, S.; Aich, A.; Ronsör, C.; Callegari, S.; Dudek, J.; Warscheid, B.; Dennerlein, S.; Rehling, P. The mitochondrial TMEM177 associates with COX20 during COX2 biogenesis. Biochim. Biophys. Acta Mol. Cell Res. 2018, 1865, $323-333$.

325. Leary, S.C.; Sasarman, F.; Nishimura, T.; Shoubridge, E.A. Human SCO2 is required for the synthesis of CO II and as a thioldisulphide oxidoreductase for SCO1. Hum. Mol. Genet. 2009, 18, 2230-2240.

326. Leary, S.; Cobine, P.A.; Kaufman, B.A.; Guercin, G.H.; Mattman, A.; Palaty, J.; Lockitch, G.; Winge, D.R.; Rustin, P.; Horvath, R.; et al. The human cytochrome c oxidase assembly factors SCO1 and SCO2 have regulatory roles in the maintenance of cellular copper homeostasis. Cell Metab. 2007, 5, 9-20. 
327. Leary, S.; Kaufman, B.A.; Pellecchia, G.; Guercin, G.H.; Mattman, A.; Jaksch, M.; Shoubridge, E.A. Human SCO1 and SCO2 have independent, cooperative functions in copper delivery to cytochrome c oxidase. Hum. Mol. Genet. 2004, 13, $1839-1848$.

328. Stroud, D.; Maher, M.J.; Lindau, C.; Vögtle, F.N.; Frazier, A.E.; Surgenor, E.; Mountford, H.; Singh, A.P.; Bonas, M.; Oeljeklaus, S.; et al. COA6 is a mitochondrial complex IV assembly factor critical for biogenesis of mtDNA-encoded COX2. Hum. Mol. Genet. 2015, 24, 5404-5415.

329. Pacheu-Grau, D.; Bareth, B.; Dudek, J.; Juris, L.; Vögtle, F.N.; Wissel, M.; Leary, S.C.; Dennerlein, S.; Rehling, P.; Deckers, M. Cooperation between COA6 and SCO2 in COX2 maturation during cytochrome c oxidase assembly links two mitochondrial cardiomyopathies. Cell Metab. 2015, 21, 823-833.

330. Aich, A.; Wang, C.; Chowdhury, A.; Ronsör, C.; Pacheu-Grau, D.; Richter-Dennerlein, R.; Dennerlein, S.; Rehling, P. COX16 promotes COX2 metallation and assembly during respiratory complex IV biogenesis. Elife 2018, 7, e32572.

331. Cerqua, C.; Morbidoni, V.; Desbats, M.A.; Doimo, M.; Frasson, C.; Sacconi, S.; Baldoin, M.C.; Sartori, G.; Basso, G.; Salviati, L.; et al. COX16 is required for assembly of cytochrome c oxidase in human cells and is involved in copper delivery to COX2. Biochim. Biophys. Acta 2018, 1859, 244-252.

332. Church, C.G.B.; Forsha, D.; Wazny, P.; Poyton, R.O. A role for Pet100p in the assembly of yeast cytochrome c oxidase: Interaction with a subassembly that accumulates in a pet100 mutant. J. Biol. Chem. 2005, 280, 1854-1863.

333. Antonicka, H.; Shoubridge, E.A. Mitochondrial RNA Granules Are Centers for Posttranscriptional RNA Processing and Ribosome Biogenesis. Cell Rep. 2015, 10, 920-932. [CrossRef]

334. Nobrega, M.; Nobrega, F.G.; Tzagoloff, A. COX10 codes for a protein homologous to the ORF1 product of Paracoccus denitrificans and is required for the synthesis of yeast cytochrome oxidase. J. Biol. Chem. 1990, 265, 14220-14226.

335. Glerum, D.M.; Muroff, I.; Jin, C.; Tzagoloff, A. COX15 codes for a mitochondrial protein essential for the assembly of yeast cytochrome oxidase. J. Biol. Chem. 1997, 272, 19088-19094. [CrossRef]

336. Antonicka, H.; Mattman, A.; Carlson, C.G.; Glerum, D.M.; Hoffbuhr, K.C.; Leary, S.C.; Kennaway, N.G.; Shoubridge, E.A. Mutations in COX15 produce a defect in the mitochondrial heme biosynthetic pathway, causing early-onset fatal hypertrophic cardiomyopathy. Am. J. Hum. Genet. 2003, 72, 101-114.

337. Smith, D.G.J.; Mitchell, L.; Antholine, W.E.; Hosler, J.P. Assembly of Cytochrome-c Oxidase in the Absence of Assembly Protein Surf1p Leads to Loss of the Active Site Heme. J. Biol. Chem. 2005, 280, 17652-17656.

338. Vögtle, F.N.B.J.; Rao, S.; Gerbeth, C.; Hinrichs, J.; Martinou, J.C.; Chacinska, A.; Sickmann, A.; Zahedi, R.P.; Meisinger, C. Intermembrane space proteome of yeast mitochondria. Mol. Cell Proteomics. 2012, 11, 1840-1852.

339. Schulze, M.R.G. SCO1, a yeast nuclear gene essential for accumulation of mitochondrial cytochrome c oxidase subunit II. Mol. Gen. Genet. 1988, 211, 492-498.

340. Papadopoulou, L.S.C.M.; Davidson, M.M.; Tanji, K.; Nishino, I.; Sadlock, J.E.; Krishna, S.; Walker, W.; Selby, J.; Glerum, D.M.; Coster, R.V.; et al. Fatal infantile cardioencephalomyopathy with COX deficiency and mutations in SCO2, a COX assembly gene. Nat. Genet. 1999, 23, 333-337.

341. Tzagoloff, A.; Capitanio, N.; Nobrega, M.P.; Gatti, D. Cytochrome oxidase assembly in yeast requires the product of COX11, a homolog of the P. denitrificans protein encoded by ORF3. EMBO J. 1990, 9, 2759-2764.

342. Carlson, C.G.B.A.; Tzagoloff, A.; Glerum, D.M. COX16 encodes a novel protein required for the assembly of cytochrome oxidase in Saccharomyces cerevisiae. J. Biol. Chem. 2003, 278, 3770-3775.

343. Nobrega, M.; Bandeira, S.C.; Beers, J.; Tzagoloff, A. Characterization of COX19, a widely distributed gene required for expression of mitochondrial cytochrome oxidase. J. Biol. Chem. 2002, 277, 40206-40211.

344. Weraarpachai, W.; Sasarman, F.; Nishimura, T.; Antonicka, H.; Aure, K.; Rotig, A.; Lombes, A.; Shoubridge, E.A. Mutations in C12orf62, a factor that couples COX I synthesis with cytochrome c oxidase assembly, cause fatal neonatal lactic acidosis. Am. J. Hum. Genet. 2012, 90, 142-151.

345. Hell, K.; Tzagoloff, A.; Neupert, W.; Stuart, R.A. Identification of Cox20p, a novel protein involved in the maturation and assembly of cytochrome oxidase subunit 2. J. Biol. Chem. 2000, 275, 4571-4578.

346. Church, C.C.C.; Poyton, R.O. Cloning and characterization of PET100, a gene required for the assembly of yeast cytochrome c oxidase. J. Biol. Chem. 1996, 271, 18499-18507.

347. Lim, S.C.S.K.; Stroud, D.A.; Compton, A.G.; Tucker, E.J.; Dasvarma, A.; Gandolfo, L.C.; Marum, J.E.; McKenzie, M.; Peters, H.L.; Mowat, D.; et al. A founder mutation in PET100 causes isolated complex IV deficiency in Lebanese individuals with Leigh syndrome. Am. J. Hum. Genet. 2014, 94, 209-222.

348. Oláhová, M.; Haack, T.B.; Alston, C.L.; Houghton, J.A.; He, L.; Morris, A.A.; Brown, G.K.; McFarland, R.; ChrzanowskaLightowlers, Z.M.; Lightowlers, R.N.; et al. A truncating PET100 variant causing fatal infantile lactic acidosis and isolated cytochrome c oxidase deficiency. Eur. J. Hum. Genet. EJHG 2015, 23, 935-939. [CrossRef]

349. McEwen, J.; Hong, K.H.; Park, S.; Preciado, G.T. Sequence and chromosomal localization of two PET genes required for cytochrome c oxidase assembly in Saccharomyces cerevisiae. Curr. Genet. 1993, 23, 9-14.

350. Renkema, G.H.V.G.; Baertling, F.; Wintjes, L.T.; Wolters, V.M.; van Montfrans, J.; de Kort, G.A.P.; Nikkels, P.G.J.; van Hasselt, P.M.; van der Crabben, S.N.; Rodenburg, R.J.T. Mutated PET117 causes complex IV deficiency and is associated with neurodevelopmental regression and medulla oblongata lesions. Hum. Genet. 2017, 136, 759-769. 
351. Signes, A.C.R.; Dickson, A.S.; Benincá, C.; Hinchy, E.C.; Ghezzi, D.; Carrozzo, R.; Bertini, E.; Murphy, M.P.; Nathan, J.A.; Viscomi, C.; et al. APOPT1/COA8 assists COX assembly and is oppositely regulated by UPS and ROS. EMBO Mol. Med. 2019, 11, e9582.

352. Souza, R.L.G.-W.N.; Fox, T.D.; Tzagoloff, A.; Nobrega, F.G. Cloning and characterization of COX18, a Saccharomyces cerevisiae PET gene required for the assembly of cytochrome oxidase. J. Biol. Chem. 2000, 275, 14898-14902.

353. Bourens, M.; Barrientos, A. Human mitochondrial cytochrome c oxidase assembly factor COX18 acts transiently as a membrane insertase within the subunit 2 maturation module. J. Biol. Chem. 2017, 292, 7774-7783. [CrossRef]

354. Brischigliaro, M.; Zeviani, M. Cytochrome c oxidase deficiency. Biochim. Biophys. Acta Bioenerg. 2021, 1862, 148335. [CrossRef]

355. Lamperti, C.; Diodato, D.; Lamantea, E.; Carrara, F.; Ghezzi, D.; Mereghetti, P.; Rizzi, R.; Zeviani, M. MELAS-like encephalomyopathy caused by a new pathogenic mutation in the mitochondrial DNA encoded cytochrome c oxidase subunit I. Neuromuscul. Disord. 2012, 22, 990-994.

356. Valente, L.P.D.; Lamantea, E.; Carrara, F.; Uziel, G.; Cudia, P.; Zani, A.; Farina, L.; Morandi, L.; Mora, M. Identification of novel mutations in five patients with mitochondrial encephalomyopathy. Biochim. Biophys. Acta 2009, 1787, 491-501.

357. Comi, G.P.B.A.; Salani, S.; Franceschina, L.; Sciacco, M.; Prelle, A.; Fortunato, F.; Zeviani, M.; Napoli, L.; Bresolin, N. Cytochrome c oxidase subunit I microdeletion in a patient with motor neuron disease. Ann. Neurol. 1998, 43, 110-116.

358. D'Aurelio, M.P.F.; Barrientos, A.; Gajewski, C.D.; Kwong, J.Q.; Bruno, C.; Beal, M.F.; Manfredi, G. In vivo regulation of oxidative phosphorylation in cells harboring a stop-codon mutation in mitochondrial DNA-encoded cytochrome c oxidase subunit I. J. Biol. Chem. 2001, 276, 46925-46932.

359. Nishigaki, Y.U.H.; Coku, J.; Koga, Y.; Fujii, T.; Sahashi, K.; Nakano, K.; Yoneda, M.; Nonaka, M.; Tang, L. Extensive screening system using suspension array technology to detect mitochondrial DNA point mutations. Mitochondrion 2010, 10, 300-308.

360. Clark, K.M.; Taylor, R.W.; Johnson, M.A.; Chinnery, P.F.; Chrzanowska-Lightowlers, Z.M.; Andrews, R.M.; Nelson, I.P.; Wood, N.W.; Lamont, P.J.; Hanna, M.G. An mtDNA mutation in the initiation codon of the cytochrome C oxidase subunit II gene results in lower levels of the protein and a mitochondrial encephalomyopathy. Am. J. Hum. Genet. 1999, 64, $1330-1339$.

361. Abu-Amero, K.K.; Bosley, T.M. Mitochondrial abnormalities in patients with LHON-like optic neuropathies. Invest. Ophthalmol. Vis. Sci. 2006, 47, 4211-4220.

362. Rahman, S.; Taanman, J.W.; Cooper, J.M.; Nelson, I.; Hargreaves, I.; Meunier, B.; Hanna, M.G.; Garcia, J.J.; Capaldi, R.A.; Lake, B.D. A missense mutation of cytochrome oxidase subunit II causes defective assembly and myopathy. Am. J. Hum. Genet. 1999, 65, 1030-1039.

363. Wei, Y.L.; Yu, C.A.; Yang, P.; Li, A.L.; Wen, J.Y.; Zhao, S.M.; Liu, H.X.; Ke, Y.N.; Campbell, W.; Zhang, Y.G. Novel mitochondrial DNA mutations associated with Chinese familial hypertrophic cardiomyopathy. Clin. Exp. Pharmacol. Physiol. 2006, 36, 933-939.

364. Tabebi, M.; Mkaouar-Rebai, E.; Mnif, M.; Kallabi, F.; Ben Mahmoud, A.; Ben Saad, W.; Charfi, N.; Keskes-Ammar, L.; Kamoun, H.; Abid, M. A novel mutation MT-COIII m.9267G>C and MT-COI m.5913G>A mutation in mitochondrial genes in a Tunisian family with maternally inherited diabetes and deafness (MIDD) associated with severe nephropathy. Biochem. Biophys. Res. Commun. 2015, 459, 353-360.

365. Horvath, R.S.C.; Hoeltzenbein, M.; Do, B.H.; Schroder, C.; Warzok, R.; Vogelgesang, S.; Lochmuller, H.; Muller-Hocker, J.; Gerbitz, K.D. Childhood onset mitochondrial myopathy and lactic acidosis caused by a stop mutation in the mitochondrial cytochrome c oxidase III gene. J. Med. Genet. 2002, 39, 812-816.

366. Mkaouar-Rebai, E.E.E.; Chamkha, I.; Kammoun, F.; Triki, C.; Fakhfakh, F. Molecular-clinical correlation in a family with a novel heteroplasmic Leigh syndrome missense mutation in the mitochondrial cytochrome c oxidase III gene. J. Child Neurol. 2011, 26, 12-20.

367. Bosley, T.M.B.M.C.; Glasier, C.M.; Abu-Amero, K.K. Sporadic bilateral optic neuropathy in children: The role of mitochondrial abnormalities. Invest. Ophthalmol. Vis. Sci. 2008, 49, 5250-5256.

368. Marotta, R.C.J.; Kirby, D.M.; Chiotis, M.; Cook, M.; Collins, S.J. Novel single base pair COX III subunit deletion of mitochondrial DNA associated with rhabdomyolysis. J. Clin. Neurosci. 2011, 18, 290-292.

369. Hanna, M.G.; Nelson, I.P.; Rahman, S.; Lane, R.J.; Land, J.; Heales, S.; Cooper, M.J.; Schapira, A.H.; Morgan-Hughes, J.A.; Wood, N.W. Cytochrome c oxidase deficiency associated with the first stop-codon point mutation in human mtDNA. Am. J. Hum. Genet. 1998, 63, 29-36.

370. Abu-Libdeh, B.; Douiev, L.; Amro, S.; Shahrour, M.; Ta-Shma, A.; Miller, C.; Elpeleg, O.; Saada, A. Mutation in the COX4I1 gene is associated with short stature, poor weight gain and increased chromosomal breaks, simulating Fanconi anemia. Eur. J. Hum. Genet. EJHG 2017, 25, 1142-1146. [CrossRef]

371. Shteyer, E.; Saada, A.; Shaag, A.; Al-Hijawi, F.A.; Kidess, R.; Revel-Vilk, S.; Elpeleg, O. Exocrine pancreatic insufficiency, dyserythropoeitic anemia, and calvarial hyperostosis are caused by a mutation in the COX4I2 gene. Am. J. Hum. Genet. 2009, 84, 412-417. [CrossRef]

372. Baertling, F.; Al-Murshedi, F.; Sánchez-Caballero, L.; Al-Senaidi, K.; Joshi, N.P.; Venselaar, H.; van den Brand, M.A.; Nijtmans, L.G.; Rodenburg, R.J. Mutation in mitochondrial complex IV subunit COX5A causes pulmonary arterial hypertension, lactic acidemia, and failure to thrive. Hum. Mutat. 2017, 38, 692-703. [CrossRef]

373. Tamiya, G.M.S.; Hayashi, M.; Abe, A.; Numakura, C.; Ueki, M.; Tanaka, A.; Ito, C.; Toshimori, K.; Ogawa, N.; Terashima, T.; et al. A mutation of COX6A1 causes a recessive axonal or mixed form of Charcot-Marie-Tooth disease. Am. J. Hum. Genet. 2014, 95, 294-300. 
374. Inoue, M.; Uchino, S.; Iida, A.; Noguchi, S.; Hayashi, S.; Takahashi, T.; Fujii, K.; Komaki, H.; Takeshita, E.; Nonaka, I.; et al. COX6A2 variants cause a muscle-specific cytochrome c oxidase deficiency. Ann. Neurol. 2019, 86, 193-202. [CrossRef]

375. Massa, V.F.-V.E.; Alshahwan, S.; Bakhsh, E.; Goffrini, P.; Ferrero, I.; Mereghetti, P.; D'Adamo, P.; Gasparini, P.; Zeviani, M. Severe infantile encephalomyopathy caused by a mutation in COX6B1, a nucleus-encoded subunit of cytochrome c oxidase. Am. J. Hum. Genet. 2008, 82, 1281-1289.

376. Vondrackova, A.; Vesela, K.; Hansikova, H.; Docekalova, D.Z.; Rozsypalova, E.; Zeman, J.; Tesarova, M. High-resolution melting analysis of 15 genes in 60 patients with cytochrome-c oxidase deficiency. J. Hum. Genet. 2012, 57, 442-448. [CrossRef]

377. Indrieri, A.v.R.V.; Tiranti, V.; Morleo, M.; Iaconis, D.; Tammaro, R.; D'Amato, I.; Conte, I.; Maystadt, I.; Demuth, S.; Zvulunov, A.; et al. Mutations in COX7B cause microphthalmia with linear skin lesions, an unconventional mitochondrial disease. Am. J. Hum. Genet. 2012, 91, 942-949.

378. Hallmann, K.; Kudin, A.P.; Zsurka, G.; Kornblum, C.; Reimann, J.; Stüve, B.; Waltz, S.; Hattingen, E.; Thiele, H.; Nürnberg, P.; et al. Loss of the smallest subunit of cytochrome c oxidase, COX8A, causes Leigh-like syndrome and epilepsy. Brain J. Neurol. 2016, 139, 338-345. [CrossRef]

379. Tiranti, V.H.K.; Carrozzo, R. Mutations of SURF-1 in Leigh disease associated with cytochrome c oxidase deficiency. Am. J. Hum. Genet. 1998, 63, 1609-1621.

380. Echaniz-Laguna, A.; Ghezzi, D.; Chassagne, M.; Mayençon, M.; Padet, S.; Melchionda, L.; Rouvet, I.; Lannes, B.; Bozon, D.; Latour, P.; et al. SURF1 deficiency causes demyelinating Charcot-Marie-Tooth disease. Neurology 2013, 81, 1523-1530. [CrossRef]

381. Szklarczyk, R.W.B.; Nijtmans, L.G.; Rodenburg, R.J.; Zschocke, J.; Dikow, N.; van den Brand, M.A.; Hendriks-Franssen, M.G.; Gilissen, C.; Veltman, J.A.; Nooteboom, M.; et al. A mutation in the FAM36A gene, the human ortholog of COX20, impairs cytochrome c oxidase assembly and is associated with ataxia and muscle hypotonia. Hum. Mol. Genet. 2013, $22,656-667$.

382. Melchionda, L.H.T.B.; Hardy, S.; Abbink, T.E.; Fernandez-Vizarra, E.; Lamantea, E. Mutations in APOPT1, encoding a mitochondrial protein, cause cavitating leukoencephalopathy with cytochrome c oxidase deficiency. Am. J. Hum. Genet. 2014, 95, 315-325.

383. Pronicki, M.; Kowalski, P.; Piekutowska-Abramczuk, D.; Taybert, J.; Karkucinska-Wieckowska, A.; Szymanska-Debinska, T.; Karczmarewicz, E.; Pajdowska, M.; Migdal, M.; Milewska-Bobula, B.; et al. A homozygous mutation in the SCO2 gene causes a spinal muscular atrophy like presentation with stridor and respiratory insufficiency. Eur. J. Paediatr. Neurol. 2010, 14, $253-260$.

384. Rebelo, A.; Saade, D.; Pereira, C.V.; Farooq, A.; Huff, T.C.; Abreu, L.; Moraes, C.T.; Mnatsakanova, D.; Mathews, K.; Yang, H.; et al. $\mathrm{SCO} 2$ mutations cause early-onset axonal Charcot-Marie-Tooth disease associated with cellular copper deficiency. Brain J. Neurol. 2018, 141, 662-672.

385. Baertling, F.A.M.; van den Brand, M.; Hertecant, J.L.; Al-Shamsi, A.; van den Heuvel, L.P.; Distelmaier, F.; Mayatepek, E.; Smeitink, J.A.; Nijtmans, L.G.; Rodenburg, R.J. Mutations in COA6 cause cytochrome c oxidase deficiency and neonatal hypertrophic cardiomyopathy. Hum. Mutat. 2015, 36, 34-38.

386. Huigsloot, M.; Nijtmans, L.G.; Szklarczyk, R.; Baars, M.J.; van den Brand, M.A.; Hendriksfranssen, M.G.; van den Heuvel, L.P.; Smeitink, J.A.; Huynen, M.A.; Rodenburg, R.J. A mutation in C2orf64 causes impaired cytochrome c oxidase assembly and mitochondrial cardiomyopathy. Am. J. Hum. Genet. 2011, 88, 488-493. [CrossRef]

387. Ghezzi, D.; Saada, A.; D’Adamo, P.; Fernandez-Vizarra, E.; Gasparini, P.; Tiranti, V.; Elpeleg, O.; Zeviani, M. FASTKD2 nonsense mutation in an infantile mitochondrial encephalomyopathy associated with cytochrome c oxidase deficiency. Am. J. Hum. Genet. 2008, 83, 415-423. [CrossRef]

388. Wei, X.; Du, M.; Li, D.; Wen, S.; Xie, J.; Li, Y.; Chen, A.; Zhang, K.; Xu, P.; Jia, M.; et al. Mutations in FASTKD2 are associated with mitochondrial disease with multi-OXPHOS deficiency. Hum. Mutat. 2020, 41, 961-972. [CrossRef]

389. Mootha, V.K.; Lepage, P.; Miller, K.; Bunkenborg, J.; Reich, M.; Hjerrild, M.; Delmonte, T.; Villeneuve, A.; Sladek, R.; Xu, F.; et al. Identification of a gene causing human cytochrome c oxidase deficiency by integrative genomics. Proc. Natl. Acad. Sci. USA 2003, 100, 605-610. [CrossRef]

390. Jonckheere, A.I.; Smeitink, J.A.; Rodenburg, R.J. Mitochondrial ATP synthase: Architecture, function and pathology. J. Inherit. Metab. Dis. 2012, 35, 211-225. [CrossRef]

391. Abrahams, J.P.; Leslie, A.G.; Lutter, R.; Walker, J.E. Structure at 2.8 A resolution of F1-ATPase from bovine heart mitochondria. Nature 1994, 370, 621-628. [CrossRef]

392. He, J.; Ford, H.C.; Carroll, J.; Douglas, C.; Gonzales, E.; Ding, S.; Fearnley, I.M.; Walker, J.E. Assembly of the membrane domain of ATP synthase in human mitochondria. Proc. Natl. Acad. Sci. USA 2018, 115, 2988-2993. [CrossRef]

393. Watt, I.N.; Montgomery, M.G.; Runswick, M.J.; Leslie, A.G.; Walker, J.E. Bioenergetic cost of making an adenosine triphosphate molecule in animal mitochondria. Proc. Natl. Acad. Sci. USA 2010, 107, 16823-16827. [CrossRef]

394. Kuhlbrandt, W. Structure and Mechanisms of F-Type ATP Synthases. Annu. Rev. Biochem. 2019, 88, 515-549. [CrossRef]

395. Wittig, I.; Schagger, H. Structural organization of mitochondrial ATP synthase. Biochim. Biophys. Acta 2008, 1777, 592-598. [CrossRef]

396. Ackerman, S.H.; Tzagoloff, A. Identification of two nuclear genes (ATP11, ATP12) required for assembly of the yeast F1-ATPase. Proc. Natl. Acad. Sci. USA 1990, 87, 4986-4990. [CrossRef]

397. Walker, J.E. The ATP synthase: The understood, the uncertain and the unknown. Biochem. Soc. Trans. 2013, 41, 1-16. [CrossRef]

398. He, J.; Ford, H.C.; Carroll, J.; Ding, S.; Fearnley, I.M.; Walker, J.E. Persistence of the mitochondrial permeability transition in the absence of subunit c of human ATP synthase. Proc. Natl. Acad. Sci. USA 2017, 114, 3409-3414. [CrossRef] 
399. Zeng, X.; Barros, M.H.; Shulman, T.; Tzagoloff, A. ATP25, a new nuclear gene of Saccharomyces cerevisiae required for expression and assembly of the Atp9p subunit of mitochondrial ATPase. Mol. Biol. Cell 2008, 19, 1366-1377. [CrossRef]

400. Rak, M.; Gokova, S.; Tzagoloff, A. Modular assembly of yeast mitochondrial ATP synthase. EMBO J. 2011, 30, 920-930. [CrossRef]

401. Lytovchenko, O.; Naumenko, N.; Oeljeklaus, S.; Schmidt, B.; von der Malsburg, K.; Deckers, M.; Warscheid, B.; van der Laan, M.; Rehling, P. The INA complex facilitates assembly of the peripheral stalk of the mitochondrial F1Fo-ATP synthase. EMBO J. 2014, 33, 1624-1638. [CrossRef]

402. López-Gallardo, E.; Solano, A.; Herrero-Martín, M.D.; Martínez-Romero, I.; Castaño-Pérez, M.D.; Andreu, A.L.; Herrera, A.; López-Pérez, M.J.; Ruiz-Pesini, E.; Montoya, J. NARP syndrome in a patient harbouring an insertion in the MT-ATP6 gene that results in a truncated protein. J. Med. Genet. 2009, 46, 64-67. [CrossRef]

403. D'Aurelio, M.; Vives-Bauza, C.; Davidson, M.M.; Manfredi, G. Mitochondrial DNA background modifies the bioenergetics of NARP/MILS ATP6 mutant cells. Hum. Mol. Genet. 2010, 19, 374-386. [CrossRef]

404. Jonckheere, A.I.; Hogeveen, M.; Nijtmans, L.; van den Brand, M.; Janssen, A.; Diepstra, H.; van den Brandt, F.; van den Heuvel, B.; Hol, F.; Hofste, T.; et al. A novel mitochondrial ATP8 gene mutation in a patient with apical hypertrophic cardiomyopathy and neuropathy. BMJ Case Rep. 2009, 2009. [CrossRef]

405. Mayr, J.A.H.V.; Zimmermann, F.; Magler, I.; Kaplanová, V.; Jesina, P.; Pecinová, A.; Nusková, H.; Koch, J.; Sperl, W.; Houstek, J. Mitochondrial ATP synthase deficiency due to a mutation in the ATP5E gene for the F1 epsilon subunit. Hum. Mol. Genet. 2010, 19, 3430-3439.

406. Tatuch, Y.; Robinson, B.H. The mitochondrial DNA mutation at 8993 associated with NARP slows the rate of ATP synthesis in isolated lymphoblast mitochondria. Biochem. Biophys. Res. Commun. 1993, 192, 124-128. [CrossRef]

407. Jonckheere, A.I.H.M.; Nijtmans, L.G.; van den Brand, M.A.; Janssen, A.J.; Diepstra, J.H.; van den Brandt, F.C.; van den Heuvel, L.P.; Hol, F.A.; Hofste, T.G.; Kapusta, L.; et al. A novel mitochondrial ATP8 gene mutation in a patient with apical hypertrophic cardiomyopathy and neuropathy. J. Med. Genet. 2008, 45, 129-133.

408. Jonckheere, A.I.; Renkema, G.H.; Bras, M.; van den Heuvel, L.P.; Hoischen, A.; Gilissen, C.; Nabuurs, S.B.; Huynen, M.A.; de Vries, M.C.; Smeitink, J.A.; et al. A complex V ATP5A1 defect causes fatal neonatal mitochondrial encephalopathy. Brain J. Neurol. 2013, 136, 1544-1554. [CrossRef]

409. Hejzlarová, K.; Mráček, T.; Vrbacký, M.; Kaplanová, V.; Karbanová, V.; Nůsková, H.; Pecina, P.; Houštěk, J. Nuclear genetic defects of mitochondrial ATP synthase. Physiol. Res. 2014, 63 (Suppl. 1), S57-S71.

410. de Coo, I.F.; Smeets, H.J.; Gabreëls, F.J.; Arts, N.; van Oost, B.A. Isolated case of mental retardation and ataxia due to a de novo mitochondrial T8993G mutation. Am. J. Hum. Genet. 1996, 58, 636-638.

411. Ware, S.M.; El-Hassan, N.; Kahler, S.G.; Zhang, Q.; Ma, Y.W.; Miller, E.; Wong, B.; Spicer, R.L.; Craigen, W.J.; Kozel, B.A.; et al. Infantile cardiomyopathy caused by a mutation in the overlapping region of mitochondrial ATPase 6 and 8 genes. J. Med. Genet. 2009, 46, 308-314. [CrossRef]

412. De Meirleir, L.; Seneca, S.; Lissens, W.; De Clercq, I.; Eyskens, F.; Gerlo, E.; Smet, J.; Van Coster, R. Respiratory chain complex V deficiency due to a mutation in the assembly gene ATP12. J. Med. Genet. 2004, 41, 120-124.

413. Lieber, D.S.; Calvo, S.E.; Shanahan, K.; Slate, N.G.; Liu, S.; Hershman, S.G.; Gold, N.B.; Chapman, B.A.; Thorburn, D.R.; Berry, G.T.; et al. Targeted exome sequencing of suspected mitochondrial disorders. Neurology 2013, 80, 1762-1770. [CrossRef]

414. Oláhová, M.; Yoon, W.H.; Thompson, K.; Jangam, S.; Fernandez, L.; Davidson, J.M.; Kyle, J.E.; Grove, M.E.; Fisk, D.G.; Kohler, J.N.; et al. Biallelic Mutations in ATP5F1D, which Encodes a Subunit of ATP Synthase, Cause a Metabolic Disorder. Am. J. Hum. Genet. 2018, 102, 494-504. [CrossRef]

415. Scheffler, I.E. Mitochondria; Wiley-Liss: New York, NY, USA, 1999.

416. Gilkerson, R.W.S.J.; Capaldi, R.A. The cristal membrane of mitochondria is the principal site of oxidative phosphorylation. FEBS Lett. 2003, 546, 355-358.

417. Vogel, F.B.C.; Neupert, W.; Reichert, A.S. Dynamic subcompartmentalization of the mitochondrial inner membrane. J. Cell Biol. 2006, 175, 237-247.

418. Stoldt, S.W.D.; Kehrein, K.; Riedel, D.; Ott, M.; Jakobs, S. Spatial orchestration of mitochondrial translation and OXPHOS complex assembly. Nat. Cell Biol. 2018, 20, 528-534.

419. Schägger, H.; von Jagow, G. Blue native electrophoresis for isolation of membrane protein complexes in enzymatically active form. Anal. Biochem. 1991, 199, 223-231.

420. Hackenbrock, C.; Chazotte, B.; Gupte, S.S. The random collision model and a critical assessment of diffusion and collision in mitochondrial electron transport. J. Bioenerg. Biomembr. 1986, 18, 331-368.

421. Höchli, M.H.C. Lateral translational diffusion of cytochrome c oxidase in the mitochondrial energy-transducing membrane. Proc. Natl. Acad. Sci. USA 1979, 76, 1236-1240.

422. Sowers, A.E.H.C. Rate of lateral diffusion of intramembrane particles: Measurement by electrophoretic displacement and rerandomization. Proc. Natl. Acad. Sci. USA 1981, 78, 6246-6250.

423. Fato, R.; Battino, M.; Degli Esposti, M.; Parenti Castelli, G.; Lenaz, G. Determination of partition and lateral diffusion coefficients of ubiquinones by fluorescence quenching of $\mathrm{n}$-(9-anthroyloxy)stearic acids in phospholipid vesicles and mitochondrial membranes. Biochemistry 1986, 25, 3378-3390.

424. Lenaz, G.F.R.; Di Bernardo, S.; Jarreta, D.; Costa, A.; Genova, M.L.; Parenti Castelli, G. Localization and mobility of coenzyme Q in lipid bilayers and membranes. Biofactors 1999, 9, 87-93. 
425. Schägger, H.P.K. Supercomplexes in the respiratory chains of yeast and mammalian mitochondria. EMBO J. 2000, 19, 1777-1783.

426. Schägger, H.P.K. The ratio of oxidative phosphorylation complexes I-V in bovine heart mitochondria and the composition of respiratory chain supercomplexes. J. Biol. Chem. 2001, 276, 37861-37867.

427. Stroh, A.A.O.; Pfeiffer, K.; Yagi, T.; Finel, M.; Ludwig, B.; Schägger, H. Assembly of respiratory complexes I, III, and IV into NADH oxidase supercomplex stabilizes complex I in Paracoccus denitrificans. J. Biol. Chem. 2004, 279, 5000-5007.

428. Schäfer, E.; Seelert, H.; Reifschneider, N.H.; Krause, F.; Dencher, N.A.; Vonck, J. Architecture of active mammalian respiratory chain supercomplexes. J. Biol. Chem. 2006, 281, 15370-15375.

429. Dudkina, N.; Eubel, H.; Keegstra, W.; Boekema, E.J.; Braun, H.P. Structure of a mitochondrial supercomplex formed by respiratorychain complexes I and III. Proc. Natl. Acad. Sci. USA 2005, 102, 3225-3229.

430. Keilin, D.; Hartree, E.F. Activity of the cytochrome system in heart muscle preparations. Biochem. J. 1947, 41, 500-502. [CrossRef]

431. Chance, B.; Williams, G.R. A method for the localization of sites for oxidative phosphorylation. Nature 1955, 176, 250-254. [CrossRef]

432. Hatefi, Y.; Haavik, A.G.; Fowler, L.R.; Griffiths, D.E. Studies on the electron transfer system. XLII. Reconstitution of the electron transfer system. J. Biol. Chem. 1962, 237, 2661-2669.

433. Trouillard, M.; Meunier, B.; Rappaport, F. Questioning the functional relevance of mitochondrial supercomplexes by time-resolved analysis of the respiratory chain. Proc. Natl. Acad. Sci. USA 2011, 108, E1027-E1034. [CrossRef]

434. Lapuente-Brun, E.; Moreno-Loshuertos, R.; Acin-Perez, R.; Latorre-Pellicer, A.; Colas, C.; Balsa, E.; Perales-Clemente, E.; Quiros, P.M.; Calvo, E.; Rodriguez-Hernandez, M.A.; et al. Supercomplex assembly determines electron flux in the mitochondrial electron transport chain. Science (N. Y.) 2013, 340, 1567-1570. [CrossRef]

435. Blaza, J.N.; Serreli, R.; Jones, A.J.; Mohammed, K.; Hirst, J. Kinetic evidence against partitioning of the ubiquinone pool and the catalytic relevance of respiratory-chain supercomplexes. Proc. Natl. Acad. Sci. USA 2014, 111, 15735-15740. [CrossRef]

436. Fedor, J.G.; Hirst, J. Mitochondrial Supercomplexes Do Not Enhance Catalysis by Quinone Channeling. Cell Metab. 2018, 28, 525-531.e524. [CrossRef]

437. Acin-Perez, R.; Fernandez-Silva, P.; Peleato, M.L.; Perez-Martos, A.; Enriquez, J.A. Respiratory active mitochondrial supercomplexes. Mol. Cell 2008, 32, 529-539. [CrossRef]

438. Acin-Perez, R.; Enriquez, J.A. The function of the respiratory supercomplexes: The plasticity model. Biochim. Biophys. Acta 2014, 1837, 444-450. [CrossRef]

439. Letts, J.A.F.K.; Sazanov, L.A. The architecture of respiratory supercomplexes. Nature 2016, 537, $644-648$.

440. Gu, J.; Wu, M.; Guo, R.; Yan, K.; Lei, J.; Gao, N.; Yang, M. The architecture of the mammalian respirasome. Nature 2016, 537, 639-643.

441. Guo, R.; Zong, S.; Wu, M.; Gu, J.; Yang, M. Architecture of Human Mitochondrial Respiratory Megacomplex I2III2IV2. Cell 2017, $170,1247-1257$.

442. Letts, J.A.; Fiedorczuk, K.; Degliesposti, G.; Skehel, M.; Sazanov, L.A. Structures of Respiratory Supercomplex I+III(2) Reveal Functional and Conformational Crosstalk. Mol. Cell 2019, 75, 1131-1146.e1136. [CrossRef]

443. Dudkina, N.V.K.M.; Stahlberg, H.; Boekema, E.J. Interaction of complexes I, III, and IV within the bovine respirasome by single particle cryoelectron tomography. Proc. Natl. Acad. Sci. USA 2011, 108, 15196-15200.

444. Davies, K.M.; Blum, T.B.; Kühlbrandt, W. Conserved in situ arrangement of complex I and III2 in mitochondrial respiratory chain supercomplexes of mammals, yeast, and plants. Proc. Natl. Acad. Sci. USA 2018, 115, 3024-3029.

445. Hartley, A.M.; Lukoyanova, N.; Zhang, Y.; Cabrera-Orefice, A.; Arnold, S.; Meunier, B.; Pinotsis, N.; Maréchal, A. Structure of yeast cytochrome c oxidase in a supercomplex with cytochrome bc(1). Nat. Struct. Mol. Biol. 2019, 26, 78-83. [CrossRef]

446. Rathore, S.; Berndtsson, J.; Marin-Buera, L.; Conrad, J.; Carroni, M.; Brzezinski, P.; Ott, M. Cryo-EM structure of the yeast respiratory supercomplex. Nat. Struct. Mol. Biol. 2019, 26, 50-57. [CrossRef]

447. Schagger, H. Respiratory chain supercomplexes of mitochondria and bacteria. Biochim. Biophys. Acta 2002, 1555, 154-159. [CrossRef]

448. Vukotic, M.; Oeljeklaus, S.; Wiese, S.; Vogtle, F.N.; Meisinger, C.; Meyer, H.E.; Zieseniss, A.; Katschinski, D.M.; Jans, D.C.; Jakobs, S.; et al. Rcf1 mediates cytochrome oxidase assembly and respirasome formation, revealing heterogeneity of the enzyme complex. Cell Metab. 2012, 15, 336-347. [CrossRef]

449. Marcet-Houben, M.M.G.; Gabaldón, T. Phylogenomics of the oxidative phosphorylation in fungi reveals extensive gene duplication followed by functional divergence. BMC Evol Biol. 2009, 9, 295.

450. Friedrich, T.; Dekovic, D.K.; Burschel, S. Assembly of the Escherichia coli NADH:ubiquinone oxidoreductase (respiratory complex I). Biochim. Biophys. Acta 2016, 1857, 214-223. [CrossRef]

451. Llorente-Garcia, I.; Lenn, T.; Erhardt, H.; Harriman, O.L.; Liu, L.N.; Robson, A.; Chiu, S.W.; Matthews, S.; Willis, N.J.; Bray, C.D.; et al. Single-molecule in vivo imaging of bacterial respiratory complexes indicates delocalized oxidative phosphorylation. Biochim. Biophys. Acta 2014, 1837, 811-824. [CrossRef]

452. Milenkovic, D.; Blaza, J.N.; Larsson, N.G.; Hirst, J. The Enigma of the Respiratory Chain Supercomplex. Cell Metab. 2017, 25, 765-776. [CrossRef]

453. Lobo-Jarne, T.; Nyvltova, E.; Perez-Perez, R.; Timon-Gomez, A.; Molinie, T.; Choi, A.; Mourier, A.; Fontanesi, F.; Ugalde, C.; Barrientos, A. Human COX7A2L Regulates Complex III Biogenesis and Promotes Supercomplex Organization Remodeling without Affecting Mitochondrial Bioenergetics. Cell Rep. 2018, 25, 1786-1799.e1784. [CrossRef] 
454. Letts, J.A.; Sazanov, L.A. Clarifying the supercomplex: The higher-order organization of the mitochondrial electron transport chain. Nat. Struct. Mol. Biol. 2017, 24, 800-808. [CrossRef]

455. Greggio, C.; Jha, P.; Kulkarni, S.S.; Lagarrigue, S.; Broskey, N.T.; Boutant, M.; Wang, X.; Conde Alonso, S.; Ofori, E.; Auwerx, J.; et al. Enhanced Respiratory Chain Supercomplex Formation in Response to Exercise in Human Skeletal Muscle. Cell Metab. 2017, 25, 301-311. [CrossRef]

456. Lobo-Jarne, T.; Ugalde, C. Respiratory chain supercomplexes: Structures, function and biogenesis. Semin. Cell Dev. Biol. 2018, 76, 179-190. [CrossRef]

457. Mileykovskaya, E.; Penczek, P.A.; Fang, J.; Mallampalli, V.K.; Sparagna, G.C.; Dowhan, W. Arrangement of the respiratory chain complexes in Saccharomyces cerevisiae supercomplex III2IV2 revealed by single particle cryo-electron microscopy. J. Biol. Chem. 2012, 287, 23095-23103. [CrossRef]

458. Turrens, J.F. Mitochondrial formation of reactive oxygen species. J. Physiol. 2003, 552, 335-344. [CrossRef]

459. Maranzana, E.; Barbero, G.; Falasca, A.I.; Lenaz, G.; Genova, M.L. Mitochondrial respiratory supercomplex association limits production of reactive oxygen species from complex I. Antioxid. Redox Signal. 2013, 19, 1469-1480. [CrossRef]

460. Lopez-Fabuel, I.; Le Douce, J.; Logan, A.; James, A.M.; Bonvento, G.; Murphy, M.P.; Almeida, A.; Bolanos, J.P. Complex I assembly into supercomplexes determines differential mitochondrial ROS production in neurons and astrocytes. Proc. Natl. Acad. Sci. USA 2016, 113, 13063-13068. [CrossRef]

461. Blakely, E.L.; Mitchell, A.L.; Fisher, N.; Meunier, B.; Nijtmans, L.G.; Schaefer, A.M.; Jackson, M.J.; Turnbull, D.M.; Taylor, R.W. A mitochondrial cytochrome $\mathrm{b}$ mutation causing severe respiratory chain enzyme deficiency in humans and yeast. FEBS J. 2005, 272, 3583-3592. [CrossRef]

462. Andreu, A.L.; Hanna, M.G.; Reichmann, H.; Bruno, C.; Penn, A.S.; Tanji, K.; Pallotti, F.; Iwata, S.; Bonilla, E.; Lach, B.; et al. Exercise intolerance due to mutations in the cytochrome b gene of mitochondrial DNA. N. Engl. J. Med. 1999, 341, 1037-1044. [CrossRef]

463. Lamantea, E.; Carrara, F.; Mariotti, C.; Morandi, L.; Tiranti, V.; Zeviani, M. A novel nonsense mutation (Q352X) in the mitochondrial cytochrome b gene associated with a combined deficiency of complexes I and III. Neuromuscul. Disord. NMD 2002, 12, 49-52. [CrossRef]

464. Moran, M.; Marin-Buera, L.; Gil-Borlado, M.C.; Rivera, H.; Blazquez, A.; Seneca, S.; Vazquez-Lopez, M.; Arenas, J.; Martin, M.A.; Ugalde, C. Cellular pathophysiological consequences of BCS1L mutations in mitochondrial complex III enzyme deficiency. Hum. Mutat. 2010, 31, 930-941. [CrossRef]

465. Diaz, F.; Fukui, H.; Garcia, S.; Moraes, C.T. Cytochrome c oxidase is required for the assembly/stability of respiratory complex I in mouse fibroblasts. Mol. Cell Biol. 2006, 26, 4872-4881. [CrossRef]

466. Acin-Perez, R.; Bayona-Bafaluy, M.P.; Fernandez-Silva, P.; Moreno-Loshuertos, R.; Perez-Martos, A.; Bruno, C.; Moraes, C.T.; Enriquez, J.A. Respiratory complex III is required to maintain complex I in mammalian mitochondria. Mol. Cell 2004, 13, 805-815. [CrossRef]

467. Guaras, A.; Perales-Clemente, E.; Calvo, E.; Acin-Perez, R.; Loureiro-Lopez, M.; Pujol, C.; Martinez-Carrascoso, I.; Nunez, E.; Garcia-Marques, F.; Rodriguez-Hernandez, M.A.; et al. The CoQH2/CoQ Ratio Serves as a Sensor of Respiratory Chain Efficiency. Cell Rep. 2016, 15, 197-209. [CrossRef]

468. Diaz, F.; Enríquez, J.A.; Moraes, C.T. Cells lacking Rieske iron-sulfur protein have a reactive oxygen species-associated decrease in respiratory complexes I and IV. Mol. Cell Biol. 2012, 32, 415-429. [CrossRef]

469. Moreno-Lastres, D.; Fontanesi, F.; Garcia-Consuegra, I.; Martin, M.A.; Arenas, J.; Barrientos, A.; Ugalde, C. Mitochondrial complex I plays an essential role in human respirasome assembly. Cell Metab. 2012, 15, 324-335. [CrossRef]

470. Habersetzer, J.; Ziani, W.; Larrieu, I.; Stines-Chaumeil, C.; Giraud, M.F.; Brèthes, D.; Dautant, A.; Paumard, P. ATP synthase oligomerization: From the enzyme models to the mitochondrial morphology. Int. J. Biochem. Cell Biol. 2013, 45, 99-105. [CrossRef]

471. Strauss, M.; Hofhaus, G.; Schroder, R.R.; Kuhlbrandt, W. Dimer ribbons of ATP synthase shape the inner mitochondrial membrane. EMBO J. 2008, 27, 1154-1160. [CrossRef]

472. Pérez-Pérez, R.L.-J.T.; Milenkovic, D.; Mourier, A.; Bratic, A.; García-Bartolomé, A.; Fernández-Vizarra, E.; Cadenas, S.; Delmiro, A.; García-Consuegra, I.; Arenas, J.; et al. COX7A2L Is a Mitochondrial Complex III Binding Protein that Stabilizes the III2+IV Supercomplex without Affecting Respirasome Formation. Cell Rep. 2016, 16, 2387-2398.

473. Williams, E.G.; Wu, Y.; Jha, P.; Dubuis, S.; Blattmann, P.; Argmann, C.A.; Houten, S.M.; Amariuta, T.; Wolski, W.; Zamboni, N.; et al. Systems proteomics of liver mitochondria function. Science (N. Y.) 2016, 352, aad0189. [CrossRef]

474. Mourier, A.; Matic, S.; Ruzzenente, B.; Larsson, N.G.; Milenkovic, D. The respiratory chain supercomplex organization is independent of COX7a2l isoforms. Cell Metab. 2014, 20, 1069-1075. [CrossRef]

475. Dawitz, H.; Schäfer, J.; Schaart, J.M.; Magits, W.; Brzezinski, P.; Ott, M. Rcf1 Modulates Cytochrome c Oxidase Activity Especially Under Energy-Demanding Conditions. Front. Physiol. 2019, 10, 1555. [CrossRef]

476. Strogolova, V.; Hoang, N.H.; Hosler, J.; Stuart, R.A. The yeast mitochondrial proteins Rcf1 and Rcf2 support the enzymology of the cytochrome c oxidase complex and generation of the proton motive force. J. Biol. Chem. 2019, 294, 4867-4877. [CrossRef]

477. Hartley, A.M.; Meunier, B.; Pinotsis, N.; Maréchal, A. Rcf2 revealed in cryo-EM structures of hypoxic isoforms of mature mitochondrial III-IV supercomplexes. Proc. Natl. Acad. Sci. USA 2020, 117, 9329-9337. [CrossRef]

478. Timón-Gómez, A.; Garlich, J.; Stuart, R.A.; Ugalde, C.; Barrientos, A. Distinct Roles of Mitochondrial HIGD1A and HIGD2A in Respiratory Complex and Supercomplex Biogenesis. Cell Rep. 2020, 31, 107607. [CrossRef] 
479. Chen, Y.C.; Taylor, E.B.; Dephoure, N.; Heo, J.M.; Tonhato, A.; Papandreou, I.; Nath, N.; Denko, N.C.; Gygi, S.P.; Rutter, J. Identification of a protein mediating respiratory supercomplex stability. Cell Metab. 2012, 15, 348-360. [CrossRef]

480. Rieger, B.; Shalaeva, D.N.; Sohnel, A.C.; Kohl, W.; Duwe, P.; Mulkidjanian, A.Y.; Busch, K.B. Lifetime imaging of GFP at CoxVIIIa reports respiratory supercomplex assembly in live cells. Sci. Rep. 2017, 7, 46055. [CrossRef]

481. Hock, D.H.; Reljic, B.; Ang, C.S.; Muellner-Wong, L.; Mountford, H.S.; Compton, A.G.; Ryan, M.T.; Thorburn, D.R.; Stroud, D.A. HIGD2A is required for assembly of the COX3 module of human mitochondrial complex IV. Mol. Cell. Proteom. MCP 2020. [CrossRef]

482. Reinders, J.; Wagner, K.; Zahedi, R.P.; Stojanovski, D.; Eyrich, B.; van der Laan, M.; Rehling, P.; Sickmann, A.; Pfanner, N.; Meisinger, C. Profiling phosphoproteins of yeast mitochondria reveals a role of phosphorylation in assembly of the ATP synthase. Mol. Cell. Proteom. MCP 2007, 6, 1896-1906. [CrossRef]

483. Brandner, K.; Mick, D.U.; Frazier, A.E.; Taylor, R.D.; Meisinger, C.; Rehling, P. Taz1, an outer mitochondrial membrane protein, affects stability and assembly of inner membrane protein complexes: Implications for Barth Syndrome. Mol. Biol. Cell 2005, 16, 5202-5214. [CrossRef]

484. McKenzie, M.; Lazarou, M.; Thorburn, D.R.; Ryan, M.T. Mitochondrial respiratory chain supercomplexes are destabilized in Barth Syndrome patients. J. Mol. Biol. 2006, 361, 462-469. [CrossRef] 